\title{
AVALIAÇÃO DE MÉTODOS PARAMÉTRICOS E NÃO \\ PARAMÉTRICOS NA ANÁLISE DA EFICIÊNCIA \\ DA PRODUÇÃO DE LEITE
}

Daniel Pacífico Homem De Souza

Tese apresentada à Escola Superior de Agricultura "Luiz de Queiroz", Universidade de São Paulo, para obtenção do título de Doutor em Ciências, Área de Concentração: Economia Aplicada.

P I R A C I C A B A

Estado de São Paulo - Brasil

Setembro - 2003 


\title{
AVALIAÇÃO DE MÉTODOS PARAMÉTRICOS E NÃO \\ PARAMÉTRICOS NA ANÁLISE DA EFICIÊNCIA \\ DA PRODUÇÃO DE LEITE
}

\author{
Daniel Pacífico Homem de Souza \\ Engenheiro Agrônomo
}

Orientador: Prof. Dr. EVARISTO MARZABAL NEVES

Tese apresentada à Escola Superior de Agricultura "Luiz de Queiroz", Universidade de São Paulo, para obtenção do título de Doutor em Ciências, Área de Concentração: Economia Aplicada.

P I R A C I C A B A

Estado de São Paulo - Brasil

Setembro - 2003 
Dados Internacionais de Catalogação na Publicação (CIP)
DIVISÃO DE BIBLIOTECA E DOCUMENTAÇÃO - ESALQ/USP

Souza, Da niel Pa cífic o Homem de

Avaliação de métodos paramétricose não paramétric osna análise da eficiência da produção de leite / Daniel Pacífico Homem de Souza. - Piracicaba, 2003.

$136 \mathrm{p.}$

Tese (doutorado) - Escola Superior de Agricultura Luiz de Queiroz, 2003. Bibliografia.

1. Custo econômico 2. Econometria 3. Indicadores econômicos 4. Inferência não paramétrica 5. Insumosagńc olas6. Leite - Produção 7. Produtor rural 8 . Testes de hipóteses I. Título

CDD 338.17111

\section{'Permitida a cópia total ou parcial deste documento, desde que citada a fonte-O autor"}


"Faça as coisas mais simples que você puder,

porém não a mais simples"

Einsten 


\section{AGRADECIMENTOS}

À Deus por me dar forças para a realização deste sonho e por sempre iluminar o meu caminho.

A minha esposa Lilyan pelo amor, dedicação e compreensão pelos longos períodos em que estive ausente de casa. Em especial a minha filha Paula. Com seu inocente sorriso ao me receber em casa, recarregava minhas energias para mais um dia de trabalho.

Aos meus pais, Cássia e Luiz, e minhas irmãs, Carolina e Manuela, pelo incentivo. Agradeço em especial ao meu pai, por sempre estar disposto a me ajudar e ser um grande exemplo de vida.

Ao departamento de Economia, Sociologia e Administração da Escola Superior de Agricultura "Luiz de Queiroz", conjuntamente com seu corpo docente, pela formação acadêmica. Em especial ao meu orientador, professor Evaristo pela colaboração e ao professor Pedro Marques pelas agradáveis conversas.

Ao ilustre amigo Eliseu Alves, pela amizade, orientação e aos grandes ensinamentos por ele me transmitido. Ensinamentos que transbordam do cunho acadêmico e passam para a vida pessoal.

À CAPES, por ser o órgão patrocinador da pesquisa.

Aos pesquisadores do Centro de Estudos Avançados em Economia Aplic ada (CEPEAUSP) por colaborarem quando foi preciso e disponibilização dos dados.

Ao professor Sebastião Teixeira Gomes da Universidade Federal de Viçosa e ao pesquisador Adilson Ferreira pela disponibilização dos dados.

A todos os colegas de curso, que conjuntamente passaram horas no laboratório de informática.

Aos funcionários do departamento, em especial à Maielli, por sempre estar disposta a ajudar os alunos, de uma forma atenciosa e bem humorada. E a todas as pessoas que de alguma forma contribuíram para a elaboração deste trabalho. 


\section{SUMÁRIO}

Página

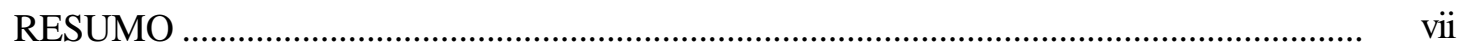

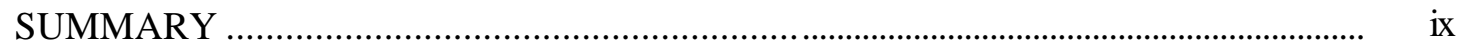

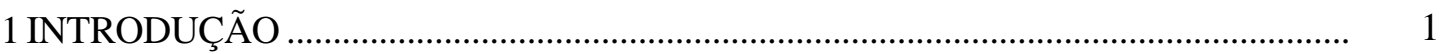

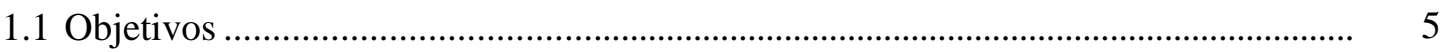

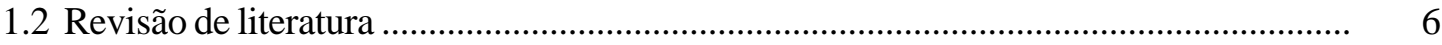

1.3 Definição do problema ............................................................................................... 11

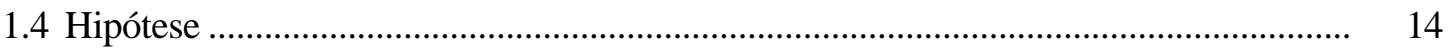

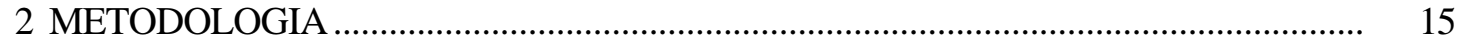

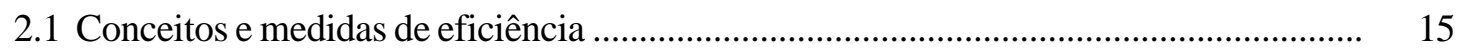

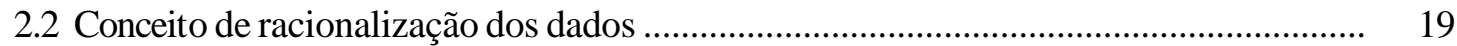

2.3 Modelos econométricos de estimação de fronteira e eficiência ........................................ 20

2.4 Análise envoltória de dados (DEA) ………………..................................................... 26

2.5 Teste de hipótese de minimização de custos ........................................................................ 36

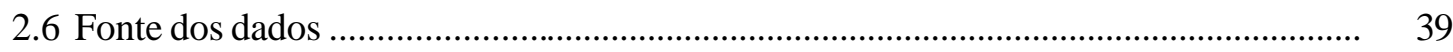

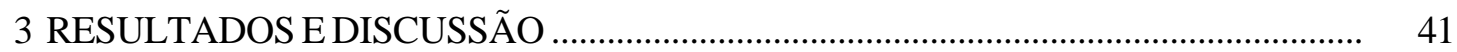

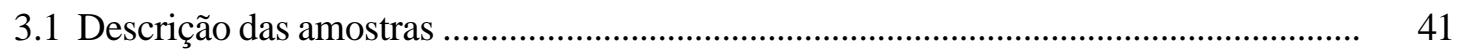

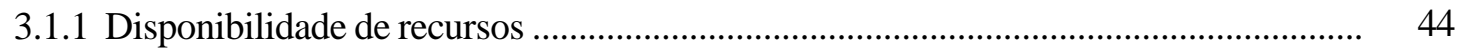

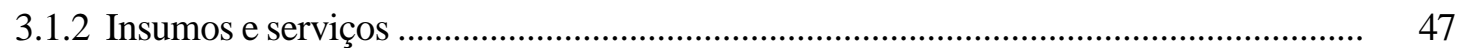




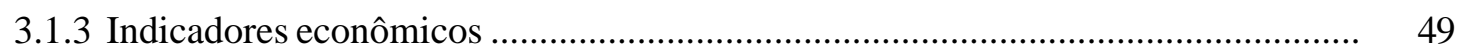

3.2 Teste da hipótese da minimização dos custos: orientação insumo .................................... 58

3.3 Teste da hipótese da minimização dos custos: orientação produto ................................... 65

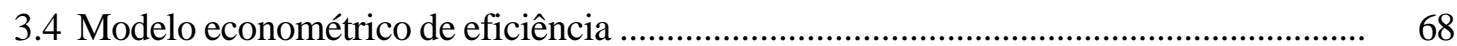

3.5 Análise envoltória de dados (DEA): orientação insumo .................................................... 73

3.6 Análise envoltória de dados (DEA): orientação produto ………………………….......... 80

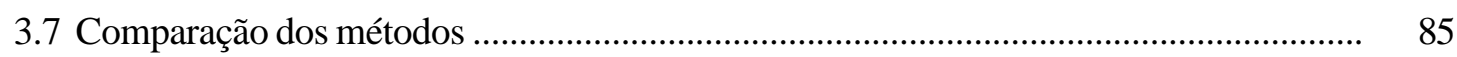

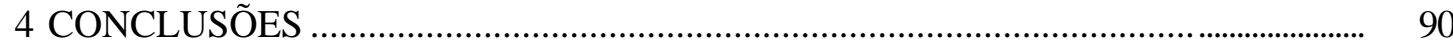

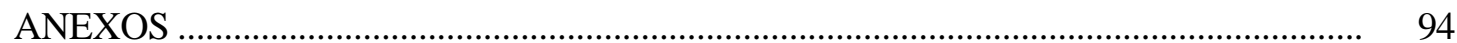

REFERÊNCIAS BIBLIOGRÁFICAS _......................................................................... 100

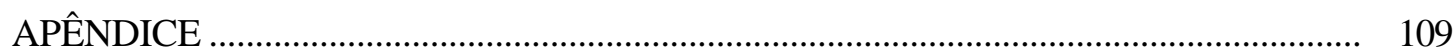




\title{
AVALIAÇÃo dE MÉTOdOS PARAMÉTRICOS E NÃO PARAMÉTRICOS NA ANÁLISE DA EFICIÊNCIA DA PRODUÇÃO DE LEITE
}

\author{
Autor: DANIEL PACIFICO HOMEM DE SOUZA
}

Orientador: Prof. Dr. EVARISTO MARZABAL NEVES

\section{RESUMO}

O objetivo principal do estudo é ofercer uma contribuição metodológica testando os métodos mais usados na análise da eficiência relativa, vis a vis comparando um produtor com um grupo de produtores assemelhados, ou então, um produtor com toda a amostra, como é o caso da fronteira estocástica. Os métodos testados foram o DEA (análise envoltória de dados), a fronteira estocástica e o procedimento de Varian, tendo como objetivo da investigação produtores de leite. Para se testar a hipótese que os produtores de leite são eficientes, quanto à escolha da isoquanta e do ponto que minimiza custo, dada a pressuposição de que os agricultores realizam escolhas corretas, utilizam-se dois grupos de métodos. Os métodos não paramétricos aproximam-se mais do ideal de comparar um produtor com o grupo em que se insere. A base de tecnologia é a do grupo, sem apelo à função de produção. Os paramétricos são mais exigentes, pois pressupõem uma função de produção que tem que ser estimada; porém, são mais ricos e consistentes, no que tange ao teste de hipótese. O DEA é classificado de não paramétrico, porque não propõe uma função com os parâmetros que são estimados. Mas, 
implicitamente, gera uma função de produção, via programação linear. São menos estruturados que a fronteira estocástica, e mais exigentes que o procedimento de Varian, no sentido de que este não pressupõe qualquer fronteira explícita, como o método da fronteira estocástica, ou fronteira implícita, como o DEA. O DEA e o procedimento de Varian são deterministas, visto não associar aos modelos qualquer estrutura de probabilidade. A fronteira estocástica explicitamente associa ao modelo uma estrutura de probabilidade, pela forma que se define o termo do erro da regressão; desta forma é mais rica em testes de hipótese. Duas amostras foram utilizadas para se testar as hipóteses propostas. A primeira refere-se a um grupo de 143 produtores comerciais de leite, com as propriedades distribuídas nos seis maiores estados produtores do Brasil. A segunda amostra de produtores de leite é composta de 114 observações localizadas no estado de Minas Gerais. O método de Varian foi o que produziu menos distúrios em relação aos insumos ou produto. Estabelece maiores incrementos à renda líquida que a fronteira estocástica e menos do que DEA. Sua solução fica mais próxima daquilo que é factível para cada produtor fazer. O método prescinde do conceito de uma fronteira, reordenando os custos em relação aos produtores que produziram mais e gastaram menos, embora o procedimento de reordenamento requeira programação quadrática. Portanto, é um método aderente à gestão. A fronteira estocástica não objetiva nem aumentar a renda líquida e nem reduzir custos. Seu efeito sobre a renda líquida foi até negativo e produziu um maior distúrbio nos insumos e muito pequeno no produto, o que sempre ocorrerá, quando a função de produção se ajustar adequadamente aos dados. O método Varian foi mais apropriado para testar a hpótese de que os produtores, por tentativa e erro, acabam se localizando na fronteira eficiente, no ponto que minimiza o custo. Uma ves que exige somente que os agricultores racionalizem os custos, obedecendo à regra de racionalização, e passando ao largo da dinâmica de mercado, pela qual os produtores convergem para o custo mínimo, o que pode demandar muito tempo, em função de restrições, inclusive de emprego em outros setores da economia. Com os dados de um ano ou de poucos anos, quando não se pode captar o movimento de convergência, o DEA e a maximização da renda líquida são procedimentos inadequados para testar a hipótese de Schultz. 


\section{EVALUATION OF METHODS PARAMETRIC AND NON PARAMETRIC IN THE ANALYSIS OF THE EFFICIENCY OF THE MILK PRODUCTION}

Author: DANIEL PACÍFICO HOMEM DE SOUZA

Adviser: Prof. Dr. EVARISTO MARZABAL NEVES

SUMMARY

The objective of the study is test the most applied methods in the analysis of the relative efficiency, purposing the comparation between a producer and a group of resembled producers, or a producer with the entire sample, as the stochastic frontier's (random border) case. The tested methods were the DEA (Data Envelopment Analysis), the stochastic frontier and the Varian procedure, analyzing mainly milk producers. Looking for testing the hypothesis that the milk producers are efficient, relating choice of isoquant and the cost minimization point, giving the assumption of the producers achieve correct choices, and it was selected two group methods. The non parametric methods (distribution free) is the best approach to compare a producer with its group. The technology basis is supported by the group, without going through the production function. The parametric procedures are more exigent because they assume a production function that has been estimated, however is more consistent to the hypothesis test. The DEA is classified of non parametric approach, because it does not consider a function with estimated parameters, but, implicitly, it generates a production function, using 
linear programming. Its less structuralized than the stochastic frontier, more exigent than the Varian procedure, considering the sense that this method does not estimate any frontier, explicitly, as the stochastic frontier method (implicit border), or the DEA. The DEA and the Varian procedure are deterministic, not associated with models that hold back some structure of probability. The stochastic frontier is an associate to the probability structure model, since it defines the term of the regression error making richer the hypothesis tests. Two samples had been used to test the hypotheses. The first one takes a group of 143 commercial milk producers, whose farm enterprises were distributed in the six biggest producer states of Brazil. The second is established by a group of 114 milk producers located in the state of Minas Gerais. The Varian method produced little disturb related to the inputs or outputs. The net income obtained was bigger than the stochastic frontier and smaller than the DEA. This solution is near to the decision of producer based on feasible to make. The method requires the concept of a frontier, rearranging the costs in related to the producers that had produced more and spent less, even so, the reordering procedure requires quadratic programming. Therefore, it is a very convenient method of management. The stochastic frontier doesn't pursue increase in the net income reduce the costs. In this study the effect on the net income was negative and produced larger disturbs in the inputs and smaller in the products. Facts that will always occur when the production function is adjust to the data. The Varian method was more appropriate in testing hypothesis of the producers, using the experiment and error test, locating them in the efficient frontier, where the point minimizes the costs is located. Therefore it demands that the producer rationalize the costs following the rationalization rule, where the producers drive themselves minimum cost. This procedure can demand much time, in function of constraints of the other sectors of the economy. Considering data of one or more years the DEA and the maximization of the net income have been inadequate procedures to test the hypothesis of Schultz, when it cannot collect convergence movement. 


\section{INTRODUÇÃOO}

A bovinocultura de leite constitui importante atividade do setor agropecuário e desempenha função relevante no desenvolvimento econômico e social do País.

É notório os seus impactos alocativos considerando-se o uso de extensas áreas de terra, o emprego de grande contigente de mão-de-obra, a significativa participação na formação da renda do setor agropecuário e da renda nacional, no fornecimento de alimento de alto valor nutritivo para população e de matéria prima para as indústrias de laticínios. Além disso, o produto por ela gerado é um componente de peso considerável nos índices de custo de vida e no orçamento familiar dos consumidores.

O segmento produtivo é formado por cerca de 1,2 milhões de produtores, destes aproximadamente 480 mil fornecem leite para laticínios, sob inspeção. O setor produtivo gerou um valor bruto de produção de R \$ 6,6 bilhões, em 2000 (Confederação Nacional da Agricultura, 2001).

Após meio século de poucas mudanças, em grande parte explicadas pela forte intervenção do governo no mercado de lácteos, a cadeia produtiva de leite começou, no início dos anos 90, a experimentar transformações em todos os segmentos, da produção ao consumo (Gomes, 1999) ${ }^{1}$.

As transformações provocam mudanças na estrutura e na capacidade de competir. Cresce a preocupação com a eficiência econômica do setor. Os produtores reavaliam suas metas e seus métodos para assegurarem sobrevivência e poderem crescer.

\footnotetext{
${ }^{1}$ GOMES, S.T. Transformações da produção de leite e o capital humano. Viçosa: UFV, 1999. 2p.
} 
A complexidade da produção vai além da obtenção de bons resultados zootécnicos e engloba os resultados econômicos. Mesmo que os produtores obtenham bons resultados zootécnicos, eles podem ser incompatíveis com a sobrevivência do empreendimento.

Os produtores têm utilizado índices zootécnicos para medir a eficiência dos seus sistemas de produção. Tais índices não levam em conta, diretamente, as quantidades e os preços dos insumos utilizados no processo de produção; portanto, podem não refletir a eficiência econômica.

Tanto eficiência quanto a produtividade são indicadores de sucesso, medidas de desempenho, por meio das quais as empresas são avaliadas. Somente pela medida da eficiência e da produtividade, quando se isolam os efeitos daqueles relacionados ao ambiente de produção, pode-se explorar hipóteses relacionadas a fontes de diferenças entre eficiência e produtividade (Lovell, 1993).

A produtividade de uma unidade produtiva $^{2}$ é entendida como a relação entre as quantidades de seus produtos e insumos. Esta varia devido a diferenças na tecnologia de produção, na eficiência dos processos de produção e no ambiente em que ocorre a produção. Quanto à eficiência de uma unidade produtiva, esta é entendida como uma comparação entre valores observados e valores ótimos de insumos e produtos.

A microeconomia, a econometria e a pesquisa operacional avançaram bastante no desenvolvimento de técnicas para análise de eficiência de empresas (Lovell et al., 1988). De acordo com os autores, a aplicação empírica de técnicas de análise de eficiência a diferentes contextos é considerada uma linha de estudo importante e que se desenvolve rapidamente.

Quando altos níveis de eficiência, altos níveis de produtividade e altas taxas de crescimento da produtividade são objetivos desejados pelas empresas, torna-se importante definir e medir a eficiência e a produtividade de acordo com a teoria econômica. É, assim, possível gerar informações úteis para administradores de empresas e formuladores de políticas.

\footnotetext{
${ }^{2}$ Entende-se como unidade produtiva uma empresa agrícola, agroindustrial, etc.
} 
O desempenho de qualquer empresa é visto como função do estado de tecnologia e do grau de eficiência econômica. O primeiro define uma relação de fronteira entre insumos e produtos. O último incorpora o desperdício e má alocação de recursos à fronteira (Fried et al., 1993).

A estimativa da eficiência de uma empresa ajuda na decisão de como melhorar o desempenho ou introduzir novas tecnologias para aumentar a produção, com racionalidade. É útil também para identificar o desnível entre o potencial e o atual nível de produção (Kalirajan, 1982). A estimativa da eficiência é útil, ainda, para fins estratégicos (comparação com outras empresas), táticos (permitir à gerência controlar o desempenho da empresa pelos resultados técnicos obtidos), de planejamento (comparar os resultados do uso de diferentes combinações de fatores) ou para avaliar o desempenho de fatores relacionados àadministração interna.

Apesar da preocupação com a eficiência na utilização dos fatores produtivos, Tupy et al. (2002) salientam que os produtores não têm utilizado a tecnologia disponível de análise de eficiência. Por isso, destaca-se a importância do desenvolvimento de trabalhos que analisem como os produtores de leite alocam seus insumos.

Ainda, a identificação do nível de eficiência e do nível de produtividade é fundamental para o desenvolvimento de políticas públicas e de ações do setor privado, visando ao abastecimento adequado do mercado, substituir importações e à exportar mais.

A eficiência de uma empresa, na dimensão dos insumos, pode ser obtida a partir da estimativa da função fronteira. A fronteira estimada é o padrão em relação ao qual será medida a eficiência da firma. São os casos das funções de produção, custo e lucro, todas definidas como conceitos de fronteira. Por exemplo, a função de produção dá o máximo de produto possível, dado o nível de insumos. Similarmente, a função custo dá o nível mínimo de custo, para algum nível de produto e nível de preços de insumos. Finalmente, uma função de lucro dá o lucro máximo para cada nível de preços de produtos e de insumos.

Desvios da fronteira podem ser interpretados como ineficiência (Fø̛rsund et al., 1980). De acordo com os mesmos autores, o montante pelo qual uma firma fica abaixo 
de suas fronteiras de produção e de lucro, e o montante pelo qual ela fica acima da sua fronteira de custo, podem ser considerados, respectivamente, como medida de ineficiência técnica, lucro ou de custo.

Dos diferentes métodos existentes na literatura, Lovell et al. (1988) consideram quatro abordagens metodológicas: a programação pura, a programação modificada, a fronteira determinista e a fronteira estocástica.

A abordagem de programação pura utiliza uma sequência de programas lineares para construir fronteira e para estimar a eficiência relativa a esta. A técnica foi proposta por Farrel (1957).

A abordagem de programação modificada, também utiliza uma sequência de programação linear para construir as fronteiras e para computar a eficiência relativa a elas. Difere da programação pura por ser a fronteira construída parametricamente. Este método também foi sugerido por Farrel (1957) e melhorado, posteriormente, por Aigner et al.(1968), Førsund et al. (1977) e Førsund et al.(1979).

A terceira abordagem, em contraste com as anteriores, utiliza técnicas estatísticas para estimar a fronteira e computar a eficiência relativa a esta. O método foi proposto inicialmente por Afriat (1972), ampliado por Richmond (1974) e Greene (1980a), entre outros. A quarta abordagem diz respeito à fronteira estocástica. Utiliza técnicas estatísticas para estimar a fronteira e computar a eficiência relativa a esta. Este método foi, simultaneamente, proposto por Aigner et al. (1977) e Meeusen et al.(1977).

As abordagens acima diferem, portanto, no modo como especificam a fronteira (não paramétrica e paramétrica), no modo de como a fronteira é construída (técnicas estatísticas ou de programação) e no modo como os desvios da fronteira são interpretados, ou seja, como simplesmente ineficiência ou uma mistura de ineficiência e ruído. 
Bauer (1990) simplificou as abordagens metodológicas acima. Para este autor, existem dois paradigmas de como construir fronteiras. Um considera técnicas de programação matemática e o outro usa técnicas econométricas. A maior vantagem da programação matemática é a de que não necessita impor uma forma funcional explícita sobre os dados. Contudo, a fronteira calculada pode ser deformada se os dados são contaminados por ruídos estatísticos. A abordagem econométrica, por outro lado, pode manipular os ruídos estatísticos. Mas impõe uma forma funcional explícita e restritiva à tecnologia.

Varian, em uma série de artigos, citados em Varian (1985), propõe nova técnica não paramétrica para análise de eficiência. Detalhes, acessíveis em português, estão em Alves (2000). O método permite identificar se os produtores minimizam o custo de produção e propõe um teste estatístico para a hipótese nula, que será especificada posteriormente.

\subsection{Objetivos}

O estudo tem como objetivo principal avaliar os métodos paramétricos e não paramétricos na análise da eficiência da produção de leite.

Os objetivos específicos são:

a) Testar a hipótese que afirma que os produtores minimizam o custo de produção;

b) Estimar a eficiência, utilizando o método paramétrico, como ferramental de análise;

c) Estimar a eficiência econômica, utilizando o método não paramétrico de programação linear;

d) Comparar os métodos de análise e analisar seus pontos fortes e fracos. 


\subsection{Revisão de literatura}

Diversos são os trabalhos que utilizam métodos paramétricos e não paramétricos na análise de eficiência, sendo aplicados na indústria de alimentos, industria têxtil, agências do correio, ferrovias, agências bancárias, setor elétrico, sistemas de produção de pesquisa agropecuária, entre outros. Desta forma, optourse por apresentar apenas os trabalhos aplicados à agricultura.

Utilizando dados agrícolas predominam aplicações do método paramétrico, mais especificamente, estimação de fronteira via modelos econométricos. Battese et al. (1977) estimaram funções de produção de fronteira Cobb-Douglas determinista e estocástica, com dados de 146 propriedades de três estados da Zona Pastoral do Este da Austrália, anos 19731974. Encontraram diferenças significativas com o uso das duas especific ações.

Uma série de artigos utilizando dados agrícolas podem ser encontrados em Battese (1992). O autor faz uma rica revisão de trabalhos que utilizam modelos paramétricos de estimação de fronteira, tanto determinista quanto estocástica.

Bravo-Ureta (1986) utilizou uma função de produção de fronteira Cobb-Douglas determinista para medir a eficiência em uma amostra de 222 fazendas produtores de leite da região de Nova Inglaterra, EEUU, com dados do ano de 1981. A eficiência técnica variou de 0,58 a 1,00, com média 0,82 . O autor concluiu que eficiência técnica e tamanho da fazenda eram variáveis não correlacionadas, e que a concentração da produção em um número menor de fazendas miores devia-se mais ao baixo nível de renda das fazendas menores do que a uma maior eficiência das fazendas maiores.

Empregando dados de 116 fazendas produtoras de leite de Utah, EEUU, funções de produção de fronteiras estocásticas foram estimadas por Kumbhakar et al. (1989). Os resultados indicaram associação positiva entre anos de estudo e produtividades.

A partir de estimação de uma função de produção de fronteira Cobb-Douglas estocástica, Bravo-Ureta et al. (1991) concluíram, com dados de uma amostra de 511 produtores de leite da Nova Inglaterra (EEUU) do ano de 1984, que os níveis das medidas de eficiência técnica, eficiência alocativa e eficiência média não eram muito diferentes, e 
que os mesmos não eram marcantemente afetados por tamanho da fazenda, educação, extensão e experiência, apesar de algumas relações estatisticamente significativas.

Lemberg et al. (1998), utilizando uma abordagem não paramétrica baseada na minimização de custos, avaliaram a eficiência técnica e econômica de uma amostra de 107 produtores de trigo do Kansas, USA, constatando a ocorrência de ineficiência técnica e alocativa para a maioria das observações. Os índices de eficiência técnica, alocativa e de custo apresentaram uma relação positiva com o nível de produto, tanto sob retornos constantes como variáveis à escala, embora esta relação não tenha sido estatisticamente significante para eficiência técnica. A variável área cultivada mostrou uma elação positiva com os índices de eficiência alocativa. Sob retornos constantes à escala, a eficiência técnica cresceu levemente com o aumento da área cultivada e, sob retornos variáveis à escala, apresentou uma relação inversa.

Sharma et al. (1999) analisaram a eficiência na produção de suínos no Havaí comparando medidas de eficiência obtidas através de modelo paramétrico (fronteira estocástica) e não paramétrico (data envelopment analysis - DEA). Os resultados obtidos pelas duas abordagens revelaram considerável ineficiência na produção. Sob retornos constantes à escala, os índices médios de eficiência técnica e econômica estimados foram maiores para o modelo paramétrico do que aqueles obtidos por DEA. Sob retornos variáveis estes índices foram, geralmente, maiores para o modelo DEA. Os resultados mostram ainda um efeito fortemente positivo do tamanho da exploração com os níveis de eficiência e que as firmas que produzem suínos para o mercado foram mais eficientes do que aquelas que produzem para o consumo.

Lee et al. (1978) ajustaram uma função de produção de fronteira Cobb-Douglas estocástica com dados de 850 indústrias brasileiras do ano de 1971, estimando a eficiência média em 0,62 ou 0,69, dependendo da especificação adotada para a distribuição do termo que explica a ineficiência (normal truncada ou exponencial).

Uma análise dos efeitos do PRODEMATA sobre as eficiências técnica e alocativa de produtores tradicionais da Zona da Mata, Minas Gerais, com dados do ano agrícola 19811982, foi efetuada por Taylor et al. (1986), a partir de uma função de produção de fronteira Cobb-Douglas determinista, cujos parâmetros foram estimados por mínimos quadrados 
ordinários corrigidos e por máxima verossimilhança. A distribuição gama foi escolhida para variável que explica a ineficiência. Os objetivos do PRODEMATA, financiado pelo Banco Mundial, eram de aumentar a produção agrícola, produtividades e renda de pequenos produtores tradicionais da região, fornecendo crédito subsidiado combinado com atividade de extensão rural, pesquisa e campos de demonstração e efetuando investimentos em saúde, condições sanitárias e educação. Os autores compararam os níveis de eficiência técnica de participantes (amostra de 181 propriedades) e não participantes (amostra de 252 propriedades) do programa, obtendo níveis médios de eficiência técnica de 0,18 e 0,17, respectivamente, que não diferiam estatisticamente. Portanto, o programa não teve efeito significativo sobre a eficiência técnica dos participantes. A eficiência alocativa dos participantes do programa $(0,70)$, que tiveram acesso a crédito em condição especiais, foi significativamente menor do que as dos outros produtores $(0,77)$.

Desai et al. (1989), empregaram dados de 284 propriedades da Zona da Mata, do ano de 1982, para analisar a eficiência na produção com uma abordagem não paramétrica (DEA). Os resultados obtidos mostraram uma enorme variação nos níveis de eficiência, variando de 0,06 a 1,00 para os produtores de milho e arroz. Os autores verificaram que os índices de eficiência estavam correlacionados aos fatores como uso de fertilizantes em milho e de tração animal em todas as culturas.

Toreson et al. (1995), utilizando dados médios de quantidades de insumos e produtos, avaliaram a eficiência técnica de 17 empresas agrícolas típicas de Santa Catarina, empregando um modelo DEA. Os resultados indicaram que as pequenas empresas produtoras de fumo e as empresas médias produtores de suínos e grãos foram as que com maior frequência, apareceram como referência (benchmarks) para as empresas menos eficientes. Indicam ainda que a inclusão de atividades como fumo e criações intensivas nas empresas voltadas para a produção de mandioca ou grãos podem melhorar seus níveis de produtividade e eficiência na agregação de valor ao conjunto dos insumos empregados.

Tupy (1996) analisou a eficiência econômica de uma amostra de produtores de frangos de corte utilizando um modelo de fronteiras estocástica, obtendo estimativas de funções do tipo Cobb-Douglas na forma log-linear e com especificações meio-normal e exponencial. Os resultados evidenciaram uma eficiência econômica alta, variando de 0,93 a 
1,00 , indicando que ganhos de produtividade no setor advirão predominantemente da introdução de novas tecnologias.

Araújo (1997), usando dados de cross-section, aplicou um modelo não paramétrico MOTAD (Minimização do Desvio Absoluto Total) para analisar a eficiência econômica sob condições de risco de empresas agrícolas da região sul de Santa Catarina. Pela identificação ao longo da fronteira de eficiência dos pontos de máxima margem bruta e utilidade observou a existência de um potencial de crescimento da margem bruta de 49,9\% e 62,6 \% se o produtor adotasse, respectivamente, o plano de máxima utilidade e de máximo retorno, dada a disponibilidade de fatores de produção e o nível de risco que deseja suportar.

Conceição (1998), com dados primários referentes ao ano agrícola 1989-1990 de uma amostra de propriedades modernas/comerciais de 4 regiões do Brasil, analisou a eficiência técnica a partir de um modelo de função de produção estocástica. A eficiência técnica média estimada da amostra foi de 0,73 , variaram no intervalo de 0,41 e $0,93 \mathrm{com}$ aproximadamente $52 \%$ dos produtores com eficiência técnica entre 0,75 e 0,90.

Com o objetivo de obter índices de eficiência para produtores de leite, a fim de verificar a posição relativa ocupada por estes produtores em uma amostra selecionada. Alves et al. (1998) utilizaram métodos não paramétricos (DEA) em dados coletados junto a produtores de leite do estado de Minas Gerais, do ano de 1995. A eficiência preço, que indica se é possível reduzir a quantidade de nsumos utilizados mantendo o mesmo nível de produção, foi a principal responsável pela não obtenção da máxima eficiência custo, que também foi afetada pela escala de produção, bem como pela congestão e tecnologia inadequada.

Utilizando análise não paramétrica (DEA) para determinar eficiência produtiva, em uma amostra de 241 produtores de leite, Gomes A. (1999), simulou comportamentos da produção de leite, no Brasil, com o objetivo de determinar quais seriam os impactos no número de produtores. $\mathrm{O}$ autor, considerou a taxa histórica de crescimento da produção de 3,3 \% ao ano, projetando a produção de leite para 2010, para 29,6 bilhões de litros. Caso esta produção seja realizada apenas por produtores eficientes, o número de produtores necessários para atingir será de 107,7 mil a 338,9 mil, dependendo da estrutura produtiva considerada. Isto representa uma redução no número de produtores de 15,75 e 8,5 \% ao ano, 
respectivamente. Concluindo que seja qual for a situação, a permanência de apenas produtores eficientes na atividade leiteira reduzirá, drasticamente, o número de produtores.

Para analisar a eficiência produtiva da pequena produção familiar agrícola na região Recôncavo do Estado da Bahia através de uma amostra de 44 produtores. Pereira Filho (2000), utilizou uma abordagem não paramétrica, num contexto de minimização de custos sob retornos constantes à escala, para derivar medidas de eficiência técnica, de escala, alocativa e econômica. Os resultados indicaram que a maior fonte de ineficiência na pequena produção familiar agrícola da região estudada, refere-se à ineficiência alocativa, ou seja, as relações de preços dos fatores não têm sido observadas.

Com relação a trabalhos comparativos, métodos paramétricos versus não paramétricos, poucas pesquisas vêm sendo desenvolvidas. Perelman et al. (1999), compararam os resultados obtidos na estimativa da ineficiência técnica de ferrovias da Europa. Os métodos utilizados foram; construção da fronteira paramétrica utilizando programação linear, análise envoltória de dados (DEA) e a estimação pelo método dos mínimos quadrados ordinários corrigidos. Os resultados encontrados indicaram um forte grau de correlação entre o modelo com orientação produto e orientação insumo nos três métodos. A correlações mais significativas foram entre os resultados obtidos pela programação linear paramétrica e o método dos mínimos quadrados ordinários corrigidos. A conclusão dos autores foi a sugestão da combinação dos métodos para estimação dos índices de eficiência.

Sarafidis (2002) analisou a utilização de técnicas paramétricas e não paramétricas para o cálculo de índices de eficiência. Segundo o autor a escolha entre os métodos; regressão simples, fronteira estocástica e a análise envoltória de dados, não é uma tarefa trivial. Especialmente porque as técnicas são fundamentalmente diferentes e, consequentemente, geram resultados diferentes. Segundo o autor, de fato nenhum método está livre de críticas. Todos os métodos enfrentam seus próprios problemas no lado teórico e prático, implicando que as estimativas finais da eficiência não devem ser interpretadas como sendo medidas definitivas de ineficiência. 


\subsection{Definição do problema}

Nos últimos anos o surgimento, no cenário internacional, de acordos bilaterais, regionais e mundiais, como o MERCOSUL, a desregulamentação do setor, após mais de quarenta anos de controle governamental e a estabilização da economia brasileira, com o Plano Real, vêm provocando mudanças na estrutura da pecuária de leite e acentuando a competição nas dimensões interna e externa (Gomes, 2001).

Por isto, cresce a preocupação com a eficiência econômica. Os produtores reavaliam as metas e seus métodos para assegurarem viabilidade e capacidade de sobrevivência.

A pecuária de leite passa por transformações profundas na direção de uma eficiência maior, como reflexos na redução do número de produtores. Do ponto de vista de política agrícola, é muito importante conhecer a direção e intensidade das mudanças.

$\mathrm{O}$ ajuste à nova realidade é mais rápido nas regiões de pecuaristas mais instruídos, de melhor infra-estrutura, próximas dos principais mercados e para os produtos de maior base tecnológica. Alguns produtos já estão na fase final de ajustamento, como são os casos da soja, cana-de-açúcar, citros, arroz irrigado, suínos e aves. Há produtos que estão em transição, como o algodão, milho, feijão, café e cacau. Finalmente, a pecuária de leite e de corte começaram a se mover, muito recentemente. Do ponto de vista regional, as regiões Sudeste, Sul e CentroOeste já percorreram muito do caminho do ajustamento. O Norte e o Nordeste são consideradas regiões retardatárias, à exceção de alguns pólos.

Para Alves $(2000)^{3}$ é o mercado que determina as tecnologias que prevalecem. Mas, em função de seu dinamismo, não fica claro o que está ocorrendo. Muitas tecnologias para produzir o mesmo produto sobrevivem, num dado momento. Mas, quais as que sobreviverão, num prazo mais longo, é uma pergunta mais difícil de responder.

\footnotetext{
${ }^{3}$ ALVES, E. Difusão de tecnologia Brasília: Embrapa, 2000. 16p.
} 
$\mathrm{Na}$ busca de maior eficiência, os produtores precisam de uma contabilidade detalhada do empreendimento. Não existe outro método para conhecer os pontos fracos e fortes. É importante que cada fator de produção renda o máximo possível. Não pode haver desperdícios nem de mão-de-obra, equipamentos e máquinas, nem de terras, fertilizantes e herbicidas. Não pode haver erros em relação à escolha de tecnologias. Ser moderno é uma imposição do mercado. Mas não é o espírito do modernismo que deve guiar a escolha da tecnologia, e, sim, uma análise econômica bem feita.

Certamente interessa a cada produtor obter o maior rendimento dos recursos que comanda. Um bom começo é verificar como se situa, em termos de eficiência, em relação aos produtores que se assemelham. Mesmo que se encontre no topo, cabe perguntar: que melhorias ainda podem ser realizadas? Mas em primeiro lugar, procura-se identificar a posição relativa, em comparação àqueles parecidos. Melhorar em relação aos semelhantes, conhecida a situação deles, é algo de concreto e mesmo possível. Em segundo lugar, é saber como se pode superar o melhor dos semelhantes. Aqui se escorrega para o terreno de elevado risco, porque exige inovar, ou seja, percorrer caminhos desconhecidos, pelos menos para os agricultores da mesma classe (Alves et al. 1998).

Embora a competitividade de uma firma ou de um setor econômico dependa de um conjunto de fatores macroeconômicos e microeconômicos, a análise da eficiência, focalizada nos fatores microeconômicos, é de grande relevância na explicação da competitividade, principalmente, quando se considera que as firmas mais eficientes serão, provavelmente, mais competitivas (Pereira Filho, 2000).

O mercado de competição perfeita aproxima bem a situação em que vivem os produtores rurais. Se não houver distúrbios, espera-se que haja uma convergência dos produtores para a mesma tecnologia e escolha do ponto que maximiza a renda líquida, respeitada as restrições de cada um. Quem não for capaz de atingir o nível máximo de eficiência, ou seja, de renda líquida, será eliminado pelo mercado. Claro que não imediatamente, mas como decorrer do tempo.

Mesmo num mundo sem distúrbios, o ajuste para o nível máximo de renda líquida toma tempo. Assim, num dado momento, espera-se que os agricultores se agrupem em torno de grupos de rendas líquidas, respeitadas as restrições relevantes. 
Pode-se examinar a mesma questão do ângulo do custo. Dois ajustes são importantes: conhecida a tecnologia, o agricultor escolhe a isoquanta, abaixo da qual é impossível produzir a quantidade estabelecida; dada a linha de preços (isocusto), ela tangência a isoquanta preestabelecida, no ponto de custo mínimo.

Considere-se um agricultor que utiliza dois insumos $\left(x_{1}\right.$ e $\left.x_{2}\right)$ para produzir um produto (y). O ponto no qual este agricultor irá produzir, com o custo mínimo, dado o respectivo preço do produto e dos insumos, é representado por A, na Figura 1. Então, dois tipos de ineficiências são possíveis: escolha incorreta da isoquanta e escolha incorreta do ponto que minimiza custo. Novamente, num regime de competição perfeita, espera-se que os agricultores agrupem em torno da isoquanta envoltória e em torno do ponto de custo mínimo ${ }^{4}$.

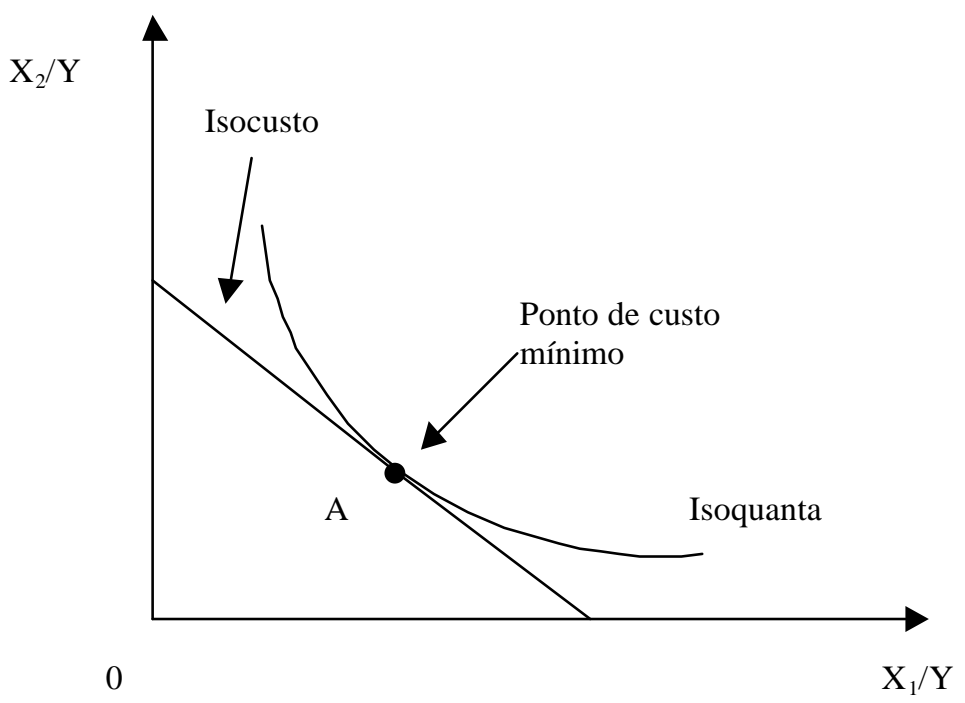

Figura 1 - Isoquanta e isocusto, dada uma tecnologia de produção que utiliza dois insumos $\left(x_{1}\right.$ e $\left.x_{2}\right)$ para produzir um produto $(y)$.

\footnotetext{
${ }^{4}$ A cada nível de produção, fixada a linha de preços, corresponde um custo mínimo.
} 


\subsection{Hipótese}

A hipótese que é testada nesta pesquisa é que os produtores de leite são eficientes, quanto à escolha da isoquanta e do ponto que minimiza custo, dada a pressuposição de que os agricultores realizam escolhas corretas quanto à isoquanta e ao ponto que minimiza custo.

Os produtores vivem num mundo cheio de incertezas, de choques de tecnologias e de ambigüidade de políticas econômicas. A dificuldade principal é isolar estes efeitos. O caminho escolhido baseia na hipótese de que os efeitos são simétricos em relação aos produtores, não discriminam e nem beneficiam nenhum produtor em particular. Para se aproximar deste ideal, é preciso ter cuidado nas comparações que são feitas entre grupos de produtores: dentro de cada grupo, pelo menos em tese, cada qual pode efetuar a escolha que corresponde ao mais eficiente deles.

A pesquisa irá utilizar dois grupos de métodos para testar a hipótese de que os produtores são eficientes. Os métodos não paramétricos aproximam mais do ideal de comparar um produtor com o grupo em que se insere. A base de tecnologia é a do grupo, sem apelo à função de produção. Os paramétricos são mais exigentes, pois pressupõem uma função de produção que tem que ser estimada; entretanto, são mais ricos no que tange ao teste de hipótese. 


\section{METODOLOGIA}

\subsection{Conceitos e medidas de eficiência}

Em um processo de produção, podem-se identificar dois tipos de eficiência: técnica e econômica. A eficiência técnica refere-se à proficiência com que os insumos utilizados no processo de produção são convertidos em produtos. Nesse sentido, diz-se que um produtor, que produz dois ou mais produtos, é tecnicamente eficiente para certa quantidade de insumos, se ele somente conseguir aumentar a produção de um produto, quando diminui a produção de algum outro, isto é, quando não há desperdícios de insumos. Ou ainda, uma produção é tecnicamente eficiente se não existir outro processo, ou combinação de processos, que consiga alcançar o mesmonível de produção, utilizando-se uma quantidade inferior de pelo menos um insumo.

$\mathrm{O}$ conceito de eficiência econômica refere-se à otimização de custo e de lucro. O processo produtivo é economicamente eficiente se não existir processo altemativo, ou combinação de processos, que produza a mesma quantidade, a menor custo. Ou então, quando produtos e insumos são variáveis, se não existir combinação de processos que gere maior lucro.

A eficiência técnica diz respeito ao aspecto físico da produção. A eficiência econômica é uma extensão da eficiência técnica, diz respeito ao custo e ao lucro, e envolve aspetos físicos e monetários. Assim o processo para ser economicamente eficiente requer a máxima eficiência técnica

Segundo Tupy et al. (1998), a eficiência de uma fima (ou unidade produtiva) é medida pela comparação entre valores observados e valores ótimos de insumos e produtos. Essa comparação pode ser feita em relação ao produto obtido e o nível máximo, fixada a quantidade de insumos utilizada; ou entre a quantidade de insumo utilizado e o mínimo requenido para produzir determinada quantidade de produto; ou, ainda, com a combinação dos dois anteriores. 
Num caso a eficiência técnica é orientada para produto; no outro, para insumo. A eficiência econômica tem duas dimensões: a do custo mínimo, quando a produção é fixada e se variam os insumose, a da renda líquida máxima, quando produtos e insumos são variáveis.

O ótimo pode ser estimado em relação a uma situação ideal, em que se leva, apenas em conta, a restrição do produtor. Por exemplo, estima-se a função de produção, e calcula-se a renda líquida máxima que é a base de comparação. Ou ainda, estima-se a função custo e deriva-se o custo mínimo, em relação ao qual o custo observado é avaliado. Mas, o ótimo pode ser calculado para cada grupo de produtores. Assim, um produtor somente é comparado com os que produzem mais ou igual com quantidade de insumos igual ou menor. Neste procedimento, alcança-se a eficiência relativa.

Funções de fronteira são as bases das estimativas de eficiência. As funçães custo e de produção são dois exemplos. A função de produção é a envoltónia superior e a função custo comesponde àenvoltónia inferior. Outro exemplo de envoltónia superioré a função renda líquida.

O estudo das medidas de eficiência teve início com Farrel (1957), que propôs um modelo empírico para eficiência relativa, em oposição ao modelo de função de produção. Segundo o autor, é melhor determinar a medida de eficiência da firma em relação ao melhor nível de eficiência observado, do que em relação a algum ideal inatingível. A fronteira de eficiência, nessa formulação, é construída pelos valores observados de insumos e produtos, e não por valores estimados. Que critérios utilizar para selecionar as observações? Farrel (1957), propôs um método econométrico para estimar a função de produção e para medir eficiência técnica e alocativa ${ }^{5}$, queé um método não paramétrico de fronteira determinista.

Considere-se uma firma produzindo $y$ com o uso dos insumos $x_{1}$ e $x_{2}$, e admita que a função de produção de fronteira é $y=f\left(x_{1}, x_{2}\right)$. Sob retomos constantes à escala, pode-se escrever $1=f\left(x_{1}, x_{2}\right)$. Expressando-se $x_{2}$ em função de $x_{1}$, obtém-se a isoquanta unitária (Figura 2), que é a fronteira técnica.

\footnotetext{
${ }^{5}$ Pode-se argumentar que as decisões dos agentes econômicos são simultâneas; portanto, as que afetam a eficiência alocativa influenciam também a eficiência técnica, e vice-versa. Farrel (1957) admitiu a possibilidade de desagregação das decisões conjuntas para medir seus efeitos (Kopp, 1981).
} 


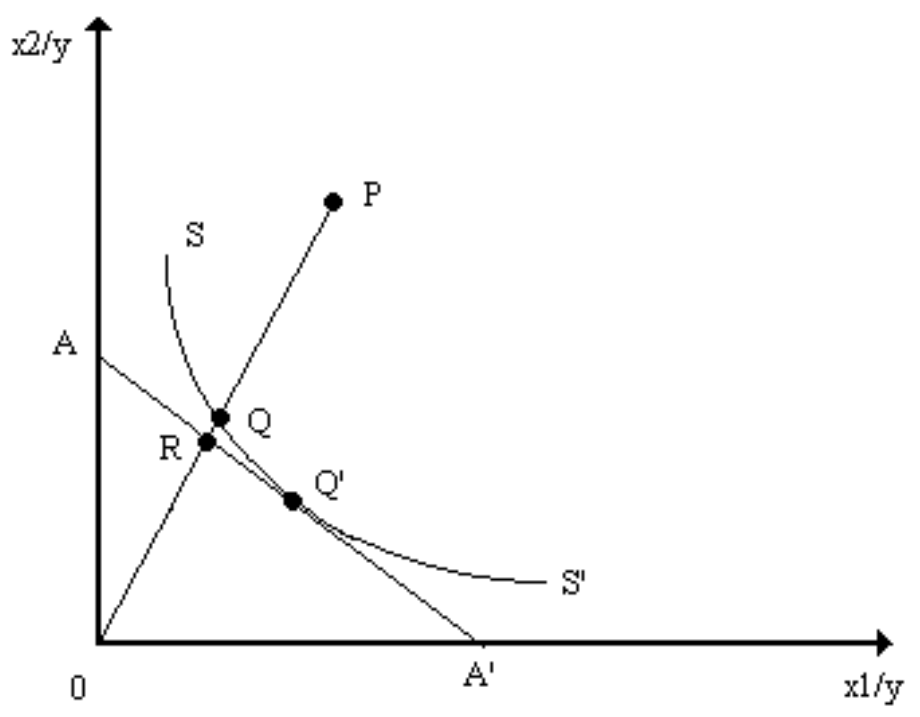

Figura 2 - Medidas de eficiência com orientação insumo.

Na Figura 2, SS' representa a isoquanta unitária da firma eficiente. Nota-se que esta isoquanta é desconhecida na prática, sendo necessária estimar a função de produção da firma eficiente. Se outra firma usa a quantidade de insumos, definida pelo ponto $\mathrm{P}$, para produzir a mesma quantidade de produto, sua ineficiência técnica é representada pela distância QP, que indica a quantidade pela qual os dois insumos podem ser, proporcionalmente, reduzidos, sem diminuir a produção. A razão $\mathrm{QP} / 0 \mathrm{P}$ mede a ineficiência técnica. A eficiência técnica (ET) iguala-se a,

$$
\mathrm{ET}=1-\frac{\mathrm{QP}}{\mathrm{OP}} .
$$

Claro que $0<\mathrm{ET} \leq 1$. Se ET $=1$, a firma é, tecnicamente eficiente, porque está sobre a isoquanta eficiente, como é o caso do ponto $\mathrm{Q}$. 
Quando se conhecem a razões entre os preços dos insumos, representada pela isocusto AA', na Figura 2, pode-se calcular a eficiência alocativa (EA). Considerando-se uma firma que opera em $\mathrm{P}$, tem-se:

$$
\mathrm{EA}=\frac{\mathrm{OR}}{\mathrm{OQ}}
$$

A distância RQ representa redução dos custos de produção que ocorre, quando a firma opera em Q', em vez do ponto Q, que é tecnicamente eficiente, mas alocativamente ineficiente.

Assim, de acordo com Førsund et al. (1980), a ineficiência técnica é o resultado do uso excessivo de insumos, para dado nível de produção. A ineficiência alocativa decorre do emprego dos insumos em proporções inadequadas, dados seus respectivos preços, ou seja, quando a taxa marginal de substituição entre os insumos não for igual à razão dos seus preços.

A eficiência econômica total (EE) seria dada pelo produto das eficiências técnica e alocativa:

$$
\mathrm{EE}=\frac{O \mathrm{Q}}{\mathrm{OP}} \mathrm{x} \frac{\mathrm{OR}}{\mathrm{OQ}}=\frac{\mathrm{OR}}{\mathrm{OP}} .
$$

O próprio conceito de ineficiência técnica não é sempre aceito. Muller (1974) destaca a existência de insumos não-físicos, em especial informações e conhecimento, que limitariam o uso correto de tecnologia pelas firmas. A não inclusão desses insumos distorce a fronteira estimada e invalidam as estimativas de ineficiência. Contudo, apesar das críticas, as funções de fronteira são muito utilizadas. 


\subsection{Conceito de racionalização dos dados}

Dado que conhecem-se as observações, $\left(w^{i}, x^{i}, y^{i}\right) i=1,2, \ldots, \mathrm{n}$, de $n$ produtores, em que $w$ é o vetor preço de insumos, $x$ o vetor de insumos e $y$ o vetor de produto, é possível saber se elas foram geradas por empreendedores que minimizam custo ou que maximizam a renda líquida. Afriat (1967) desenvolveu a teoria, em grande parte, e ela foi aperfeiçoada por Varian, numa série de artigos, citados em Varian (1985). Uma exposição dos artigos de Varian está em Alves (2000).

Se o agricultor A escolheu uma combinação de insumos $x$ para produzir o produto $y$, então, ela não pode custar mais que qualquer outra combinação de outro produtor, quando o dispêndio é avaliado pelos preços do agricultor A. Ora esta definição somente faz sentido se os produtores tiverem acesso à mesma tecnologia, representada pelo conjunto de produção $V(y)=\{x: x$ produz $y\}$.

Podemos relaxar a hipótese de um único conjunto de produção, específico de cada produtor, que é muito forte, exigindo que ele seja um conjunto encadeado. Ora, se cada produtor, particularizado para $\mathbf{A}$, tiver o conjunto de produção que lhe é específico, segue-se que a racionalização é, trivialmente, obedecida, porque qualquer outra combinação que produza $y$ ou não pertence ao conjunto de produção do agricultor $\mathbf{A}$, ou se pertencesse e custasse menos, teria sido escolhida.

Dois conjuntos de produção dizem-se encadeados, se $y \geq z \rightarrow V(z) \supseteq V(y)$. Se a produção $y$ é maior ou igual que a produção $z$, então, se a combinação $x$ de insumos produz $y$, então, ela produz $z$, também. Admite-se um único produto. Outra propriedade importante, seja $\mathbf{a}$ e $\mathbf{b}$ duas combinações de insumos. Seja $\mathbf{a} \geq \mathbf{b}^{6}$. Se $\mathbf{b}$ produz $y$, então $\mathbf{a}$ também produz $y$. Permite-se, assim, o desperdício de recursos sem se impor nenhum custo. Admite-se que $V(y)$ é encadeado, pressuposição 1, e que permite o desperdício, pressuposição 2. Sem a pressuposição 2, é impossível falar-se de ineficiência técnica.

Formaliza-se a definição de racionalização, como se trata de custo, designemola por c-racionalização .

\footnotetext{
${ }^{6} \mathbf{a} \geq \mathbf{b}$ significa que cada componente do vetor $\mathbf{a}$ é maior ou igual que a correspondente do vetor be, pelo menos, um é diferente.
} 
Existe c-racionalização se a seguinte condição verificar-se: quando $x$ é a combinação de insumos observada do agricultor $i$ e $z$, qualquer outra combinação também observada de outros agricultores, $w^{i} * x^{i} \leq w^{i} * z^{j} j=1,2, \ldots, n$.

Com esta preparação, Varian demonstrou o teorema que é base do estudo, a demonstração pode ser encontrada em Alves (2000). O teorema diz que as seguintes cond ições são equivalentes:

(i) Existe uma família encadeada de conjuntos de produção, $V(y)$, que $c$ racionaliza as observações;

(ii) Se $y^{j} \geq y^{i}, \rightarrow w^{i} * x^{j} \geq w^{i} * x^{i}$. Quem produz mais ou igual não gasta menos do que quem produz a mesma quantidade ou menos, dispêndio avaliado pelos preços de quem produz menos;

(iii) Existe uma família encadeada de conjuntos de produção, que são convexos, fechados e satisfazem as pressuposições 1 e 2 .

A condição (ii) é o fundamento do estudo. Os dados, dificilmente, não contém algumas violações da condição (ii). É importante descobrir qual é a menor perturbação necessária, no sentido de modificar a combinação de insumos de modo que satisfaça (ii). E depois testar a hipótese nula que afirma que os agricultores c-racionalizam os dados e derivar uma medida de eficiência.

\subsection{Modelos econométricos de estimação de fronteira e eficiência}

A função de produção retorna o máximo de produção correspondente a cada combinação de insumos. Descreve, assim, a tecnologia da firma. É o envelope superior, definido por $F(x)=\operatorname{Supremo}\{y: x \in V(y)\}$, quando para cada $x, V(y)$ é um conjunto compacto. Note-se que $V(y)$ é o conjunto de $y$ 's que a combinação de insumos $x$ produz.

Outro exemplo é a função-custo $C(w, y)=\operatorname{Min}_{x}\{w * x: f(x) \geq y, x \geq 0\}$, e $f(x)$ é semicontínua superior. Esta função retorna o menor dispêndio necessário à produção de $y$, quando os preços dos insumos correspondem ao vetor $w$. Uma terceira representação é 
dada pela função lucro, $\pi(p, w)=\operatorname{Max}_{y, x}\{p * y-w * x: x \geq 0, y \geq 0\}$ em que $w$ é vetor preço de insumos, $p$ o vetor preço de produtos, $y$ uma combinação de produtos e $x$ de insumos. Retorna o lucro máximo, dados os preços dos produtos e dos insumos ${ }^{7}$. Na literatura econométrica $f(x), c(y, w)$ e $\pi(p, w)$ caracterizam o comportamento otimizante do produtor, e estabelecem os limites (superior ou inferior) das variáveis dependentes (Førsund et al., 1980).

Seja a cesta de produto e insumos $\left(y^{0}, x^{0}\right)$ e $y=f(x)$ a função de produção. Logo, $y>f\left(x^{o}\right)$ não é possível. Se $y<f\left(x^{o}\right)$, quando $y$ corresponde à cesta de insumos $x^{0}$, o produtor é ineficiente. A medida de eficiência técnica, neste contexto, é definida por $E=\frac{y}{f\left(x^{0}\right)} . \operatorname{Logo}, 0<\mathrm{E} \leq 1$, quando $f\left(x^{0}\right)>0$. Quando $E$ for menor que 1, o custo e o lucro correspondentes não estão otimizados, mas a recíproca não é verdadeira. $\mathrm{O}$ termo ineficiência alocativa é comum na literatura. Diz respeito à alocação de recursos que difere da solução de custo mínimo ou lucro máximo.

Batesse (1992) oferece uma representação mais geral que a de Farrel. Cuida tão somente do conceito de eficiência técnica. A Figura 3 sintetiza suas idéias. A medida da eficiência técnica da firma, que opera no ponto $\mathbf{A}$, é dada pela razão y/y", onde y é a produção de fronteira associada ao nível de insumos empregados (representada no ponto B). É uma medida de eficiência técnica condicionada aos níveis de insumos empregados.

\footnotetext{
${ }^{7}$ A desvantagem da função lucro é que ela pode retornar o infinito como valor, a não ser que se imponham restrições aos insumos. E infinito não pertence ao conjunto dos números reais, e, sim, ao dos números reais estendidos.
} 


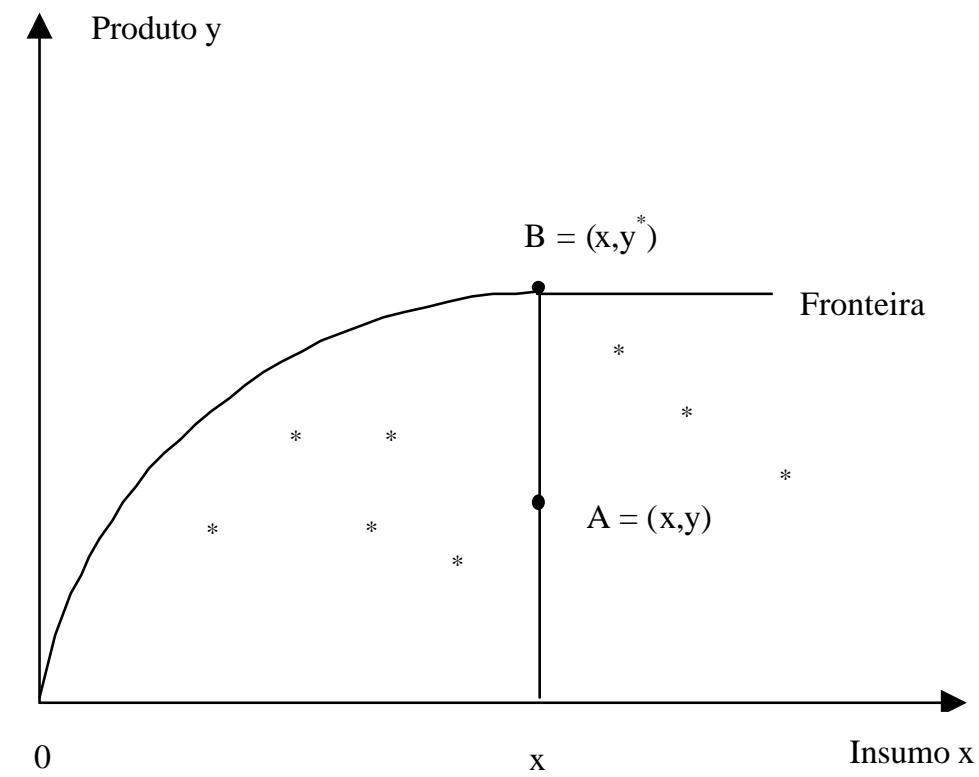

Figura 3 - Eficiência técnica das firmas baseada na função de produção fronteira determinista.

Fonte: Battese (1992)

A abordagem de Farrel (1957), emprega técnicas de programação linear para estimar a isoquanta, o que torna muito suscetível às observações extremas e a erros de medida. Esse autor propôs também o uso de métodos paramétricos, recomendando o emprego de formas funcionais, como a Cobb-Douglas. Contudo, alertou para a desvantagem de uma forma funcional específica, que é sempre restritiva. Trata-se também de uma fronteira determinista. E, a rigor, nenhuma observação pode estar acima dela.

O trabalho de Aigner et al. (1968) inicia a metodologia conhecida como modelo determinista e paramétrico de fronteira, que pode ser estimado por programação linear ou quadrática, com os pontos da amostra na fronteira e abaixo dela. Timmer (1971) sugeriu um modelo de função de produção de fronteira probabilístico, pelo qual pequena 
parcela da amostra pode estar acima da fronteira. O pecado de sua formulação, embora adequada para lidar com observações atípicas, é falta de racionalidade econômica.

Afriat (1972) iniciou a análise estatística da fronteira determinista. Conforme Battese (1992), ela é representada por;

$$
y_{i}=f\left(x_{i} ; \beta\right) e^{-U i}, \mathrm{i}=1,2, \ldots, n,
$$

onde $y$ representa o nível de produção possível para a $i$-ésima firma, $f\left(x_{i} \beta\right)$ é uma forma funcional apropriada, $x_{i}$ é o vetor de insumos, exógeno (independente de $U_{i}$ ), $\beta$ é um vetor de parâmetros desconhecidos, $U_{i}$ são variáveis aleatórias, independentes e identicamente distribuídas, não negativas, relacionadas a fatores específicos que contribuem para a firma não atingir a máxima eficiência na produção, e $n$ representa o número de firmas presentes na amostra. Como $U_{i} \geq 0 \mathrm{e}$, portanto, $0<\mathrm{e}^{-\mathrm{Ui}} \leq 1$ a produção tem que estar abaixo de $f\left(x_{i}, \beta\right)^{8}$. Para a $i$-ésima firma, define-se a eficiência relativa por,

$$
E_{i}=\frac{f\left(x_{i} ; \beta\right) e^{-U_{i}}}{f\left(x_{i} ; \beta\right)}=e^{-U_{i}} .
$$

Os modelos descritos são conhecidos como deterministas de determinação de fronteira. Ou seja, não se separa a especificação do erro da regressão da especificação da ineficiência. Ou seja, o erro de regressão é interpretado como sendo uma medida de ineficiência. Ainda, observe-se que as firmas têm a mesma fronteira de produção, ou de custo, ou de lucro, e as variações de desempenho são atribuídas ao acaso. Não contemplam, portanto, a possibilidade do desempenho individual ser afetado por fatores fora do controle das firmas. Realçam-se, entre eles, o desejo de vencer, o esforço e a sorte do produtor (Aigner et al., 1977). Ainda, destacam-se choques puramente aleatórios (Aigner et al., 1968), problemas de definição e de medida das variáveis (Timmer, 1971).

\footnotetext{
${ }^{8}$ A comparação é feita $\operatorname{com} f\left(x_{i}, \boldsymbol{\beta}\right)$, por isto, diz-se fronteira determinista.
} 
Evoluiu-se para o desenvolvimento de modelos de fronteira estocástica (Aigner et al., 1977) $)^{9}$, que possibilitam especificar o erro, em duas componentes. Uma delas é simétrica (distribuição normal), e representa os efeitos aleatórios, fora do controle da firma. A outra, não negativa, captura os efeitos controláveis (ineficiência) (Schmidt et al., 1979). É a primeira componente que dá origem ao nome fronteira estocástica.

Battese (1992) representou a fronteira probabilística por,

$$
y_{i}=f\left(x_{i} ; \boldsymbol{\beta}\right) e^{(V i-U i)} \mathrm{i}=1,2, \ldots, n,
$$

em que $V_{i}$ é o erro aleatório, com média zero, associado aos fatores fora do controle da firma. Pelo modelo, o limite superior de produção possível é dado por $f\left(x_{i}, \beta\right) e^{(V i)}$, portanto, estocástico. $V_{i}$ e $U_{i}$ são variáveis aleatórias independentes. E $U_{i}$ é uma variável aleatória não negativa.

Consideram-se duas firmas, $i$ e $j$, que produzem as quantidades $y_{i}$ e $y_{j}$, com as cestas de insumos $x_{i}$ e $x_{j}$ (Figura 4). O produto $y_{i}{ }^{*}$ excede o valor da função de produção determinista $f\left(x_{i}, \beta\right)$, porque a firma encontrou condições favoráveis de produção, e, por isto, o erro aleatório $V_{i}$ é positivo. Já a $j$-ésima firma tem $y_{j}{ }^{*}$ menor do que o valor da função de produção determinista, porque sua atividade produtiva está associada a condições desfavoráveis, representadas por $V_{j}$ negativo (Battese, 1992).

Para a $i$-ésima firma, define-se a eficiência técnica por;

$$
E T_{i}=\frac{y_{i}}{y_{i}^{*}}=\frac{f\left(x_{i} ; \beta\right) e^{(V i-U i)}}{f\left(x_{i} ; \beta\right) e^{(V i)}}=e^{(-U i)} .
$$

Embora os dois modelos conduzam a mesma nædida, simbolicamente, contudo, eles divergem na interpretação de $U$ e na técnica de estimação, por causa da especificação do termo do erro. Se a variância da componente $U_{\mathrm{i}}$ for nula, então, o modelo probabilístico equivale ao determinista.

\footnotetext{
${ }^{9}$ A especificação também foi proposta, independentemente, por Meeusen et al. (1977).
} 


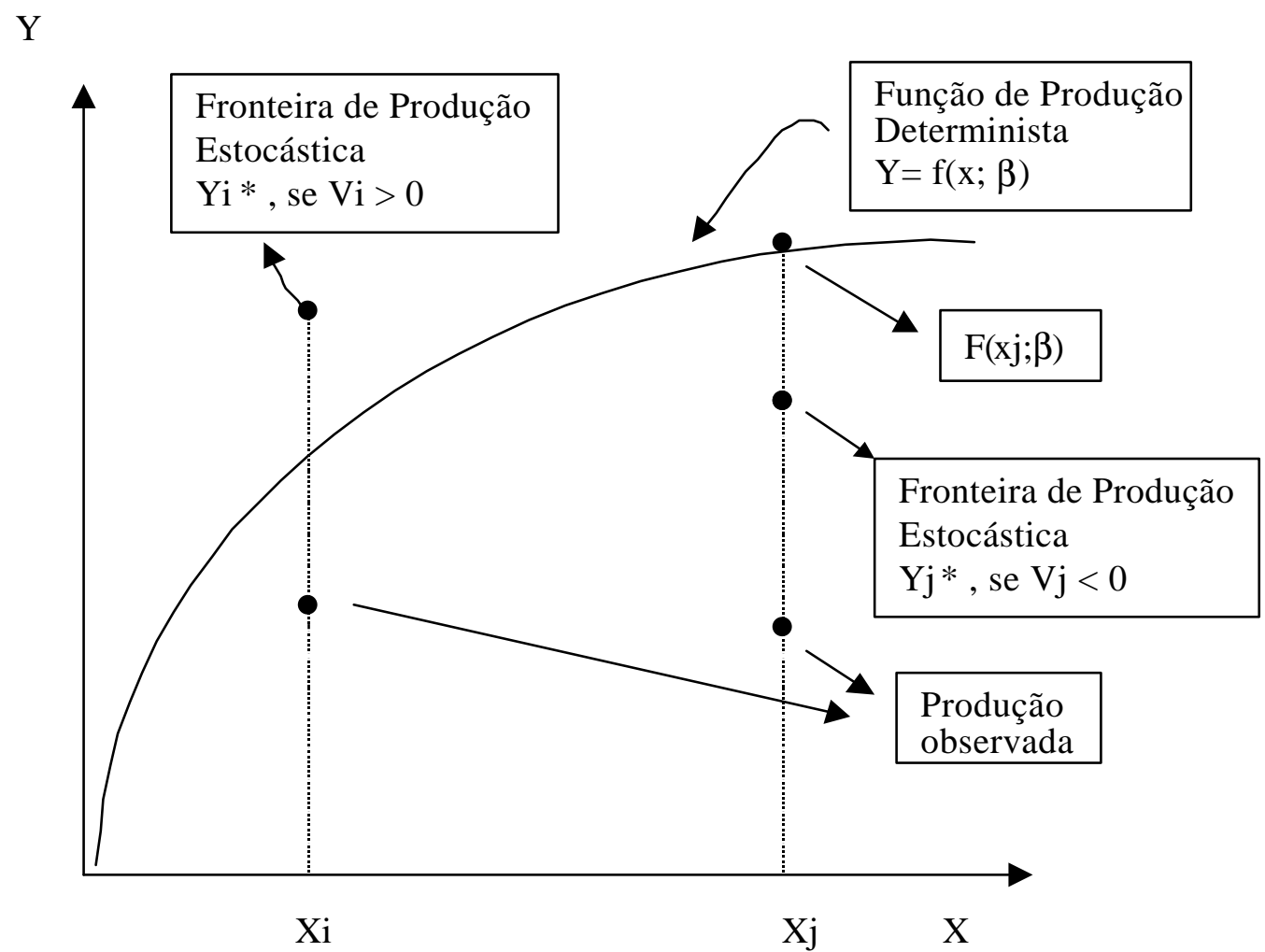

Figura 4 - Função de produção fronteira estocástica.

Fonte: Batesse (1992)

Os modelos de fronteira estocástica podem ser estimados por técnicas de máxima verossimilhança e de mínimos quadrados ordinários corrigidos. Olson et al. (1980) concluíram que o desempenho das duas técnicas é equivalente, em amostra pequena ou grande. Coelli (1995), por experimentos de Monte Carlo, concluiu pela existência de viesses, em mínimos quadrados ordinários e em máxima verossimilhança. Entretanto, o segundo estimador é melhor, visto que os viesses tendem a diminuir com o tamanho da amostra.

Van den Broeck (1980) efetuaram comparações entre funções de fronteiras estocásticas e deterministas, e concluíram que os parâmetros estimados diferem, 
consideravelmente, e de forma não-sistemática. Portanto, a escolha da especificação deve ser baseada na qualidade dos dados, no processo em que foram gerados e, principalmente, nos propósitos do estudo.

A principal desvantagem do modelo de fronteira estocástica era a impossibilidade de estimar o nível de eficiência técnica para cada observação. Jøndrow (1982) resolveu o problema para os casos em que $U$ tem distribuição meio normal (half normal) ou exponencial e, posteriormente, a solução foi melhorada por Battese et al. (1988).

As estimações de funções de produção permitem extrair informações sobre ineficiência técnica, mas não sobre ineficiência alocativa. Schmidt et al. (1979), sob pressuposições de minimização de custos, derivaram a fronteira de custo estocástica, pela especificação Cobb-Douglas, que necessita de informações sobre produtos e preços dos insumos para que seus parâmetros sejam estimados. Schmidt et al. (1980) estenderam esse modelo para casos em que as ineficiências técnicas e alocativas são correlacionadas.

Mais detalhes sobre as diferentes formas funcionais para estimações de fronteiras podem ser encontradas em: Greene (1980b); Akridge (1989); Kopp et al. (1982); Bauer (1990); Kumbhakar (1987) e Greene (1990).

No caso da agricultura, a pressuposição de que todos os desvios em relação à fronteira devem-se à ineficiência é difícil de ser aceita, visto que a produção agrícola é instável, por causa de variações climáticas, doenças, pragas, etc. Por isso, na área de economia agrícola, a abordagem econométrica tem sido preferida (Coelli et al., 1996).

\subsection{Análise envoltória de dados (DEA)}

Os modelos econométricos paramétricos, tanto estocásticos como deterministas, impõem formas funcionais para representar as tecnologias. A abordagem envoltória de dados (DEA - data envelopment analysis) não necessita desta pressuposição. A eficiência da "unidade tomadora de decisões “ (Decision Making Unit - DMU) é medida em relação a fronteira, que é gerada pelos vetores $(x, y), x$ é o vetor de insumos e $y$ é o 
vetor de produto dos produtores amostrados, como combinação linear destes vetores, respeitadas as restrições adequadas aos objetivos da análise (Seiford et al., 1990). Notese que a fronteira é gerada e não estimada.

Em situações em que várias firmas utilizam múltiplos insumos e produzem vários produtos, o cálculo da eficiência relativa é complexo para as fronteiras estocásticas. Com base em Farrel (1957), os autores Charnes et al. (1978) deram início à abordagem não-paramétrica para múltiplos insumos e produtos, e cunharam o termo data envelopment analysis (DEA), envoltória dos dados.

Os resultados do DEA são bastante detalhados, e servem para dar base às recomendações gerenciais, por isto, são auxiliares às tarefas de quem toma decisão.

A amostra de dados observados das firmas é a base factual. Os dados referemse ao par $(x, y)$, (insumo, produto). O objetivo é gerar o conjunto de referência que é convexo e fechado, a partir dos próprios dados das firmas, e, então, classificá-las em eficientes ou ineficientes, tendo a fronteira do conjunto, como referência. A envoltória é a fronteira do conjunto gerado, e os pontos observados estão sobre ela ou abaixo dela.

É necessário definir o tamanho do grupo de comparação, cuja determinação está sujeita a uma situação de conflito. Numa população grande, tem-se uma maior probabilidade de unidades de nível elevado de desempenho determinarem a fronteira de eficiência (como definida na teoria microeconômica). O maior número de unidades possibilita, além disso, uma identificação das relações típicas entre insumos e produtos. Ainda, com o aumento do número de unidades é possível incorporar mais variáveis na análise. Uma regra prática diz que o número de unidades deve ser, no mínimo, duas vezes o número de insumos e produtos. Em compensação, um grande número de unidades pode diminuir a homogeneidade, e aumenta a possibilidade de alguns resultados serem afetados por fatores exógenos, não desejáveis (Golany et al., 1989).

O modelo DEA, apresenta algumas desvantagens em comparação a técnicas paramétricas. É muito sensível à existência de observações destoantes, e erros de medida e ruídos estatísticos, em geral, podem comprometer o próprio cálculo da fronteira (Bauer, 1990). A existência de, apenas, uma observação discrepante na amostra pode 
influenciar todas as outras medidas de eficiência. Testes estatísticos foram recentemente desenvolvidos por Souza (2003).

Färe et al. (1994) decompuseram a medida de eficiência em vários componentes. O modelo é ilustrado na Figura 5 para o caso de um produto $(y)$, um insumo $(x)$ e as firmas (A, B, C e D).

Sob retornos constantes à escala, a tecnologia é limitada pelo raio 0A. Sob retornos não crescentes, a fronteira é 0ABC. Sob retornos variáveis, o uso de insumo de uma firma $j$ não pode ser menor do que a menor quantidade de insumo usada por qualquer outra firma. Isto conduz à possibilidade de retornos crescentes à escala e causa a fronteira a ficar não mais próxima ao eixo do $y$ além do ponto $\mathrm{A}\left(x_{\mathrm{a}} \mathrm{ABC}\right)$. Sob retornos variáveis à escala, as funções de distância para insumo e produto para a firma no ponto $\mathrm{C}$ são dadas, respectivamente, pelas relações $0 x_{\mathrm{b}} / 0 x_{\mathrm{a}}$ e $x_{\mathrm{b}} \mathrm{C} / x_{\mathrm{b}} \mathrm{B}$.

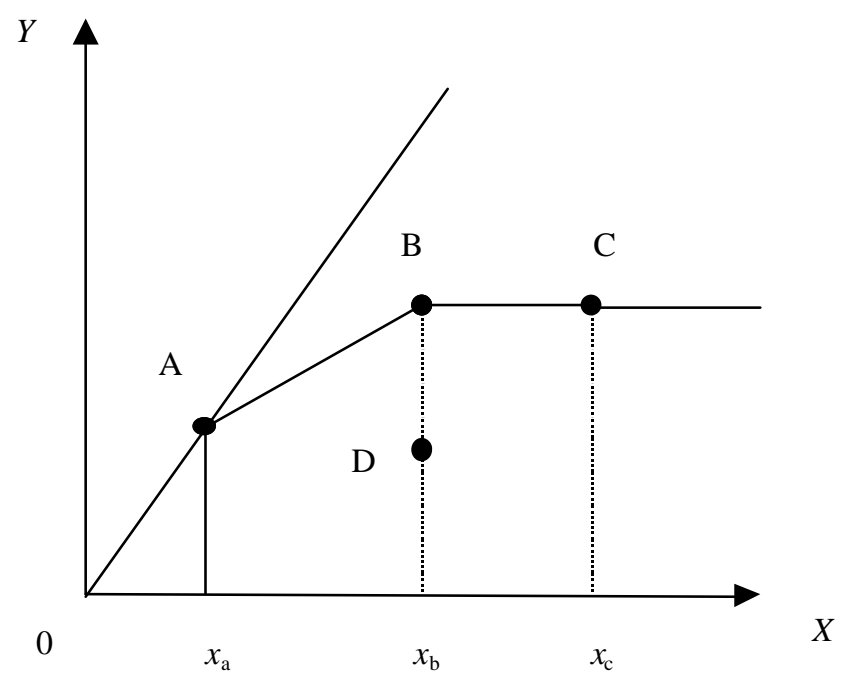

Figura 5 - Tecnologia de referência e retornos a escala.

Fonte: Färe et al. (1994) 
Para a $i$-ésima DMU, são representados os vetores $x_{\mathrm{i}}$ e $y_{\mathrm{i}}$, respectivamente, para insumos e produtos. Para cada DMU, pode-se obter uma medida de eficiência, que é a razão entre todos os produtos e todos os insumos. Para a $i$-ésima DMU, tem-se:

$$
\text { Eficiência da DMU } i=\frac{u^{\prime} y_{i}}{v^{\prime} x_{i}}=\frac{u_{1} y_{1 i}+u_{2} y_{2 i}+\cdots+u_{m} y_{m i}}{v_{1} x_{1 i}+v_{2} x_{2 i}+\cdots+v_{k} x_{k i}}
$$

em que $u$ é um vetor ( $m \times 1)$ de pesos nos produtos e $v$ é um vetor $(k \times 1)$ de pesos nos insumos. É conhecido por medida de produto-insumo (output-input), quando os $u$ 's e os $v$ 's são preços de produtos e insumos. No caso, trata-se de uma medida global de produtividade.

A pressuposição inicial é de que essa medida de eficiência requer um conjunto comum de pesos que será aplicado em todas as DMUs. Entretanto, segundo Dyson et al. (1990), existe certa dificuldade em obter um conjunto comum de pesos para determinar a eficiência relativa de cada DMU, pois as DMUs podem estabelecer valores para os insumos e produtos, de modos diferentes, e adotarem diferentes pesos. É necessário, então, estabelecer um problema de otimização que permita que cada DMU possa adotar o conjunto de pesos que lhe for mais favorável, comparativamente, com as outras unidades. Para selecionar os pesos ótimos para cada DMU, especifica-se o seguinte problema de programação matemática. Para a i-ésima DMU, tem-se:

$\operatorname{MAX}_{u, v}\left(u^{\prime} y_{i} / v^{\prime} x_{i}\right)$

sujeito a:

$$
\begin{aligned}
& u^{\prime} y_{i} / v^{\prime} x_{i} \leq 1, \mathrm{j}=1,2, \ldots, \mathrm{n} . \\
& u, v \geq 0 .
\end{aligned}
$$

Essa formulação envolve a obtenção de valores para $u$ e $v$, de tal forma que a medida de eficiência para a $i$-ésima DMU seja maximizada, sujeita à restrição de que as medidas de eficiência de todas as DMUs sejam menores ou iguais a um. Segundo Moita (1995), as características chave deste modelo é que os pesos $u$ e $v$ são tratados como incógnitas, sendo escolhidos de maneira que a eficiência da $i$-ésima DMU seja 
maximizada. Caso a eficiência obtida para a DMU, que está sendo testada, seja igual a um, ela será eficiente em relação às demais; caso contrário, será ineficiente.

O modelo pode ser linearizado, e a solução obtida por métodos de programação linear convencionais. Para isto, admite-se $v * x=1$. O dual é dado por,

$\mathrm{MIN}_{\Theta \lambda} \theta$

sujeito a:

$$
\begin{aligned}
& -y_{i}+Y \lambda \geq 0, \\
& \theta x_{i}-X \lambda \geq 0, \\
& \lambda \geq 0, \theta>0,
\end{aligned}
$$

em que $\theta$ e $\lambda$ varia no conjunto de números reais não negativos. Valor ótimo de $\theta>0$ é a medida de eficiência da $i$-ésima DMU. Se o valor de $\theta$ for um, a DMU é eficiente; e $1 \geq \boldsymbol{\theta}>0$. O parâmetro $\lambda$ é um vetor ( $n \times 1)$, cujos valores são calculados de forma a obter a solução ótima. Para uma DMU eficiente, todos os valores de $\lambda$ são zero; para uma DMU ineficiente, os valores de $\lambda$ serão os pesos utilizados na combinação linear de outras DMUs eficientes, que influenciam a projeção da DMU ineficiente sobre a fronteira calculada. Isto significa que, para uma unidade ineficiente, existe pelo menos uma unidade eficiente. As unidades eficientes que, quando combinadas, fornecem a DMU virtual para a unidade ineficiente são conhecidas como pares ou benchmarks daquela DMU. Note-se que (10) especifica que a comparação é feita com quem não produz menos e não gasta mais que $\boldsymbol{i}$.

Segundo Coelli et al. (1998), o problema apresentado nessa forma envoltória (dual) envolve menor número de restrições do que o problema primal. Como no primal existem $(k+m)$ variáveis, o dual terá $(k+m)$ restrições, que é menor que as $(n+1)$ restrições do primal, uma vez que o número de DMUs é, geralmente, superior à soma do número de insumos mais o número de produtos. Nesse sentido, o dual é preferível ao primal, pois consome menos tempo para ser resolvido. Mas, tem interpretação econômica mais complicada. Novamente, é importante notar que o problema deve ser resolvido $n$ vezes, isto é, uma vez para cada DMU da amo stra. 
O modelo de retornos constantes à escala (CCR) é reformulado, com o objetivo de possibilitar a construção da fronteira de retornos variáveis. Banker et al. (1984) propuseram o modelo, conhecido como $\mathrm{BCC}$, devido às iniciais dos nomes dos autores.

O uso da especificação de retornos constantes, quando nem todas as DMUs estão operando em escala ótima, resultará em medidas de eficiência técnica que podem ser confundidas com eficiência de escala. A utilização da especificação de retornos variáveis permite o cálculo das eficiências técnicas, livres desses efeitos de escala.

O problema de programação linear com retornos constantes pode ser modificado para atender à pressuposição de retornos variáveis, adicionando-se uma restrição de convexidade. Considerando-se o modelo dual, tem-se:

$\mathrm{MIN}_{\Theta \lambda} \theta$

sujeito a:

$$
\begin{aligned}
& -y_{i}+Y \lambda \geq 0, \\
& \Theta x_{i}-X \lambda \geq 0, \\
& N_{l}{ }^{\prime} \lambda=1, \\
& \lambda \geq 0, \text { e } \theta>0 .
\end{aligned}
$$

Em que $N_{l}$ é um vetor $(n \times 1)$ de uns. Essa abordagem forma uma superfície convexa de planos em interseção, a qual envolve os dados de forma mais compacta do que a superfície formada pelo modelo com retornos constantes. Com isto, os valores obtidos para a eficiência técnica, com a pressuposição de retornos variáveis, são maiores do que aqueles obtidos com retornos constantes. Formalmente, isto é assim porque se envolve uma restrição adicional. Se uma DMU é eficiente no modelo CCR, então ela é eficiente no modelo BCC (Seiford et al., 1999).

Quando os valores obtidos de eficiência técnica pelos dois modelos (CCR e BCC) são diferentes para uma DMU qualquer, há ineficiência de escala, ou seja, a empresa não está operando com retornos constantes à escala. Esta ineficiência é calculada pela diferença entre os $\theta$ s encontrados para retornos variáveis e os encontrados para retornos constantes. 
A Figura 6 apresenta a eficiência técnica e de escala para um insumo e um produto. Nela, RC indica a fronteira obtida pela técnica DEA para retornos constantes à escala. A linha pontilhada RV representa a fronteira para retornos variáveis.

Considere $\mathrm{P}$ na Figura 6. Sob a pressuposição de retornos constantes, a distância $\mathrm{PP}_{\mathrm{C}}$ indica a ineficiência técnica, enquanto $\mathrm{PP}_{\mathrm{V}}$ refere-se à mesma medida para retornos variáveis. A diferença entre as duas, ou seja, o segmento $\mathrm{P}_{\mathrm{C}}-\mathrm{P}_{\mathrm{V}}$ fornece a ineficiência de escala. As medidas do ponto $\mathrm{P}$, em termos de razão, ou seja, limitadas entre zero e um, são:

$$
\begin{aligned}
& \mathrm{ET}_{\mathrm{I}, \mathrm{RC}}=\mathrm{AP}_{\mathrm{C}} / \mathrm{AP}, \\
& \mathrm{ET}_{\mathrm{I}, \mathrm{RV}}=\mathrm{AP}_{\mathrm{V}} / \mathrm{AP}, \\
& \mathrm{EEsc}_{\mathrm{I}}=\mathrm{AP}_{\mathrm{C}} / \mathrm{AP}_{\mathrm{V}},
\end{aligned}
$$

em que o subscrito I indica modelos com orientação insumo; RC, retornos constantes; e $\mathrm{RV}$, retornos variáveis.

Desta forma, pode-se deduzir que a medida de eficiência técnica com retornos constantes à escala $(\mathrm{RC})$ é composta pelo produto da eficiência técnica com recursos variáveis (RV), também conhecida como pura eficiência técnica, e a eficiência de escala (EEsc). Esta medida de escala não informa se a DMU avaliada está operando em retornos crescentes ou decrescentes à escala. Sabe-se apenas se ela está operando na escala ótima $(E E s c=1)$, ou seja, com retornos constantes, ou com retornos variáveis $($ EEsc $\neq 1)$. Este problema é contornado reformulando o problema de programação linear, incluindo a restrição de retornos não crescentes ou não decrescentes. Isto é obtido substituindo a restrição $\mathrm{N}_{\mathrm{l}} \lambda=1$, em (11), por uma das restrições $\mathrm{N}_{\mathrm{l}} \lambda \leq 1$ e $\mathrm{N}_{1} \lambda \geq 1$, respectivamente. 


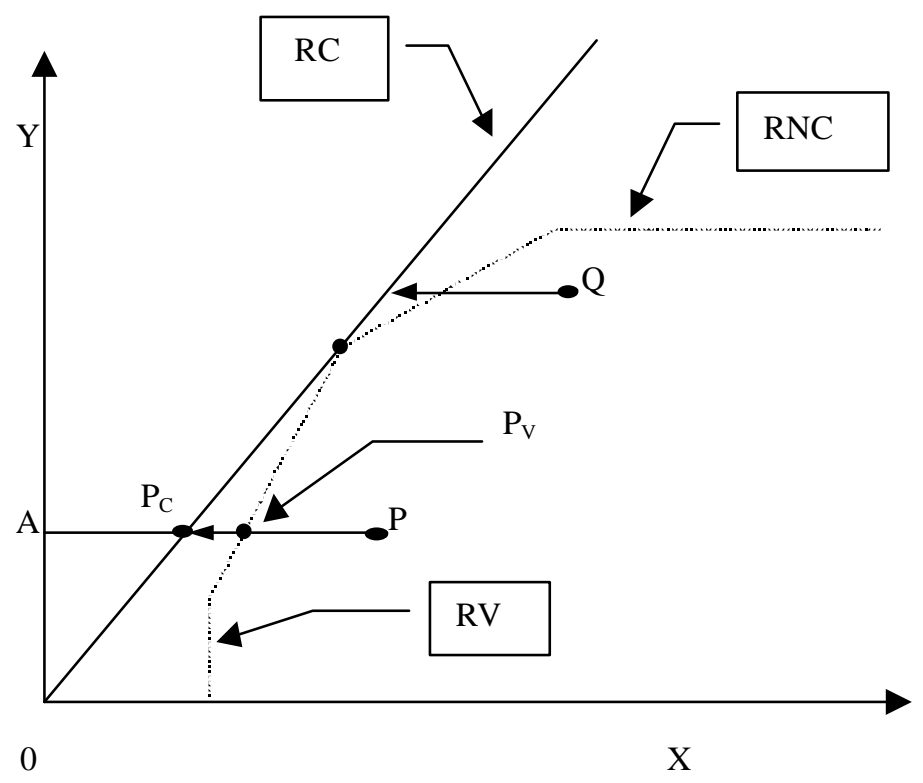

Figura 6 - Eficiência técnica e eficiência de escala.

Fonte: Coelli (1996)

A fronteira obtida para o modelo com retornos não crescentes (RNC), na Figura 6, é composta, inicialmente, por uma faixa da fronteira com retornos constantes, com origem em 0 . Em seguida é formada por uma faixa da fronteira de retornos variáveis. Para determinar a natureza da escala de uma DMU qualquer, basta verificar se o coeficiente de eficiência técnica no modelo com retornos não crescentes é igual ao do modelo com retornos variáveis. Se forem diferentes, como é o caso do ponto $\mathrm{P}$, então a DMU terá retornos crescentes à escala. Se forem iguais, como é o caso do ponto $\mathrm{Q}$, ocorrerá uma situação de retornos decrescentes, isto é;

$$
\begin{aligned}
& \text { se } \mathrm{ET}_{\mathrm{RNC}}=\mathrm{ET}_{\mathrm{RV}} \rightarrow \text { Retornos decrescentes, } \\
& \mathrm{se} \mathrm{ET}_{\mathrm{RNC}} \neq \mathrm{ET}_{\mathrm{RV}} \rightarrow \text { Retornos crescentes. }
\end{aligned}
$$


Assim, para identificar se a firma está operando com retornos crescentes ou decrescentes, basta comparar o resultado encontrado para eficiência técnica, no modelo com retornos variáveis (RV), com aquele encontrado no modelo com retornos não decrescentes (RND), ou seja:

$$
\begin{aligned}
& \text { se } \mathrm{ET}_{\mathrm{RND}}=\mathrm{ET}_{\mathrm{RV}} \rightarrow \text { Retornos crescentes, } \\
& \text { se } \mathrm{ET}_{\mathrm{RND}} \neq \mathrm{ET}_{\mathrm{RV}} \rightarrow \text { Retornos decrescentes. }
\end{aligned}
$$

Coelli (1996) cita a possibilidade de existência de modelos de congestão, ou seja, utilização excessiva de insumos. É mais uma decomposição das medidas de eficiência no modelo de retornos constantes, além da pura eficiência técnica e eficiência de escala. Nesta situação, a DMU está operando no terceiro estágio da função de produção, onde a produção se mantém ou até diminui, com o aumento do uso de insumos. É uma condição de retornos negativos. Para detectar a presença de congestão, basta modificar problema de programação linear com retornos variáveis, substituindo na restrição a desigualdade $\Theta x_{i}-X \lambda \geq 0$ pela igualdade $\Theta x_{i}=X \lambda$.

Desta forma, a seguinte seqüência de desigualdades é obedecida $0<\theta$ (retorno constante) $\leq \boldsymbol{\theta}$ (retorno não-crescente) $\leq \boldsymbol{\theta}$ (retorno variável) $\leq \boldsymbol{\theta}$ (congestivo) $\leq 1$. Logo se a medida de $\theta$ para retorno constante for igual a 1 , todas as demais medidas serão iguais a 1 .

Segundo Coelli (1996), a eficiência alocativa de cada DMU pode ser calculada mediante um modelo de minimização de custos, após a determinação da eficiência técnica. Tomando-se, como exemplo, um modelo de orientação insumo, com retornos variáveis, obtêm-se, inicialmente, os coeficientes de eficiência técnica para cada DMU. Em seguida, resolve-se o seguinte problema de minimização de custos para retornos variáveis a escala: 
$\operatorname{MIN}_{\ddot{e}, x_{i}^{*}} w_{i} x_{i}^{*}$,

sujeito a:

$$
\begin{aligned}
& -y_{i}+Y \lambda \geq 0, \\
& x_{i}{ }^{*}-X \lambda \geq 0, \\
& N_{l} \lambda=1, \\
& \lambda \geq 0,
\end{aligned}
$$

em que $w_{\mathrm{i}}$ é o vetor de preço dos insumos para a $i$-ésima DMU; e $x_{\mathrm{i}}{ }^{*}$ é o vetor que minimiza os custos das quantidades de insumos para a $i$-ésima DMU, dados os preços dos insumos $\left(w_{\mathrm{i}}\right)$ e as quantidades de produtos $\left(y_{\mathrm{i}}\right)$. O modelo admite a variação de preços entre as DMUs. O mesmo pode ser calculado para retornos constantes à escala, retirando-se a restrição de convexidade $\left(N_{1} \lambda=1\right)$. A medida de eficiência econômica total (EE) ou eficiência custo, para a $i$-ésima DMU, seria dada pela razão entre o custo mínimo e o custo observado, ou seja,

$$
\mathrm{EE}=\frac{\mathrm{w}_{\mathrm{i}}^{\prime} \mathrm{x}_{\mathrm{i}}^{*}}{\mathrm{w}_{\mathrm{i}}^{\prime} \mathrm{x}_{\mathrm{i}}}
$$

Pode-se decompor a eficiência econômica ou custo (EE) num produto de fatores. Ela pode ser feita para qualquer agricultor da amostra. Para simplificar a notação, não serão utilizados índices. Verifica-se que existe $\boldsymbol{\theta}>0$ tal que; $w x^{*}=\boldsymbol{\theta} * w *$ $x$, em que $x^{*}$ é a solução ótima. Logo $\theta=\mathrm{EE}=w x^{*} / \mathrm{w} x$. Portanto EE/ET pode ser escrita como:

$$
\frac{E E}{E T}=\frac{w(E E * x)}{w(E T * x)},
$$

onde $x$ é um vetor de insumos conhecidos. O termo (EE*x) indica quanto se tem de contrair $x$ para se obter um custo igual ao mínimo. Já sabemos que $($ ET*x) representa quanto se contrai $x$ para mover este vetor até a isoquanta correspondente. 
Em termos de movimento, temos duas etapas. Primeiramente, move-se $x$ para isoquanta correspondente e avalia-se o novo custo. Se não for igual ao mínimo, move-se $x$ para a linha de preço que passa em $x^{*}$ (ótimo). A fração mede, assim, o desvio em relação à combinação ótima, do ponto eficiente. Daí o quociente EE/ET ser designada eficiência-preço ou alocativa (EA). Segundo Coelli (1996), esse procedimento irá incluir todas as folgas dentro da medida de eficiência alocativa, uma vez que as folgas refletem a utilização de uma cesta de insumos inadequada.

Assim, pode-se decompor a eficiência econômica (EE) da seguinte forma: Eficiência econômica $=$ eficiência alocativa $*$ eficiência técnica com retornos variáveis $*$ eficiência de escala * congestão (Alves et al., 1998).

Verifica-se que $0<\mathrm{EA} \leq 1$. Logo, EE é igual a 1 se e somente se cada um dos fatores for igual a 1. O desdobramento permite verificar quais as razões de não se obter uma eficiência custo elevada: efeito alocação de fatores, escala inapropriada, efeito congestivo e, finalmente, tecnologia incorretamente escolhida (retornos crescentes e não crescentes), visto não se estar na fronteira (isoquanta).

Para EE < 1, toma-se o logaritmo de ambos os lados da igualdade e divide-se pelo logaritmo de EE, multiplicando-se por 100 ambos lados. Quanto maior for o valor obtido para uma componente da decomposição, maior terá sido sua contribuição para EE não ser 100 .

\subsection{Teste de hipótese de minimização de custos}

Erros de medição podem levar as firmas a violarem a regra de que quem produz mais não pode gastar menos do que quem produz menos. Varian (1985) admite que os desvios observados em relação à regra acima sejam devidos a erros de mensuração dos insumos. A produção e preços são conhecidos.

A regra acima se expressa, formalmente, por,

$y_{i} \leq y_{j}$, implica que $w_{i *} x_{i} \leq w_{i *} x_{j}, \forall i, i, j \in I, i \neq j$. 
No caso, a firma produz um único produto. Ordenam se as firmas segundo a ordem crescente de $y$. O custo da primeira unidade é comparado com o de todas seguintes. Pela regra, tem que ser menor ou igual. Quando isto não ocorrer, houve uma violação. O mesmo é feito com a segunda unidade, a terceira, e, assim, sucessivamente. Contam-se as violações. Pela regra acima, o número de violações para cada DMU deveria ser zero. O número de comparações é dado por $\frac{n(n-1)}{2}$.

Na prática, o número de violações é maior que zero. Mas, podemos modificar os valores dos insumos para que (16) seja obedecida. Por um critério, que será explicado a seguir, determinam-se os valores dos insumos de modo que obedeçam (16). A questão é saber se a diferença entre o valor observado e o calculado é, estatisticamente, pequena.

Admitindo-se a ocorrência de erros de medição dos dados, supõe-se que a demanda observada pelo fator $k$ na observação $i, x_{i k}$, está relacionada com a demanda "verdadeira", $z_{i k}$, da seguinte forma.

$$
x_{i k}=z_{i k}+\varepsilon_{i k}, \quad \text { para } i=1,2,3, \ldots, n, k=1,2,3, \ldots, m,
$$

onde $\varepsilon_{i k}$ é o erro, que é independente e normalmente distribuído, média zero e variância constante igual a $\sigma^{2}$. A hipótese a ser considerada é que as observações são $c$ racionalizáveis, ou seja:

$\mathrm{H}_{0}=$ os dados $\left(w_{i}, z_{i}, y_{i}\right)$ satisfazem a equação (16).

Se fosse possível observar a demanda "verdadeira" $\left(z_{i k}\right)$ e a variância $\left(\sigma^{2}\right)$ do erro, a seguinte estatística poderia ser obtida,

$$
T=\frac{\sum_{i=1}^{n} \sum_{k=1}^{m}\left(z_{i k}-x_{i k}\right)^{2}}{\sigma^{2}},
$$

que tem distribuição qui-quadrado $\left(\chi^{2}\right)$, com $m n$ graus de liberdade. Para um nível de significância $\alpha$, se $T$ for maior que o valor crítico $\chi^{2} \alpha, m n$ rejeita-se a hipótese nula. 
No entanto, a estatística $T$ não é observável já que se desconhece a demanda "verdadeira" dos fatores $\left(z_{i k}\right)$ e a variância $\left(\sigma^{2}\right)$. Pode-se, mesmo assim, testar a hipótese de minimização de custos através da solução do seguinte problema de programação quadrática:

$$
R=\operatorname{Min} \sum_{i=1}^{n} \sum_{k=1}^{m}\left(t_{i k}-x_{i k}\right)^{2}
$$

sujeito a:

$$
\sum_{k=1}^{m} w_{i k} t_{i k} \leq \sum_{k=1}^{m} w_{i k} t_{i j}, \forall j=1,2, \ldots, n, y_{i} \leq y_{j},
$$

onde $R$ é igual ao mínimo da soma dos quadrados dos desvios relativos às quantidades observadas, sendo observadas as restrições acima. Para completar, $w_{i k}$ é o preço do insumo $k$ para a $i$-ésima firma, $t_{i k}$ é representa o conjunto de variáveis, sobre as quais se busca a solução.

Considerando que a demanda de fatores seja medida em diferentes unidades, Varian (1985) sugere que a relação entre a demanda "verdadeira" e a demanda observada tenha a especificação abaixo,

$$
Z_{i k}=x_{i k}\left(1+\varepsilon_{i k}\right)
$$

Logo, admite-se que $\varepsilon_{i k}=\left(Z_{i k} / x_{i k}-1\right)$, é independente e normalmente distribuído com média zero e variância $\sigma^{2}$, e, assim, $Z_{i k} / x_{i k}$ herda a mesma distribuição, com média igual a um e variância dada por $\sigma^{2} / m^{*} n$

A função objetivo do modelo de programação quadrática, equação (19), toma a seguinte forma:

$$
R=\operatorname{Min} \sum_{i=1}^{n} \sum_{k=1}^{m}\left[\left(\frac{t_{i k}}{x_{i k}}\right)-1\right]^{2} .
$$

Sabemos que T tem distribuição qui-quadrado. Pela forma que $R$ foi calculado, $R / \sigma^{2} \leq T / \sigma^{2}$. Logo, se o teste for realizado com $R$ no lugar de $T$, aumenta-se a possibilidade de rejeição da hipótese nula. 
Contudo, $\sigma^{2}$ é desconhecido. Seja $k_{\alpha}$ o valor crítico da tabela de qui-quadrado com $m n$ graus de liberdade. Então, $R / \sigma^{2}=k_{\alpha}$ e $R$ é conhecido. Logo, $\sigma^{2}=\mathrm{R} / k_{\alpha}$. Se o valor for relativamente pequeno ${ }^{10}$, a hipótese nula não deve ser rejeitada.

Os termos do numerador da equação (18) têm, por hipótese, a mesma variância e são independentemente distribuídos. A variância de cada termo é igual a $\sigma^{2} / m^{*} n$. A média é um, e, portanto, coeficiente de variação é $\sqrt{\sigma^{2} / m^{*} n}$. Rejeita-se a hipótese de c-racionalização com base no coeficiente de variação, que mede a precisão da medida de cada insumo para cada produtor. Em vista da aproximação proposta para $\sigma$, ele é menor ou igual ao valor encontrado.

Ainda segundo Varian (1985), $R / m n$ é uma estimativa de máxima verossimilhança de $\sigma^{2}$.

\subsection{Fonte dos dados}

Os dados referem-se a propriedades produtoras de leite. Os mesmos estão divididos em duas amostras distintas. Optou-se pelas amostras porque são constituídas de fazendas que têm informações sobre as tecnologias de produção empregadas, fluxos monetários e estoque de capital da atividade.

A primeira amostra, refere-se a um grupo de 114 fazendas, do Estado de Minas Gerais, nas quais a produção de leite é a principal atividade desenvolvida na propriedade.

Para este grupo, os dados foram obtidos de fazendas de produtores de leite assistidas por técnicos da Equipe Prodap de Consultores em Produção Animal, de fazendas assistidas pelo Programa de Desenvolvimento da Pecuária de Leite da Região de Viçosa (PDPL-RV), participantes do programa Educampo, participantes do programa Produtores Referência da Itambé, filiados à Cooperativa Central dos Produtores Rurais e de fazendas que não pertencem a estes programas, mas que possuem assistência técnica.

\footnotetext{
${ }^{10}$ Salienta-se que "pequeno" para o valor de $\sigma^{2}$, irá depender da percepção do pesquisador
} 
São 114 fazendas onde existe acompanhamento de suas atividades e registros de fluxos de capitais, acompanhado por técnicos profissionais do setor. Desta forma, salienta-se que os dados foram coletados do sistema de registros implantados. Os dados foram coletados por Ferreira (2002).

O programa Educampo contribuiu com 24 fazendas. Os programas PDPL-RV e Produtor Referência da Itambé forneceram 16 e 5 fazendas, respectivamente. A Equipe Prodap de Consultores em Produção Animal forneceu 42 fazendas. Os dados das 27 fazendas restantes foram obtidos diretamente das propriedades rurais.

A segunda amostra refere-se a 143 fazendas produtoras de leite, distribuídas pelos seis principais Estados produtores de leite do Brasil (Tabela 1). Os dados fazem parte de um levantamento sobre a pecuária de leite brasileira, realizado pelo Centro de Estudos Avançados em Economia Aplicada da Escola Superior de Agricultura "Luiz de Queiroz" (CEPEA-ESALQ/USP).

A coleta dos dados foi feita pela aplicação de questionários. Foram registrados dados quantitativos, como também, as informações referentes ao processo de produção de leite. O critério de seleção dos produtores foi a produção média diária (acima de 150 litros/dia) e a comercialização do produto em laticínios. Todos os entrevistados possuem assistência técnica, que é disponibilizado pelo laticínio que comercializa o produto.

Tabela 1. Distribuição das observações nos Estados.

\begin{tabular}{lcc}
\hline Estado & Número de observações & $(\%)$ \\
\hline Goiás & 25 & 17,5 \\
Minas Gerais & 31 & 21,7 \\
Paraná & 19 & 13,3 \\
Rio Grande do Sul & 34 & 23,8 \\
Santa Catarina & 17 & 11,9 \\
São Paulo & 17 & 11,9 \\
TOTAL & 143 & 100 \\
\hline
\end{tabular}

Fonte: Resultados da pesquisa. 


\section{RESULTADOS E DISCUSSÃO}

\subsection{Descrição das amostras}

A análise concentra-se em duas amostras de produtores de leite: a de 143 observações cobre os seis maiores Estados produtores de leite do Brasil; a de 114 observações foi coletada no Estado de Minas Gerais. A amostra composta por 143 observações, será chamada de amostra Brasil para efeito da pesquisa, e a de 114 observações de amostra Minas Gerais. É importante salientar que não se pode afirmar que as amostras sejam representativas tanto do Brasil quanto do Estado de Minas Gerais, por causa do pequeno número de observações e pelo fato de que a coleta de dados não ter abrangido todas as regiões produtoras de cada Estado. Representam porém, as condições regionais prevalecentes.

Os dados da amostra Minas Gerais referem-se ao período de 12 meses e os valores monetários foram corrigidos para outubro de 2001. E os da amostra Brasil, também, referem-se ao período de 12 meses, e os valores monetários foram corrigidos para outubro de 2002. As amostras foram selecionadas entre os produtores que comercializam a produção em laticínios.

Nenhum teste de médias foi feito, pelo fato de as observações não terem sido coletadas para esta finalidade, Além disto, referem-se a períodos distintos, e as metodologias de amostragem e coleta foram diferentes.

A diversidade de amostras auxilia testar os métodos propostos de análise de eficiência e a descrição delas visa fornecer a base factual, na qual se assentam os testes.

A Tabela 2 retrata a produção diária de leite do estabelecimento. A produção diária é a média aritmética simples (somatório das produções dividido pelo total de 
observações) e o coeficiente de variação indica a heterogeneidade das observações. Consideram-se também a mediana, as separatrizes dos quartis, o máximo e mínimo. Testes de normalidade, que não foram incluídos, rejeitam a hipótese de normalidade, por isso foram dados mais detalhes da distribuição.

Os produtores de Minas Gerais são maiores que os do Brasil, o que se comprova pelas médias, medianas e separatrizes dos quartis. Conforme dados do IBGE, Censo Agropecuário 1995/96, cerca de $88 \%$ dos produtores produzem menos de 50 litros, diariamente. As duas amostras captam, assim, produtores de maior porte e que comercializam a produção.

Tabela 2. Produção, em litros por dia, amostras Brasil (2002) e Minas Gerais (2001).

\begin{tabular}{lcc}
\hline Itens & Brasil & Minas Gerais \\
\hline Número de observações & 143 & 114 \\
Média & 858 & 1133 \\
Coeficiente de Variação (\%) & 108,62 & 98,76 \\
Mediana & 559 & 828 \\
Máximo & 5954 & 6504 \\
Mínimo & 191 & 93 \\
Quartis & {$[191,362)$} & {$[93,497)$} \\
& {$[362,559)$} & {$[497,828)$} \\
& {$[559,1020)$} & {$[828,1158)$} \\
& {$[1020,5954]$} & {$[1158,6504]$} \\
\hline
\end{tabular}

Fonte: Resultados da pesquisa.

O rebanho foi classificado pelo grau de sangue. A metodologia foi proposta por Gomes S. (1999) e aplicada por Souza (2000), pela qual se dividem os produtores em três sistemas de produção: a) sistema que utiliza gado zebu (azebuado ou mestiço com predominância de sangue zebu), ou seja, menos de 1/2 europeu; b) sistema que utiliza 
gado mestiço, pelo cruzamento de uma raça zebuína e outra européia, com maior freqüência da holandesa; este grupo contém os sistemas de produção, em torno de 1/2 sangue europeu-zebu até 7/8 europeu-zebu; e c) sistema de produção que utiliza o gado europeu e, com maior frequiência, o holandês. Este grupo contém os sistemas com animais acima de $7 / 8$ de sangue holandês.

A distribuição do grau de sangue do rebanho pode ser observada na Tabela 3. A amostra Brasil é composta por $65 \%$ de produtores que utilizam animais com um grau de sangue puro de raças européias, estes com a produção média de 925 litros/dia e $22 \%$ com rebanho composto de animais com grau de sangue mestiço com produção média de 839 litros/dia.

Tabela 3. Distribuição das observações, segundo grau médio de sangue do rebanho e sua respectiva produção média (litros/dia) e média de curral (litros/vaca em lactação/dia), para as amostras Brasil e Minas Gerais.

\begin{tabular}{lcccccc}
\hline & \multicolumn{3}{c}{ Brasil } & \multicolumn{3}{c}{ Minas Gerais } \\
\cline { 2 - 7 } $\begin{array}{l}\text { Grau médio de } \\
\text { sangue do rebanho }\end{array}$ & $\begin{array}{c}\text { Obs } \\
\left(\mathrm{n}^{\mathrm{O}}\right) .\end{array}$ & $\begin{array}{c}\text { Produção } \\
\text { média } \\
(\mathrm{L} / \text { dia) }\end{array}$ & $\begin{array}{c}\text { Média de } \\
\text { Curral } \\
(\mathrm{L} / \text { vaca/dia })\end{array}$ & $\begin{array}{c}\text { Obs. } \\
\left(\mathrm{n}^{\mathrm{o}}\right)\end{array}$ & $\begin{array}{c}\text { Produção } \\
\text { média } \\
(\mathrm{L} / \text { dia })\end{array}$ & $\begin{array}{c}\text { Média de } \\
\text { Curral } \\
(\mathrm{L} / \text { vaca/dia })\end{array}$ \\
\hline Azebuado & 19 & 559 & 10,57 & 14 & 530 & 6,56 \\
Mestiço & 31 & 839 & 13,45 & 57 & 1052 & 12,66 \\
Puro raças eur opéias & 93 & 925 & 16,73 & 43 & 1434 & 17,59 \\
TOTAL & 143 & 858 & 15,20 & 114 & 1132 & 13,76 \\
\hline
\end{tabular}

Fonte: Resultados da pesquisa. 
Para a amostra Minas Gerais, o maior número de produtores está concentrado no sistema mestiço, que representa $50 \%$ do total, seguido pelo sistema puro de raças européias com $38 \%$ da amostra. Observa-se que as médias das produções diárias crescem, quando passam dos sistemas de produção de gado azebuado para o mestiço e para o puro de raças européias, em ambas as amostras.

A média de curral (litros produzidos por vacas ordenhadas por dia) na amostra Brasil situou-se em 15,20 litros e Minas Gerais em 13,76 litros. Observa-se que, em ambas as amostras, a média cresce do sistema azebuado passando pelo sistema mestiço e tendo o maior valor no sistema puro raças européias. Com o aumento da especialização do rebanho e pelo melhor manejo associado, há aumento da produtividade animal.

\subsubsection{Disponibilidade de recursos}

A área média utilizada na atividade leiteira foi de 80,7 e 164,7 ha para a amostra Brasil e Minas Gerais, respectivamente, conforme Tabela 4. Os valores médios encontrados para o hectare, para a amostra Brasil e Minas Gerais, foram de $\mathrm{R} \$$ 5.902,69/ha e R\$ 1.930,26/ha, respectivamente. Para a amostra Brasil, a metade dos produtores utilizava área menor do que 47,20 ha, e $75 \%$ área menor do que 103,0 ha, sendo o maior valor observado de 397,4 ha.

Metade dos produtores da amostra Minas Gerais, utilizavam área menor do que 106,45 ha, e $75 \%$ área menor do que 179,31 ha. O valor máximo encontrado foi de 846,85 ha. Portanto, para a amostra de Minas Gerais, observa-se produtores com área maiores imobilizadas na pecuária de leite.

A produtividade média da terra para a amostra Brasil foi de $6.268,55$ litros/ha por ano e para amostra Minas Gerais de 3.817,79 litros/ha por ano. Assim, o sistema mineiro é mais intensivo em uso de terra. 
Tabela 4. Distribuição da área utilizada pela atividade leiteira, em ha.

\begin{tabular}{lcc}
\hline \multicolumn{1}{c}{ Itens } & Brasil & Minas Gerais \\
\hline Média & 80,73 & 164,76 \\
Coeficiente de Variação (\%) & 99,10 & 100,64 \\
Mediana & 47,20 & 106,45 \\
Máximo & 397,40 & 846,85 \\
Mínimo & 5,60 & 10,27 \\
Quartis & {$[5,60,25,50)$} & {$[10,27,71,00)$} \\
& {$[25,50,47,20)$} & {$[71,00,106,45)$} \\
& {$[47,20,103,00)$} & {$[106,45,179,31)$} \\
& {$[103,00,397,40]$} & {$[179,31,846,85]$} \\
\hline
\end{tabular}

Fonte: Resultados da pesquisa.

O capital médio imobilizado pelos produtores na atividade leiteira, nas duas amostras, em terra, benfeitorias, máquinas, equipamentos e animais estão apresentadas nas Tabelas 5 e 6.

$\mathrm{Na}$ amostra Brasil, o capital médio imobilizado em terra foi de $\mathrm{R} \$ 397.541,18$ o que corresponde a 47,22\% do total, seguido pelo capital imobilizado em animais, que representa $19 \%$ do total (Tabela 5).

O capital médio imobilizado pelos produtores pertencentes à amostra Brasil, em benfeitorias, foi de R \$ 103.551,18. Sendo o máximo observado de R\$ 625.900,00 e o mínimo de $\mathrm{R} \$ 3.900,00$. Com relação ao valor do capital imobilizado em máquinas e equipamentos, este representou $18,88 \%$ do total do capital imobilizado na atividade. Verificourse que, para a metade dos produtores que compõe esta amostra, o capital fixo em máquinas e equipamentos é inferior a $\mathrm{R} \$ 95.500,00$. 
Tabela 5. Distribuição do capital imobilizado em terra, máquinas, equipamentos, benfeitorias e animais pelas propriedades na atividade leiteira, amostra Brasil, em R\$ de outubro de 2002.

\begin{tabular}{lcccc}
\hline Itens & Terra & $\begin{array}{c}\text { Máquinas e } \\
\text { equipamentos }\end{array}$ & Benfeitorias & Animais \\
\hline Média & 397541,18 & 120353,87 & 103551,18 & 142838,13 \\
Porcentagem & 47,22 & 18,88 & 14,85 & 19,05 \\
do total (\%) & 255316,48 & 95500,00 & 75100,00 & 95350,00 \\
Mediana & 3158920,00 & 538570,00 & 625900,00 & 1361000,00 \\
Máximo & 18441,17 & 9600,00 & 3900,00 & 22200,00 \\
Mínimo & & & \\
\hline
\end{tabular}

Fonte: Resultados da pesquisa.

Para a amostra Minas Gerais, a média do capital imobilizado em terra foi de $\mathrm{R} \$ 287.875,30$, que corresponde $40 \%$ do capital fixo total (Tabela 6). Os valores máximo e mínimo foram $\mathrm{R} \$ 2.118 .200,00$ e $\mathrm{R} \$$ 14.500,00, respectivamente. Com relação ao capital imobilizado em animais, a média encontrada para a amostra foi de $\mathrm{R} \$ 214.158,21$, que representa $32,8 \%$ do capital fixo total.

O capital médio em benfeitorias correspondeu a $\mathrm{R} \$ 99.081,95$, sendo que para $50 \%$ da amostra, este valor ficou abaixo de $\mathrm{R} \$ 73.583,00$. Os valores máximo e mínimo

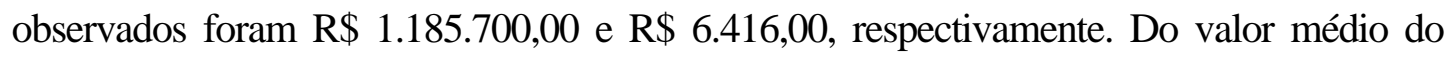
capital total imobilizado na atividade, máquinas e equipamentos representaram 11,36 \%, para a amostra Minas Gerais.

Como era de esperar, em ambas as amostras, o capital imobilizado em animais se mostrou elevado, sendo apenas superado pelo capital em terra. 
Tabela 6. Distribuição do capital imobilizado em terra, máquinas, equipamentos, benfeitorias e animais pelas propriedades na atividade leiteira, amostra Minas Gerais, em R\$ de outubro de 2001.

\begin{tabular}{lcccc}
\hline Itens & Terra & $\begin{array}{c}\text { Máquinas e } \\
\text { equipamentos }\end{array}$ & Benfeitorias & Animais \\
\hline Média & 287875,30 & 68685,58 & 99081,95 & 214158,21 \\
$\begin{array}{l}\text { Porcentagem } \\
\text { do total (\%) }\end{array}$ & 40,39 & 11,36 & 15,40 & 32,85 \\
Mediana & 170500,00 & 43700,00 & 73583,00 & 152210,00 \\
Máximo & 2118200,00 & 386290,00 & 1185700,00 & 1347000,00 \\
Mínimo & 14500,00 & 3422,17 & 6416,00 & 11523,00 \\
\hline
\end{tabular}

Fonte: Resultados da pesquisa.

\subsubsection{Insumos e serviços}

O gasto médio e a mediana dos insumos e serviços estão resumidos na Tabela 7.

O gasto médio, no período de um ano agrícola, com a mão-de-obra contratada, foi de $\mathrm{R} \$ 7.189,82$ para o Brasil e $\mathrm{R} \$ 25.079,02$ para Minas Gerais. As médias mensais foram, respectivamente, $\mathrm{R} \$ 599,15$ e $\mathrm{R} \$ 2.089,92$ para o Brasil e para Minas Gerais. Observa-se que a mediana do Brasil igualou-se a $\mathrm{R} \$$ 4.126,33/ano e a de Minas Gerais, equivaleutse a $\mathrm{R} \$ 17.519,39$ por ano.

O dispêndio mensal com mão-de-obra familiar correspondeu a $\mathrm{R} \$ 481,44$ para o Brasil e R\$ 588,31 para Minas Gerais, valores inferiores aos encontrados com mão-deobra contratada. Para um valor de R \$240,00 para o salário-mínimo, superior ao vigente quando foram coletado os dados, o proprietário e família da amostra Brasil, têm remuneração equivalente a 2 salários-mínimos. Na amostra de Minas Gerais, a remuneração equivale a 2,45 salários-mínimos. Claro que são salários imputados, e respondem, em parte, pelo vulto das rendas líquidas negativas. Optou-se porém por não ajustar os dados coletados. 
Tabela 7. Dispêndios com a produção de leite, em $\mathrm{R} \$ / \mathrm{ano}$, por amostra.

\begin{tabular}{lcccc}
\hline \multirow{2}{*}{ Itens } & \multicolumn{2}{c}{ Brasil } & \multicolumn{2}{c}{ Minas Gerais } \\
\cline { 2 - 5 } & Média & Mediana & Média & Mediana \\
\hline Mão-de-obra contratada & 7189,82 & 4126,33 & 25079,02 & 17519,39 \\
Mão-de-obra familiar & 5777,32 & 5110,00 & 7059,71 & 6480,00 \\
Concentrados e minerais & 35768,36 & 20528,00 & 59878,10 & 37057,41 \\
Volumosos & 15207,20 & 10067,00 & 29727,59 & 19113,52 \\
$\begin{array}{l}\text { Medicamentos e } \\
\text { inseminação artificial }\end{array}$ & 8452,37 & 4700,00 & 12585,48 & 8234,49 \\
$\begin{array}{l}\text { Energia, combustíveis, } \\
\text { reparo de máquinas, }\end{array}$ & & & & \\
equipamentos, benfeitorias & 11010,98 & 7691,00 & 14052,29 & 9349,73 \\
e demais gastos de custei & & & & \\
\hline
\end{tabular}

Fonte: Resultados da pesquisa.

Em ambas as amostras, $100 \%$ dos produtores utilizam concentrados e minerais como forma de complementação da alimentação do rebanho. Para o Brasil, o gasto médio com concentrados e minerais foi de $\mathrm{R} \$ 35.768,36$ por ano, o que representa um gasto médio de $\mathrm{R} \$ 2.980,70 /$ mês. Neste grupo de produtores, metade deles despendeu com concentrados e minerais quantia igual ou inferior a $\mathrm{R} \$ 1.710,67 / \mathrm{mês}$.

Com relação a Minas Gerais, a média de gastos com concentrados e minerais foi de $\mathrm{R} \$ 59.878,10 / \mathrm{ano}$, o que representa um gasto mensal de $\mathrm{R} \$ 4.989,84$.

Entenda-se como volumoso, a silagem de milho ou de qualquer outra forrageira, a cana-de-açúcar, o feno e o capim picado, quando levado ao cocho. Observase na amostra Brasil que o gasto médio foi de $\mathrm{R} \$$ 15.207,00/ano e na amostra Minas Gerais de $\mathrm{R} \$ 2$ 29.727,59/ano, o que representa gastos mensais de $\mathrm{R} \$ 1.267,00 \mathrm{e}$ $\mathrm{R} \$ 2.477,30$, respectivamente. Os valores de máximo e mínimo de ambas as amostras nos indicam que, para alguns produtores, a principal fonte de volumoso foi oriunda de pastagens, enquanto para outros, os animais foram alimentados, exclusivamente, com silagens. Para a amostra Brasil, o valor mínimo encontrado foi zero, ou seja, alimentação 
do rebanho foi feita via pastagem, e o valor máximo gasto com volumosos foi de $\mathrm{R} \$ 125.098,00 /$ ano. Para a amostra Minas Gerais, o valor máximo gasto com volumosos foi de $\mathrm{R} \$ 273.593,00$ e o mínimo de $\mathrm{R} \$ 594,00$ por ano.

Um fator importante para bom desempenho da atividade leiteira está relacionado com os aspectos sanitários e genéticos da atividade. Na Tabela 7, estão os valores médios dos gastos com medicamentos e inseminação artificial. $\mathrm{O}$ gasto médio com medicamentos e inseminação para o Brasil foi de $\mathrm{R} \$ 8.452,37 / \mathrm{ano}$, o que equivale a um gasto mensal de $\mathrm{R} \$ 704,36$, e no caso de Minas Gerais um valor de $\mathrm{R} \$ 1.048,79 /$ mês. Apesar de os valores não serem exagerados, eles variam na faixa de 5 a $8 \%$, do custo total da atividade. Os cuidados sanitários objetivam proteger o animal e produzir leite de boa qualidade, enquanto, a inseminação artificial proporciona a melhoria dos índices reprodutivos e de produtividade.

Com relação aos gastos com energia, combustíveis, reparo de benfeitorias, máquinas e equipamentos e demais gastos na atividade, a média igualourse a $\mathrm{R} \$ 11.010,98$, para o Brasil, e a $\mathrm{R} \$ 14.052,29$, para Minas Gerais, o que equivale a $\mathrm{R} \$ 917,58$ e $\mathrm{R} \$ 1.1171,02 /$ mês, respectivamente.

\subsubsection{Indicadores econômicos}

A renda bruta equivale ao valor do leite produzido mais a venda de animais. $\mathrm{Na}$ Tabela 8, estão as rendas brutas de ambas as amostras. Observa-se que a renda bruta média mensal dos produtores do Brasil foi de $\mathrm{R} \$$ 9.988,55 e a de Minas Gerais igualout se a $\mathrm{R} \$$ 15.701,09. A mediana do Brasil foi de $\mathrm{R} \$ 5.840,00$ e a de Minas Gerais corresponde a $\mathrm{R} \$ 11.562,82$. Para o Brasil, os valores extremos equivalem a R\$ 73.814,69, para o máximo e R\$ 1.769,31, para o mínimo. Em Minas Gerais, os valores extremos alcançaram $\mathrm{R} \$ 91.682,30$, para o máximo e $\mathrm{R} \$ 1.182,70$, para o mínimo. 
Tabela 8. Renda bruta mensal (a anual dividida por 12), R\$/mês, por amostra.

\begin{tabular}{lcc}
\hline Itens & Brasil & Minas Gerais \\
\hline Média & 9988,55 & 15701,09 \\
Coeficiente de Variação (\%) & 111,93 & 99,87 \\
Mediana & 5840,00 & 11562,82 \\
Máximo & 73814,69 & 91682,30 \\
Mínimo & 1769,31 & 1182,70 \\
Quartis & {$[1769,31,3787,86)$} & {$[1182,70,6421,64)$} \\
& {$[3787,86,5840,00)$} & {$[6421,64,11562,82)$} \\
& {$[5840,00,12081,85)$} & {$[11562,82,18590,93)$} \\
& {$[12081,85,73814,69]$} & {$[18590,93,91682,30]$} \\
\hline
\end{tabular}

Fonte: Resultados da pesquisa.

A renda bruta é dividida em duas partes: venda do leite e derivados e venda de animais. A Tabela 9 apresenta a participação da venda do leite na renda bruta. Para o Brasil, em média, 93 \% (soma dos índices dividido pelo número de observações) da renda bruta da atividade leiteira foram devidos à venda de leite e derivados. Existe, pelo menos, um produtor em que a venda de leite e de derivados equivale a $100 \%$ da renda bruta e um produtor em que a venda do leite e derivados corresponde a $41 \%$ da renda bruta. Entretanto, para $75 \%$ dos produtores amostrados, a venda do leite e derivados participou com $90 \%$, ou mais, da renda bruta total, no ano em que os dados se referem. Assim, na amostra Brasil, a renda da grande maioria dos produtores foi devida à venda do leite e derivados, sendo a segunda fonte de renda, a venda de animais.

Em Minas Gerais, a média da participação da venda do leite e derivados na renda bruta foi de $80 \%$. Para $75 \%$ dos produtores amostrados, no mínimo, $73 \%$ da renda bruta total foi devida à venda de leite e derivados. O valor mínimo encontrado foi de $35 \%$. Para este produtor, em particular, $65 \%$ da renda bruta anual foi devida à venda de animais. Entretanto, pode-se afirmar que, em sua grande maioria, a principal fonte de renda dos produtores da amostra Minas Gerais foi a venda de leite e derivados. 
Tabela 9. Participação da venda do leite e derivados na renda bruta total, em \%, para as amostras Brasil e Minas Gerais.

\begin{tabular}{lcc}
\hline Itens & Brasil & Minas Gerais \\
\hline Média & 0,93 & 0,80 \\
Coeficiente de Variação (\%) & 10,75 & 16,25 \\
Mediana & 0,96 & 0,82 \\
Máximo & 1,00 & 0,99 \\
Mínimo & 0,41 & 0,35 \\
Quartis & {$[0,41,0,90)$} & {$[0,35,0,73)$} \\
& {$[0,90,0,96)$} & {$[0,73,0,82)$} \\
& {$[0,96,0,99)$} & {$[0,82,0,89)$} \\
& {$[0,99,1,00]$} & {$[0,89,0,99]$}
\end{tabular}

Fonte: Resultados da pesquisa.

A renda líquida refere-se à renda bruta total menos os custos da atividade, esta pode ser de curto e longo prazo. A renda líquida de curto prazo, foi calculada subtraindo da renda bruta total os custos variáveis da produção, que são eles: dispêndios com mãode-obra contratada e familiar, dispêndios com concentrados, minerais, volumosos, medicamentos, inseminação artificial, energia, combustíveis, reparo de máquinas, equipamentos, benfeitorias e demais gastos de custeio. Já a renda líquida de longo prazo, foi calculada subtraindo da renda bruta total os custos totais, que são o somatório dos custos variáveis mais a remuneração do capital investido em terra, animais e a depreciação de máquinas, equipamentos e benfeitorias.

Na Tabela 10, estão os valores calculados para a renda líquida mensal, de curto e longo prazo. Observa-se que a renda líquida de curto prazo indica valores negativos, o que significa que os produtores não estão conseguindo pagar nem os custos variáveis da produção. Para o Brasil, a média da renda líquida mensal de curto prazo foi de $\mathrm{R} \$ 3.038,05$. Entretanto, observa-se que a mediana está bem abaixa da média, em torno 
$\mathrm{R} \$ 1.400,10$. Para $25 \%$ da amostra, o valor da renda líquida de curto prazo ficou entre os valores de $\mathrm{R} \$ 3.708,67 /$ mês e $\mathrm{R} \$ 44.494,17 /$ mês.

Em Minas Gerais, a média encontrada para a renda líquida mensal de curto prazo foi de $\mathrm{R} \$ 3.335,91$. Para a metade dos produtores amostrados, a renda líquida de curto prazo foi inferior ao valor de $\mathrm{R} \$ 2.019,34 /$ mês. Para alguns produtores foram encontrados valores negativos, significando que a renda advinda da venda de leite, derivados e animais não foi suficiente para pagar todos os custos diretos envolvidos na produção. Desta forma, pode-se afirmar que, tanto para o Brasil como para Minas Gerais, existem alguns produtores que, muito provavelmente, se não houver nenhuma modificação na estrutura produtiva, estarão fadados a terem que parar de produzir. Estes foram de número 25 e 9, que representam 17 e 7,9 \% do total da amostra, para a amostra Brasil e Minas Gerais, respectivamente.

Quando analisada a renda líquida de longo prazo, a situação piora para ambas as amostras. Neste caso é necessário que a renda bruta pague os custos variáveis e remunere o capital investido. Na amostra Brasil, a renda líquida média mensal de longo prazo encontrada foi de $\mathrm{R} \$ 1.010,56$ e de $\mathrm{R} \$ 825,59$, para Minas Gerais.

$\mathrm{Na}$ amostra Brasil, mais de $25 \%$ dos produtores têm a renda líquida de longo prazo negativa, ou seja, consome-se capital fixo para se produzir ou não se remunera adequadamente o trabalho familiar. Num período longo, estes produtores estarão com a atividade comprometida. O valor máximo encontrado para a amostra Brasil foi de R\$ 35.946,43/mês e o mínimo de R\$ -8.889,08/mês (negativo). Para metade dos produtores a renda líquida mensal de longo prazo foi inferior a $\mathrm{R} \$ 79,67$. O coeficiente de variação foi de 487,09 \%. Comparada com o salário mínimo, esta renda não retém o produtor no meio rural.

$\mathrm{Na}$ amostra Minas Gerais, renda líquida média mensal de longo prazo foi igual a $\mathrm{R} \$ 825,59$. A metade dos produtores tem renda líquida inferior a $\mathrm{R} \$ 348,48$, sendo que mais de $25 \%$ do total amostrado apresentou valor negativo. $\mathrm{O}$ coeficiente de variação encontrado foi elevado, $333,36 \%$. 
Tabela 10. Renda líquida mensal (a anual dividida por 12) de curto (RLCP) e longo prazo (RLLP), em R \$/mês, para as amostras Brasil e Minas Gerais.

\begin{tabular}{lcccc}
\hline \multirow{2}{*}{ Itens } & \multicolumn{2}{c}{ Brasil } & \multicolumn{2}{c}{ Minas Gerais } \\
\cline { 2 - 5 } & RLCP & RLLP & RLCP & RLLP \\
\hline Média & 3038,05 & 1010,56 & 3335,91 & 825,59 \\
$\begin{array}{l}\text { Coeficiente } \\
\text { de Variação }\end{array}$ & 192,91 & & & 126.37 \\
$(\%)$ & & 487,09 & & 333,36 \\
Mediana & 1400,10 & & 2019,34 & 348,48 \\
Máximo & 44494,17 & 35946,43 & 27031,25 & 16225,30 \\
Mínimo & $-4528,17$ & $-8889,08$ & $-1458,21$ & $-9680,98$ \\
Quartis & {$[-4528,17,333,26)$} & {$[-8889,08,-788,27)$} & {$[-1458,21,930,51)$} & {$[-9680,98,-389,01)$} \\
& {$[333,26,1400,10)$} & {$[-788,27,79,67)$} & {$[930,51,2019,34)$} & {$[-389,01,348,48)$} \\
& {$[1400,10,3708,67)$} & {$[79,67,1338,21)$} & {$[2019,34,4311,57)$} & {$[348,48,1461,18)$} \\
& {$[3708,67,44494,17]$} & {$[1338,21,35946,43]$} & {$[4311,57,27031,25]$} & {$[1461,18,16225,30]$} \\
\hline
\end{tabular}

Fonte: Resultados da pesquisa.

Das 143 observações da amostra Brasil, 25 observações (17 \%) obtiveram renda líquida de curto prazo negativa, sendo a média encontrada para estes produtores de R\$ - 10.502,73/mês. Considerando a renda líquida de longo prazo, o número de produtores com valores negativos foi 68 (48 \%), ou seja, quase metade da amostra. Para as observações que obtiveram renda líquida de longo prazo menor que zero, a média encontrada foi de R \$ -16.723,54/mês. Na amostra Minas Gerais, das 114 observações, 9 observações $(7,9 \%)$ têm renda líquida de curto prazo negativa, com média de $\mathrm{R} \$$-4.741,9/mês e para 43 observações (38 \%) as rendas líquidas de longo prazo foram negativas, com média de $\mathrm{R} \$-12.734,08 /$ mês.

Já se verificou que há renda líquida negativa. Por isto, resolveu-se dividir as amostras em dois grupos: renda líquida não negativa e negativa e analisar a disponibilidade de recursos e os índices de produtividade. Face a importância destes indicadores para a análise de eficiência (Tabela 11). 
Foi elevado o número de produtores com renda líquida negativa. Não conseguem remunerar, em conjunto, a terra, benfeitorias, máquinas, equipamentos e animais. Permanecendo a situação, não terão como repor o desgaste do capital. Ou reformulam o empreendimento ou terão que fechá-lo. No Brasil, são 47,6 \% da amostra, e, em Minas Gerais, 37,7 \%. Duas causas se apresentam como responsáveis: volume de produção e de recursos menores, pela área que o empreendimento comanda, e tecnologia, como revelam os índices de produtividade.

No Brasil, a produção média diária daqueles com renda líquida não negativa equivale a 1,7 dos de renda líquida negativa, ou seja, cerca de $70 \%$. Para a renda bruta, este valor corresponde a 1,9, ou seja, 90 \% maior. Em Minas Gerais, os valores são 1,7 para a produção e 1,6 para a renda bruta. Para compreensão da leitura, grupos A e B, referem-se ao grupo com renda líquida não negativa e negativa, respectivamente. Portanto, o volume de produção é muito maior para o grupo A, quando medido pela renda bruta e pela produção diária de leite.

No Brasil, a área média explorada pelo grupo A foi apenas um pouco maior que a do grupo B, na média, 3,1 hectares. Em Minas Gerais, a diferença foi bem maior, cerca de 31,2 hectares.

O grupo A teve bem mais vacas em lactação e capital acumulado que o grupo B, portanto, dispondo de mais recursos produtivos. Mas, é preciso saber fazer os recursos produtivos renderem, e isto depende de tecnologia de conhecimento dos produtores.

Uma medida de produtividade é a renda bruta dividida pelos dispêndios em custos variáveis. Indica quanto cada real despendido rendeu de fato e é expresso pela linha Renda bruta/total de gastos da Tabela 11. No Brasil, para o grupo A um real gasto rendeu $70 \%$ e somente $11 \%$ para o grupo B, o que não é ruim. Em Minas Gerais, esta medida de produtividade foi bem menor, mas o rendimento foi ainda bom para os dois grupos: respectivamente, $36 \%$ e $17 \%$ para os grupos A e B. Assim, o grupo A tem uma produtividade bem maior dos recursos que o grupo $\mathrm{B}$. 
Tabela 11. Decomposição das amostras em dois grupos de produtores segundo a renda líquida de longo prazo (RLLP) não negativa e negativa, recursos e índices de produtividade, para as amostras Brasil e Minas Gerais.

\begin{tabular}{|c|c|c|c|c|}
\hline \multirow[b]{2}{*}{ Itens } & \multicolumn{2}{|c|}{ Brasil } & \multicolumn{2}{|c|}{ Minas Gerais } \\
\hline & $\begin{array}{c}\text { RLLP } \\
\text { não negativa } \\
\text { (A) }\end{array}$ & $\begin{array}{c}\text { RLLP } \\
\text { negativa } \\
\text { (B) }\end{array}$ & $\begin{array}{c}\text { RLLP } \\
\text { não negativa } \\
\text { (A) }\end{array}$ & $\underset{\text { (B) }}{\text { RLLP }}$ \\
\hline Número de produtores & 75 & 68 & 71 & 43 \\
\hline Produção (litros/dia) & 1075,64 & 617,40 & 1332,54 & 802,42 \\
\hline Renda Bruta (R\$/mês) & 12974,66 & 6695,05 & 18211,74 & 11555,60 \\
\hline Área (ha) & 82,20 & 79,1 & 176,51 & 145,35 \\
\hline Vacas em lactação (unidade animal) & 67,24 & 41,67 & 95,87 & 59,48 \\
\hline Vacas secas (unidade animal) & 18,77 & 14,23 & 32,55 & 26,21 \\
\hline Capital total $(\mathrm{R} \$)^{1}$ & 777024,07 & 750233,22 & 707053,02 & 608291,94 \\
\hline Capital total (itros/R\$) ${ }^{1}$ & 0,54 & 0,37 & 0,78 & 0,57 \\
\hline Mão-de-obra total (litros/R\$) & 27,19 & 23,00 & 14,79 & 10,55 \\
\hline Média de curral (litros/vaca/dia) & 15,70 & 14,66 & 13,91 & 13,51 \\
\hline Custo variável (R $\$ /$ litro) & 0,24 & 0,32 & 0,32 & 0,41 \\
\hline Custo total (R\$/litro) & 0,31 & 0,43 & 0,39 & 0,53 \\
\hline Renda bruta/total de gastos ${ }^{2}$ & 1,70 & 1,11 & 1,36 & 1,17 \\
\hline
\end{tabular}

Fonte: Resultados da pesquisa.

1 Somatório do capital imobilizado em terra, máquinas, equipamentos, benfeitorias e animais.

2 Dispêndios com mão-de-obra familiar e contratada, concentrados, minerais, volumosos, medicamentos, inseminação artificial, energia, combustíveis, reparo de máquinas, equipamentos, benfeitorias e outros. Estes equivalem aos custos variáveis da atividade. 
Com relação aos índices parciais de produtividade tem-se que cada unidade monetária de capital fixo rende bem mais em litros produzidos para grupo A em comparação com o grupo B: respectivamente, 0,54 e 0,37 para o Brasil, e 0,78 e 0,57 para Minas Gerais.

A mão-de-obra do grupo A foi também mais produtiva em termos de litros produzidos por unidade monetária gasta.

As diferenças do grupo A para o grupo $\mathrm{B}$, em termos de média de curral, não foram muito elevadas. Como as diferenças foram apreciáveis nos custos de produção, no variável e no total, segue-se que o grupo A teve melhor capacidade de administrar os recursos que utiliza, o que foi coerente com a medida de produtividade total.

A Tabela 12 detalha a distribuição do custo de produção. O preço médio pago por litro de leite para a amostra Brasil foi de $\mathrm{R} \$$ 0,34/litro. Para mais de $75 \%$ dos produtores, $\mathrm{o}$ custo variável foi menor que o preço médio. Em relação ao custo total, o seu valor superou o preço pago pelo produto em cerca de $50 \%$ das observações.

Tabela 12. Distribuição do custo total (CT) e variável (CV), R\$/litro, para as amostras Brasil e Minas Gerais.

\begin{tabular}{lcccc}
\hline \multirow{2}{*}{ Itens } & \multicolumn{3}{c}{ Brasil } & \multicolumn{2}{c}{ Minas Gerais } \\
\cline { 2 - 6 } & $\mathrm{CT}$ & $\mathrm{CV}$ & $\mathrm{CT}$ & $\mathrm{CV}$ \\
\hline $\begin{array}{l}\text { Preço médio do litro } \\
\text { de leite }\end{array}$ & & 0,34 & & 0,36 \\
Média & 0,373 & 0,281 & 0,447 & 0,359 \\
Coeficiente de & 28,87 & 27,91 & 27,83 & 22,99 \\
Variação (\%) & 0,360 & 0,271 & 0,429 & 0,348 \\
Mediana & 0,814 & 0,585 & 1,063 & 0,598 \\
Máximo & 0,178 & 0,138 & 0,200 & 0,169 \\
Mínimo & {$[0,178,0,305)$} & {$[0,138,0,230)$} & {$[0,200,0,377)$} & {$[0,169,0,307)$} \\
Quartis & {$[0,305,0,360)$} & {$[0,230,0,271)$} & {$[0,377,0,429)$} & {$[0,307,0,348)$} \\
& {$[0,360,0,426)$} & {$[0,271,0,324)$} & {$[0,429,0,497)$} & {$[0,348,0,409)$} \\
& {$[0,426,0,814]$} & {$[0,324,0,585]$} & {$[0,497,1,063]$} & {$[0,409,0,598]$} \\
\hline
\end{tabular}

Fonte: Resultados da pesquisa. 
Em Minas Gerais, o custo variável médio igualou-se a $\mathrm{R} \$ 0,36$ e o custo total médio a $\mathrm{R} \$ 0,45$. O preço médio recebido pelos produtores foi de $\mathrm{R} \$ 0,36$. Comparando o preço recebido por litro de leite com o custo total, observa-se que menos de $25 \%$ dos produtores produzem a custos inferiores. Se comparado com o custo variável, o número de produtores que produzem a custos variáveis inferiores ao preço pago pelo litro de leite ficou em torno de $50 \%$ da amostra. Os valores extremos encontrados para o custo total foram $\mathrm{R} \$ 1,06$, para o máximo e $\mathrm{R} \$ 0,20$, para o mínimo. Com relação ao custo variável, o máximo foi $R$ \$ 0,60 e o mínimo $R$ \$ 0,17.

A Tabela 13 descreve a participação dos insumos no custo de produção. Os dispêndios com concentrados, minerais e volumosos foram os que mais contribuíram para o custo, tanto total quanto variável, em ambas as amostras. Na amostra Brasil, somando-se os dispêndios com concentrados, minerais, volumosos, medicamentos e inseminação artificial, a soma correspondeu a $66,14 \%$ e 50,88 \%, respectivamente, do custo variável e total. Com relação ao custo total, o valor da remuneração da terra, dos animais e a depreciação de máquinas, equipamentos e benfeitorias equivalem a 23,81 \% do total. Os dispêndios com mão-de-obra contratada e familiar foram responsáveis por $14,80 \%$ do custos total e $19,77 \%$ do custo variável, para o Brasil.

Em Minas Gerais, a remuneração da terra, animais e depreciação de máquinas, equipamentos e benfeitorias corresponderam a $18,66 \%$ do custo total. Mão-de-obra equivaleu 20,18 \% e 25,20\%, respectivamente, para o custo total e variável. Com relação aos dispêndios com concentrados, volumosos, medicamentos e inseminação artificial, a soma representou $53,14 \%$ do custo total e $64,81 \%$ do custo variável. 
Tabela 13. Participação dos itens no custo total (CT) e variável (CV), em (\%), para as amostras Brasil e Minas Gerais.

\begin{tabular}{lcccc}
\hline & \multicolumn{2}{c}{ Brasil } & \multicolumn{2}{c}{ Minas Gerais } \\
\cline { 2 - 5 } Itens & CT & CV & CT & CV \\
\hline Terra (3 \%) & 12,14 & - & 5,80 & - \\
Animais (6\%) & 7,54 & - & 7,47 & - \\
Depreciação de maquinas, equipamentos & 4,13 & - & 5,38 & - \\
e benfeitorias & 9,44 & 12,51 & 5,75 & 7,24 \\
Mão-de-obra familiar & 5,36 & 7,26 & 14,43 & 17,96 \\
Mão-de-obra contratada & 29,86 & 38,41 & 31,38 & 38,13 \\
Concentrados e minerais & 13,98 & 18,35 & 15,04 & 18,26 \\
Volumosos & 5,31 & 7,10 & 5,22 & 6,57 \\
Medicamentos & 1,73 & 2,28 & 1,50 & 1,85 \\
Inseminação artificial & 3,39 & 4,64 & 2,43 & 3,00 \\
Energia e combustíveis & 3,41 & 4,60 & 4,73 & 5,87 \\
Reparo de máquinas, equipamentos & 3,71 & 4,85 & 0,87 & 1,12 \\
e benfeitorias & 100,00 & 100,00 & 100,00 & 100,00 \\
Outros & & & & \\
TOTAL & & & & \\
\hline
\end{tabular}

Fonte: Resultados da pesquisa.

\subsection{Teste da hipótese da minimização dos custos: orientação insumo}

As duas amostras referem-se a dados de um ano. Num período de tempo curto, é possível que a firma possa ter uma renda líquida negativa e, ainda, está bem administrada. Com o tipo de dado que se tem, não se pode, portanto, afirmar que um estabelecimento que apresentou renda líquida negativa não tenha tido um comportamento racional. Mesmo assim, resolveur se analisar, em separado, os estabelecimentos de renda líquida não negativa.

$\mathrm{Na}$ amostra de Minas gerais, de 114 estabelecimentos, há 71 estabelecimentos de renda líquida não negativa, que correspondem a 62,3 \% da amostra. A amostra Brasil contém 143 estabelecimentos, e 75 tiveram renda líquida não negativa (cerca de 52,4 \%). Foi, assim, 
expressivo o número de estabelecimentos que não conseguiram, no ano a que os dados se referem, remunerar todos os fatores de produção.

Dois procedimentos servem para analisar a racionalização dos dados. O primeiro deles, simplesmente, conta as violações, conforme critério especificado a seguir. O outro realiza o teste já proposto. Para facilitar a leitura, recordar-se-áo critério de racionalização de custo.

A hipótese de minimização de custos implica que, no caso de um produto $(y)$, se $y_{i} \leq y_{j}$, então $w_{i} x_{i} \leq w_{i} x_{j}, \quad \forall i i, j \in \mathrm{I}$, onde $y_{i}$ e $y_{j}$ representam a produção das firmas $i$ e $j, w_{i} \mathrm{o}$ preço do insumo utilizado pela firma $i$ e $x_{i}$ e $x_{j}$ as respectivas quantidades dos insumos. Ou seja, quem produz mais não gasta menos do quem produz menos.

A produção foi agregada na variável $y$, que mede o valor da produção, em $\mathrm{R} \$$. Os insumos estão distribuídos em quatro tipos, a saber:

$\mathrm{X}_{1}=3 \%$ do valor da terra, $6 \%$ do valor dos animais utilizado na produção e o valor da depreciação de máquinas, equipamentos e benfeitorias.

$\mathrm{X}_{2}=$ Dispêndio com mão-de-obra familiar e contratada.

$\mathrm{X}_{3}=$ Dispêndio com concentrados, minerais, volumosos, inseminação artificial e medicamentos.

$\mathrm{X}_{4}=$ Dispêndio com energia, combustíveis, manutenção de máquinas, equipamentos e benfeitorias e demais gastos.

O custo btal é igual a soma dos valores dos quatro insumos, representado por $C_{i}$ para a observação $i$.

As observações foram ordenadas do menor valor da produção para o maior. Em seguida, comparourse o custo da observação $i$ com o custo da observação $j$, sendo $j \geq i$. Assim, a primeira observação foi comparada com todas outras; a segunda com $(n-1)$ observações seguintes, e, assim, sucessivamente. Pela regra acima $C_{i} \leq C_{j}$ se $i \leq j$. Quando isto ocorre, verifica-se um acerto, e atribui-se o valor 1 para o acerto e 0 (zero) para o erro, ou seja, quando $C_{i}>C_{j}$ se $i \leq j$. Como se trata de uma progressão aritmética de $n$ termos e razão igual a 1 , o número de comparações equivale a $n *(n-1) / 2$, que é o número máximo de acertos. Os resultados estão na Tabela 14. 
Tabela 14. Número de acertos, de acordo com o axioma da minimização de custos. Comparação do custo de uma observação com todas as seguintes.

\begin{tabular}{lccc}
\hline Amostra & $\begin{array}{c}\text { Possíveis } \\
n *(n-1) / 2\end{array}$ & Observados & $\begin{array}{c}\text { Observados/ } \\
\text { Possíveis (\%) }\end{array}$ \\
\hline Brasil & 10153 & 8844 & 87,1 \\
Brasil R.L. não negativa & 2775 & 2558 & 92,2 \\
Minas Gerais & 6441 & 6130 & 95,2 \\
Minas Gerais R.L. não negativa & 2485 & 2405 & 96,8 \\
\hline
\end{tabular}

Fonte: Resultados da pesquisa.

No caso das observações de renda líquida não negativa o número de acertos foi muito elevado nas duas amostras (Tabela 14). Em Minas Gerais os acertos foram muito elevados para toda a amostra e renda líquida não negativa. Considerando-se as 143 observações do Brasil, o número de acertos foi um pouco menor, cerca de 87,1 \%. Assim, pela contagem dos acertos, poucos estabelecimentos violaram a regra de racionalização das observações. Não é surpreendente que o número de violações seja menor para Minas Gerais, quando comparado com o Brasil, já que, naquele estado, os agricultores amostrados tinham registros estruturados das observações. A surpresa recai no Brasil, onde a memória do produtor foi a principal base das informações.

Reportando-se a metodologia, foi visto que é necessário encontrar na tabela o valor de qui-quadrado correspondente a $m n$ graus de liberdade, $95 \%$ de probabilidade, designado por $K_{\mathbf{\alpha}}$ A seguir deriva-se a variância pela forma $\sigma^{2}=R / K_{\mathbf{O}}$ em que $R$ é solução dada pela programação quadrática.

Como se viu na seção de metodologia, $R$ / $m n$ é uma estimativa de verossimilhança da variância, condicionada às restrições mencionadas, mas como assegura Varian (1985) desconhece-se sua distribuição e o procedimento exige um grau de liberdade a mais do que se dispõe. 
Pelas hipóteses feitas, o quociente $\frac{x_{\text {otimo }}}{x_{o b s}}$ tem média 1 e desvio padrão $\sigma$. Logo o desvio padrão é igual ao coeficiente de variação. Que é dado por, $\frac{\sigma}{\sqrt{\text { graus liberdade }}}$. Os resultados estão na Tabela 15. Como todos eles foram menores que $2 \%$, os dados não oferecem evidências para a rejeição da hipótese de c-racionalização. E, por este teste, a hipótese de que os agricultores sejam racionais não foi rejeitada.

O algoritmo usado na programação quadrática foi o congra do SAS. Adicionou-se a restrição que garante que o custo calculado fosse menor ou igual ao observado. Isto implica em se admitir ser possível reduzir os custos com a mesma produção.

Tabela 15. Resultados da programação quadrática, para as amostras em estudo: orientação insumo.

\begin{tabular}{lcccc}
\hline Itens & Brasil & $\begin{array}{c}\text { Brasil } \\
\text { R.L. } \\
\text { não negativa }\end{array}$ & $\begin{array}{c}\text { Minas } \\
\text { Gerais }\end{array}$ & $\begin{array}{c}\text { Minas Gerais } \\
\text { R.L. } \\
\text { não negativa }\end{array}$ \\
\hline Número de observações & 143 & 75 & 114 & 71 \\
Programação quadrática $(R)$ & 51,19 & 13,67 & 7,25 & 3,23 \\
Graus de liberdade $(m n)$ & 572 & 300 & 456 & 284 \\
$\chi^{2}$ & 639,68 & 349,39 & 516,58 & 332,09 \\
Desvio padrão $(R / m n)$ & 0,2992 & 0,2135 & 0,1261 & 0,1066 \\
Desvio padrão: programação com $\chi^{2}$ & 0,2829 & 0,1978 & 0,1185 & 0,0986 \\
& & & & \\
Coeficiente de variação de $\left(\frac{t_{i k}}{x_{i k}}\right)$ & 0,0118 & 0,0114 & 0,0055 & 0,0059 \\
& & & & \\
\hline
\end{tabular}

Fonte: Resultados da pesquisa. 
Pode-se obter o valor da eficiência relativa. Já que a programação quadrática oferece um valor para cada insumo, desde que a soma dos quatro valores de cada produtor obedeça às restrições. Esta soma representa o custo que não viola as restrições. Dividindo-se a soma pelo valor observado, obtém-se uma estimativa da eficiência.

Entre os produtores de Minas Gerais de renda líquida não negativa, em número de setenta e um, 13 observações apresentaram eficiência igual a 1, o que representa 18,3\% do total. E para eficiência maior que 0,9 , o número de produtores corresponde a 80,3\% da amostra. Quando analisado a amostra com as 114 observações, observa-se maior dispersão em torno da eficiência igual a 1 . Agricultores com eficiência maior ou igual a 0,9 foram de 67, representando 58,7 \% da amostra. Valores de eficiência entre 0,75 e 0,9 representaram $28,1 \%$ do total da amostra. (Tabela 16). Há, assim, uma forte concentração em torno de 1.

Tabela 16. Medida de eficiência, amostra Minas Gerais, orientação insumo.

\begin{tabular}{ccccc}
\hline Classes de eficiência & $\begin{array}{c}\text { Observações } \\
\text { (número) }\end{array}$ & $(\%)$ & $\begin{array}{c}\text { Observações } \\
\text { (R.L. não negativa) }\end{array}$ & $(\%)$ \\
\hline 1 & 25 & 21,9 & 13 & 18,3 \\
{$[0,9-1)$} & 42 & 36,8 & 44 & 62,0 \\
{$[0,75-0,9)$} & 32 & 28,1 & 9 & 12,7 \\
{$[0,25-0,75)$} & 15 & 13,2 & 4 & 5,6 \\
$(0-0,25)$ & 0 & 0 & 1 & 1,4 \\
TOTAL & 0 & 0 & 0 & 0 \\
Média & 114 & 100 & 71 & 100 \\
Coeficiente de variação (\%) & 12,60 & & 0,92 & \\
Máximo & 1,00 & & 13,09 & \\
Mínimo & 0,56 & & 0,00 & \\
\hline
\end{tabular}

Fonte: Resultados da pesquisa. 
A amostra Brasil compõe-se de 143 produtores de seis estados. Por isto, a dispersão dos dados foi muito maior. Embora o número de violações das restrições tenha sido maior que o da amostra Minas Gerais, elas não foram suficientes para rejeitar a hipótese nula.

Os índices de eficiência da amostra Brasil apresentam dispersão mais acentuada que em Minas Gerais. Cerca de 51,7 \% das 143 observações têm eficiência na classe 0,5 0,75 , e 22 observações pertencem à classe 0,25 - 0,5. Entre os de renda líquida não negativa, a concentração em torno de 1 foi bem menor que em Minas Gerais (Tabela 17).

Tabela 17. Medida de eficiência, amostra Brasil, orientação insumo.

\begin{tabular}{ccccc}
\hline Classes de eficiência & $\begin{array}{c}\text { Observações } \\
\text { (número) }\end{array}$ & $(\%)$ & $\begin{array}{c}\text { Observações } \\
\text { (R.L. não negativa) }\end{array}$ & $(\%)$ \\
\hline 1 & 19 & 13,3 & 20 & 26,7 \\
{$[0,9-1)$} & 13 & 9,1 & 11 & 14,7 \\
{$[0,5-0,75)$} & 15 & 10,5 & 11 & 14,7 \\
{$[0,25-0,5)$} & 74 & 51,7 & 32 & 42,7 \\
$(0-0,25)$ & 22 & 15,4 & 1 & 1,3 \\
TOTAL & 0 & 0,0 & 0 & 0 \\
Média & 143 & 100 & 75 & 100 \\
Coeficiente de variação $(\%)$ & 0,69 & & 0,80 & \\
Máximo & 28,35 & & 22,02 & \\
Mínimo & 1,00 & & 1,00 & \\
\hline
\end{tabular}

Fonte: Resultados da pesquisa. 
Cabe indagar o que ocorreria com a renda líquida, caso os produtores ajustassem a produção aos resultados da produção quadrática, admitindo-se não mudar a renda bruta com a mudança da composição dos insumos. Este conceito é mais próximo da programação linear não paramétrica, orientação insumo.

Não deve ter passado despercebido que se admitir que a mudança da composição dos insumos não influencia a renda bruta, é equivalente a supor que se permaneça na mesma isoquanta. As restrições aduzidas não garantem que isto aconteça, ou seja, quando a solução ótima reduzir o custo, não se pode garantir que uma produção, pelo menos igual à observada, possa ser obtida com a nova composição de insumos. Infere-se que há, pelo menos, um agricultor que conseguiu produzir igual ou mais com custo não inferior ao da nova composição. Nos modelos não paramétricos de programação linear, evita-se este problema.

No caso do Brasil, as observações com renda líquida não negativa equivaleriam a 142, cerca de 99,3\% das 143 observações. Sem este ajuste, como se viu, o número correspondente foi 75 , ou seja, 52,4 \% da amostra. A renda líquida média anual, evoluiu de $\mathrm{R} \$ 12.126,73$ para $\mathrm{R} \$ 43.217,95$, registrando-se um ganho respeitável de $256 \%$. Constata-se, porém, que não se eliminou completamente a renda líquida negativa.

Como as violações das restrições foram menores em Minas Gerais, é esperado que o ajuste aos resultados da programação quadrática produza um efeito de menor vulto. O número de produtores de renda líquida não negativa subiu de 71 para 108, um aumento de 52,1 \%. Em relação às 114 observações, os de renda não negativa, sem o ajuste, ou seja 71 observações, equivaleram a 62,3\%, e, com ajuste, 94,7 \%. A renda líquida média anual cresceu de $\mathrm{R} \$ 9.907,12$ para $\mathrm{R} \$ 35.785,67$, um crescimento de $261 \%$. 


\subsection{Teste da hipótese da minimização dos custos: orientação produto}

O tema foi, indiretamente, tratado por Varian (1985); porém, é uma extensão trivial de seu método. Os dados foram ordenados na direção do menor dispêndio para o maior. Pela regra de racionalização, quem produziu mais não pode ter gastado menos do quem produziu menos. Assim, $C_{\mathrm{i}} \quad C_{j}$ não pode implicar $y_{\mathrm{i}}>y_{j}$. Logo, os $y$ 's seguem a mesma ordenação dos $C$ s. E o processo de contagem de acertos foi igual ao descrito, com $y$ no lugar de $C$. Os resultados estão na Tabela 18 , sem se dividir a amostra, quanto à renda líquida. Obviamente, os resultados têm que ser os mesmos quando, comparados com o modelo orientação insumo, o que foi confirmado, no comparativo com a Tabela 14.

Tabela 18. Número de acertos, de acordo com o axioma da minimização de custos. Comparação da renda bruta de uma observação com todas as seguintes.

\begin{tabular}{lccc}
\hline Amostras & $\begin{array}{c}\text { Possíveis } \\
n *(n-1) / 2\end{array}$ & Observados & $\begin{array}{c}\text { Observados/ } \\
\text { Possíveis (\%) }\end{array}$ \\
\hline Brasil & 10153 & 8844 & 87,1 \\
Minas Gerais & 6441 & 6130 & 95,2 \\
\hline
\end{tabular}

Fonte: Resultados da pesquisa.

Para se testar a hipótese nula, foi minimizado a soma dos quadrados em relação à renda bruta observada, com as restrições ditadas pela regra da racionalização. Adicionou-se a restrição que garante que a renda bruta ótima fosse pelo menos igual à observada. Isto implica em se admitir ser possível produzir a mesma coisa a mais com os mesmos gastos. O modelo não garante que uma produção maior possa ser possível, ao contrário da programação linear não paramétrica. 
A média de $\frac{y_{\text {otimo }}}{y_{\text {obs }}}$ é igual a 1 . O coeficiente de variação, que dá precisão da medida da renda bruta de cada agricultor (Tabela 19), foi bem pequeno para a amostra Minas Gerais, menor que $2 \%$ e chegou a $6,43 \%$ para a amostra Brasil. Considerando-se a dispersão dos dados referentes ao Brasil, este valor não foi suficiente para se rejeitar a hipótese de c-racionalização. Além do mais este valor está superestimado, pelo fato de se ter introduzido uma restrição adicional, exigindo-se que a solução ótima fosse maior ou igual àrenda bruta observada.

A solução da programação quadrática fornece os y's tais que se passa a obedecer às restrições, com o mínimo de perturbação possível, e, ainda, obtém-se uma renda bruta nunca menor que a observada. Denomine-se a solução por $y_{\mathrm{ot}} \mathrm{e}$ a renda bruta observada por $y_{\mathrm{ob}}$. Uma medida de eficiência é dada por $E=\frac{y_{o b}}{y_{o t}}$.

Tabela 19. Resultados da programação quadrática, para as amostras em estudo: orientação produto.

\begin{tabular}{lcc}
\hline Itens & Brasil & Minas Gerais \\
\hline Número de observações & 143 & 114 \\
Programação quadrática $(R)$ & 104,92 & 3,95 \\
Graus de liberdade $(m n)$ & 143 & 114 \\
$\chi^{2}$ & 177,51 & 144,95 \\
Desvio padrão $(R / m n)$ & 0,8566 & 0,1861 \\
Desvio padrão: programação com $\chi^{2}$ & 0,7688 & 0,1651 \\
Coeficiente de variação de $\left(\frac{t_{i k}}{y_{i k}}\right)$ & 0,0643 & 0,0155 \\
\hline
\end{tabular}

Fonte: Resultados da pesquisa. 
Sob ótica do produto, observa-se que a amostra Minas Gerais se destaca novamente, em relação aos índices de eficiência (Tabela 20).

Deve-se esperar que a renda líquida cresça, porque se permitiu à produção crescer sem alterar os custos. De fato, isto ocorreu. Tendo-se em vista a nova renda gerada pela programação quadrática, nenhuma observação da amostra Brasil teve renda líquida negativa. Das 114 observações na amostra Minas Gerais, apenas 6 ficaram com renda líquida negativa.

$\mathrm{Na}$ amostra Brasil, a nova renda líquida média anual igualou-se a $\mathrm{R} \$ 61.223,46$, que foi bem maior que a renda líquida observada que foi igual $\mathrm{R} \$ 38.284,32$ para as 75 observações (cerca de 1,6 vez). No caso de Minas Gerais, os números foram, respectivamente, $\mathrm{R}$ \$29.055,46 (109 observações) e R \$ 23.619,39 (71 observações), cerca de 1,2 vez maior.

Tabela 20. Medida de eficiência, Brasil e Minas Gerais, orientação produto.

\begin{tabular}{|c|c|c|c|c|}
\hline \multirow{2}{*}{ Classes de eficiência } & \multicolumn{2}{|c|}{ Brasil } & \multicolumn{2}{|c|}{ Minas Gerais } \\
\hline & Número & $(\%)$ & Número & $(\%)$ \\
\hline 1 & 14 & 9,8 & 25 & 21,9 \\
\hline$[0,9-1)$ & 10 & 7,0 & 42 & 36,9 \\
\hline$[0,75-0,9)$ & 36 & 25,2 & 35 & 30,7 \\
\hline$[0,5-0,75)$ & 57 & 39,9 & 12 & 10,5 \\
\hline$[0,25-0,5)$ & 25 & 17,5 & 0 & 0 \\
\hline$(0-0,25)$ & 1 & 0,6 & 0 & 0 \\
\hline TOTAL & 143 & 100 & 114 & 100 \\
\hline Média & \multicolumn{2}{|c|}{0,69} & \multicolumn{2}{|c|}{0,90} \\
\hline Coeficiente de variação $(\%)$ & \multicolumn{2}{|c|}{28,57} & \multicolumn{2}{|c|}{11,07} \\
\hline Máximo & \multicolumn{2}{|c|}{1,00} & \multicolumn{2}{|c|}{1,00} \\
\hline Mínimo & \multicolumn{2}{|c|}{0,24} & \multicolumn{2}{|c|}{0,58} \\
\hline
\end{tabular}

Fonte: Resultados da pesquisa. 


\subsection{Modelo econométrico de eficiência}

Optou-se pela forma funcional geral $y_{i}=f\left(x_{i} ; \beta\right) e^{(V i-U i)}$, justificada na seção metodologia. A distribuição de $u_{\mathrm{i}}$ escolhida foi a meio-normal ${ }^{11}$. A função CobbDouglas ajustou-se muito bem aos dados. Adicionourse variável dummy, que é igual a um para os produtores de renda líquida não negativa. $\mathrm{O}$ valor da produção foi a variável dependente: o valor da venda do leite mais a venda de animais, em $\mathrm{R} \$$.

As variáveis explicativas estão medidas em $\mathrm{R} \$$ e foram:

$\mathrm{X}_{1}=3 \%$ do valor da terra, $6 \%$ do valor dos animais utilizado na produção, valor da depreciação de máquinas, equipamentos e benfeitorias.

$\mathrm{X}_{2}=$ Dispêndio com mão-de-obra familiar e contratada.

$\mathrm{X}_{3}=$ Dispêndio com concentrados, minerais, volumoso, inseminação artificial e medicamentos.

$\mathrm{X}_{4}=$ Dispêndio com energia, combustíveis, manutenção de máquinas, equipamentos e benfeitorias e demais gastos.

$\mathrm{X}_{5}=$ Dummy de intercepto para a renda líquida.

A Tabela 21 relata a estimativa do modelo, por máxima verossimilhança. As variáveis foram significativamente diferentes de zero, a $1 \%$ de probabilidade, a exceção de $x_{2}$ (dispêndio com mão-de-obra familiar e contratada) que foi diferente de zero a $2,6 \%$ de probabilidade.

Os parâmetros $\lambda=\sigma_{\mathrm{u}} / \sigma_{\mathrm{v}}$ e $\sigma^{2}=\sigma_{\mathrm{u}}^{2}+\sigma^{2}{ }_{\mathrm{v}}$ são fundamentais. A razão de variâncias $\sigma_{\mathrm{u}}^{2} / \sigma_{\mathrm{v}}^{2}$ indica a influência da componente de ineficiência na variância total. Os valores encontrados para $\sigma_{\mathrm{u}}^{2}$ e $\sigma_{\mathrm{v}}^{2}$ foram 0,0061 e 0,0479 , respectivamente. Portanto, $\lambda=0,36$.

Para Greene (1993), a variância da variável aleatória $u$ é $[(\pi / 2)-1] \sigma^{2}{ }_{u}$ e não $\sigma^{2}{ }_{u}$. Assim, na decomposição da variância total em dois componentes, a contribuição de $u$

\footnotetext{
${ }^{11}$ Para maiores detalhes sobre a distribuição meio-normal consultar Aigner et al. (1977).
} 
para a variância total foi estimada como $[(\pi / 2)-1] \sigma^{2}{ }_{u} /\left\{\sigma^{2}{ }_{v}+[(\pi / 2)-1] \sigma^{2}{ }_{u}\right\}$. Para amostra Brasil igualou-se a 6,7 \%.

O parâmetro $\lambda=\sigma_{\mathrm{u}} / \sigma_{\mathrm{v}}$ é interpretado como indicador da variabilidade relativa de $v$ e $u$, que distingue uma firma da outra. Se $\lambda^{2} \rightarrow 0$, o erro simétrico predomina na determinação de $\varepsilon$. Similarmente, se $\lambda^{2} \rightarrow \infty$, o erro assimétrico predomina na determinação de $\varepsilon$.

O valor de $\lambda$ encontrado para a amostra Brasil foi 0,36 , estatisticamente não é diferente de zero no nível de $5 \%$, mas sim no nível de $40 \%$ de probabilidade.

Tabela 21. Estimativas dos parâmetros para a função de produção fronteira estocástica, tipo Cobb-Douglas, com especificação meio-normal, para amostra Brasil.

\begin{tabular}{lcccc}
\hline Variáveis & $\begin{array}{c}\text { Coeficientes } \\
\text { Estimados }\end{array}$ & Erro-padrão & H: coef=0 & Probabilidade \\
\hline$\beta_{\mathrm{o}}$ & 1,2233 & 0,2822 & 4,34 & 0,0001 \\
$\beta_{1}$ & 0,2697 & 0,0339 & 7,94 & 0,0001 \\
$\beta_{2}$ & 0,0852 & 0,0380 & 2,24 & 0,0265 \\
$\beta_{3}$ & 0,4810 & 0,0306 & 15,71 & 0,0001 \\
$\beta_{4}$ & 0,1626 & 0,0325 & 5,01 & 0,0001 \\
Dummy intercepto & 0,4458 & 0,0354 & 12,61 & 0,0001 \\
$\sigma^{2}$ & 0,0541 & 0,0202 & 2,68 & 0,0083 \\
$\lambda$ & 0,3573 & 0,4213 & 0,85 & 0,3979 \\
LFV & 24,2239 & & & \\
\hline
\end{tabular}

Fonte: Resultados da pesquisa.

1 LFV é o logaritmo da função de verossimilhança (og-likelihood function). Que foi significativo à $10 \%$ de probalidade, com 1 grau de liberdade, pelo teste qui-quadrado misto. 
A Tabela 22 apresenta as classes de eficiência técnica. A média do Brasil equivaleu a 0,89 . Cerca de $54,5 \%$ das 143 observações tem eficiência técnica na classe 0,9 - 1. Apenas uma observação pertence à classe 0,5 - 0,75. Entre os de renda líquida não negativa, 35 observações, que representa $46,6 \%$ do total, estão na classe 0,9 - 1 . Para este grupo de produtores, não houve nenhuma observação com eficiência menor do que 0,75. As médias e as medianas dos dois grupos foram praticamente iguais. $\mathrm{O}$ coeficiente de variação para o grupo de produtores com renda líquida não negativa foi $2,89 \%$, enquanto que para a amostra Brasil, com as 143 observações foi 3,4 \%.

Tabela 22. Eficiência técnica, amostra Brasil.

\begin{tabular}{|c|c|c|c|c|}
\hline \multirow{2}{*}{ Eficiência Técnica } & \multicolumn{2}{|c|}{ Brasil } & \multicolumn{2}{|c|}{ Brasil R.L não negativa } \\
\hline & $\begin{array}{l}\text { Observações } \\
\text { (número) }\end{array}$ & $(\%)$ & $\begin{array}{l}\text { Observações } \\
\text { (número) }\end{array}$ & $(\%)$ \\
\hline 1 & 0 & 0 & 0 & 0 \\
\hline$[0,9-1)$ & 78 & 54,55 & 35 & 46,67 \\
\hline$[0,75-0,9)$ & 64 & 44,76 & 40 & 53,33 \\
\hline$[0,5-0,75)$ & 1 & 0,70 & 0 & 0 \\
\hline$(0-0,5)$ & 0 & 0 & 0 & 0 \\
\hline TOTAL & 143 & 100 & 75 & 100 \\
\hline Média & \multicolumn{2}{|c|}{0,8982} & \multicolumn{2}{|c|}{0,8984} \\
\hline Coeficiente de Variação (\%) & \multicolumn{2}{|c|}{3,4051} & \multicolumn{2}{|c|}{2,8916} \\
\hline Mediana & \multicolumn{2}{|c|}{0,9036} & \multicolumn{2}{|c|}{0,8974} \\
\hline Máximo & \multicolumn{2}{|c|}{0,9559} & \multicolumn{2}{|c|}{0,9560} \\
\hline Mínimo & \multicolumn{2}{|c|}{0,7340} & \multicolumn{2}{|c|}{0,8528} \\
\hline
\end{tabular}

Fonte: Resultados da pesquisa. 
O modelo econométrico de Minas Gerais foi o mesmo do Brasil. O valor de $\lambda=\sigma_{\mathrm{u}} / \sigma_{\mathrm{v}}$, resultou igual a 0,00002 , que não foi diferente de zero, a $1 \%$ de probabilidade. Ou seja, a componente de ineficiência tem variância nula, e as firmas foram, igualmente, eficientes. E a eficiência foi igual a 1. O valor encontrado para o logaritmo da função de verossimilhança (log-likelihood function) foi de 110,61, que foi, praticamente, igual ao valor dos mínimos quadrados ordinários.

A escolha da distribuição de $u_{\mathrm{i}}$ condiciona os resultados de estimativas de máxima verossimilhança, e não existem razões definidas a priori para a escolha, a menos de conveniências estatísticas (Førsund et al., 1980). Admitindo-se a distribuição exponencial de $u_{\mathrm{i}}$, obteve-se a mesma conclusão, ou seja, não se pode rejeitar a hipótese de ineficiência zero entre as firmas.

Como decorrência dos resultados da estimativa de verossimilhança, optou-se pelos mínimos quadrados ordinários, admitindo-se as pressuposições usuais sobre o erro. Os resultados da estimativa dos parâmetros estão apresentados na Tabela 23.

Todas as variáveis foram diferentes de zero, nível $1 \%$ de probabilidade, com exceção da variável $x_{4}$ (dispêndio com energia, combustíveis, manutenção de máquinas, equipamentos e benfeitorias e demais gastos) em que o nível foi de 3,2 \% de probabilidade. O R ${ }^{2}$ ajustado foi igual a 0,98 e $\mathrm{F}_{[5,108]}=1778,25$, diferente de zero, a $1 \%$ de probabilidade. Os resíduos não violaram os pressupostos do modelo. 
Tabela 23. Estimativas de parâmetros da função de produção Cobb-Douglas, amostra Minas Gerais.

\begin{tabular}{lcccc}
\hline Variáveis & $\begin{array}{c}\text { Coeficientes } \\
\text { Estimados }\end{array}$ & Erro-padrão & H: coef=0 & Probabilidade \\
\hline$\beta_{\mathrm{o}}$ & 1,05742 & 0,12572 & 8,41 & 0,0001 \\
$\beta_{1}$ & 0,24383 & 0,02222 & 10,97 & 0,0001 \\
$\beta_{2}$ & 0,21336 & 0,02549 & 8,37 & 0,0001 \\
$\beta_{3}$ & 0,50278 & 0,01982 & 25,37 & 0,0001 \\
$\beta_{4}$ & 0,04695 & 0,02163 & 2,17 & 0,0322 \\
Dummy intercepto & 0,20533 & 0,01853 & 11,08 & 0,0001 \\
$\mathrm{~F}[5,108]$ & 1778,25 & & & 0,0001 \\
$\mathrm{R}^{2}$ ajustado & 0,98 & & & \\
\hline
\end{tabular}

Fonte: Resultados da pesquisa.

Foi construído um intervalo de confiança a $95 \%$ de probabilidade para os valores preditos, e tem-se uma fronteira superior e a inferior. Se o valor da renda bruta observado estiver dentro do limite da fronteira, então, a eficiência técnica é igual a um. Nenhuma observação ficou acima da fronteira superior e abaixo da inferior. Estatisticamente, todas as observações têm eficiência técnica igual a 1. A Tabela 24 ilustra os resultados obtidos.

Tabela 24. Eficiência técnica para amostra Minas Gerais.

\begin{tabular}{lcc}
\hline & Minas Gerais & Minas Gerais R.L não negativa \\
\hline Observações & 114 & 71 \\
Média & 0,9770 & 0,9784 \\
Coeficiente de Variação (\%) & 0,2413 & 0,1513 \\
Máximo & 0,9825 & 0,9825 \\
Mínimo & 0,9711 & 0,9759 \\
Mediana & 0,9773 & 0,9781 \\
\hline
\end{tabular}

Fonte: Resultados da pesquisa. 


\subsection{Análise envoltória de dados (DEA): orientação insumo}

Formulou-se o modelo de programação linear com orientação insumo. $\mathrm{O}$ vetor de produção refere-se à renda bruta da atividade leiteira: venda do leite e derivados mais venda de animais. Os insumos foram medidos em valor $(R \$)$ e foram os seguintes: $x_{1}=3$ $\%$ do valor da terra mais $6 \%$ do valor dos animais utilizado na produção e mais valor da depreciação de máquinas, equipamentos e benfeitorias; $\mathrm{x}=$ dispêndio com mão-de-obra familiar e contratada; $\mathrm{x}_{3}=$ dispêndio com concentrados, minerais, volumosos, inseminação artificial e medicamentos; e $\mathrm{x}_{4}=$ dispêndio com energia, combustíveis, manutenção de máquinas, equipamentos e benfeitorias e demais gastos.

$\mathrm{Na}$ amostra Brasil, 11 produtores alcançaram a eficiência técnica máxima, ou seja, estão na fronteira do modelo de retornos constantes à escala. Revelando a ausência de problemas de escala. Eles equivalem a 7,7 \% da amostra. Com relação à amostra Minas Gerais, 8 produtores obtiveram eficiência técnica igual a 1, o que representa $7 \%$ da amostra. Assim, nas duas amostras, o número de produtores de eficiência técnica máxima foi pequeno, considerando-se como paradigma o modelo de retornos constantes àescala (Tabela 25).

A média da eficiência técnica da amostra Brasil igualoutse a 0,53 e, para a amostra Minas Gerais, a 0,58.

Com relação à escala, é importante saber quantos agricultores estão em cada região da fronteira de produção, isto é, em condições de retornos crescentes, constantes e decrescentes. Para a amostra Brasil, foram encontrados 124 produtores operando na região de retornos crescentes $(86,7 \%)$. Estes podem expandir a escala de produção a custos decrescentes. Na região de retornos decrescentes, estão 5 produtores $(3,5 \%)$, que poderiam aumentar sua eficiência técnica, caso reduzissem o tamanho da produção. Finalmente, 14 produtores $(9,8 \%)$ estão operando na região de retornos constantes da função de produção. É interessante notar que, na amostra Brasil, dos 14 produtores, 11 estão na fronteira de retornos constantes, os outros três estão na faixa de retornos constantes, porém não se localizam na fronteira eficiente. 
Com relação a amostra Minas Gerais, 104 produtores, o que representa 91,3\% da amostra, estão operando na faixa de retornos crescentes. Na faixa de retornos decrescentes, apenas 2 produtores $(1,7 \%)$. Há 8 produtores $(7 \%)$ com retornos constantes à escala.

Os dados estão sujeitos a erros de entrevista. Como os dados foram tabulados em valor, é inevitável o erro de agregação. Schultz (1964) formulou a hipótese de que os agricultores são eficientes. Por tentativa e erro, acabam-se localizando na fronteira eficiente, no ponto que minimiza o custo ${ }^{12}$.

A fim de se testar a hipótese de eficiência igual a um, considerou-se que não violaram os produtores que obtiveram índices maiores que 0,9. Adere-se, de forma fraca, à hipótese de Schultz (1964), onde se tem violação fraca apresentando índices maiores que 0,75 e menores ou iguais 0,9 ; violação moderada, índices maiores que 0,5 e menores ou iguais a 0,75 ; violação forte, maiores que 0,25 e menores que ou iguais a 0,50; e finalmente, violação muito forte, índices menores ou iguais a 0,25.

Convém salientar que a hipótese original de Schultz refere-se à eficiência econômica, mas uma condição necessária para que ela seja válida é que a eficiência técnica seja igual a um. A classificação foi adaptada de Ray et al. (1993), e procura traduzir o grau de violação da condição de eficiência máxima.

Observa-se que, para a amostra Brasil, 11,2 \% dos produtores não violaram a hipótese de eficiência. Na classe da violação fraca há 14 observações e com violação moderada 42 produtores, o que representa, 9,8 e 29,4\%, respectivamente, do total. A maior concentração de produtores ficou na classe violação forte, que foram 54 produtores, representando cerca de $38 \%$ da amostra (Tabela 25).

\footnotetext{
${ }^{12}$ Note-se que pelo método Varian, não se rejeita a hipótese de Schultz, visto que as evidências não foram suficientes para rejeitar a hipótese de c-racionalização dos dados.
} 
Tabela 25. Eficiência técnica, retornos constantes à escala, para as amostras Brasil e Minas Gerais, orientação insumo.

\begin{tabular}{|c|c|c|c|c|}
\hline \multirow{2}{*}{ Classe de eficiência } & \multicolumn{2}{|c|}{ Brasil } & \multicolumn{2}{|c|}{ Minas Gerais } \\
\hline & $\begin{array}{l}\text { Observações } \\
\text { (número) }\end{array}$ & $(\%)$ & $\begin{array}{l}\text { Observações } \\
\text { (número) }\end{array}$ & $(\%)$ \\
\hline 1 & 11 & 7,7 & 8 & 7,0 \\
\hline$[0,9-1)$ & 5 & 3,5 & 2 & 1,8 \\
\hline$[0,75-0,9)$ & 14 & 9,8 & 9 & 7,9 \\
\hline$[0,5-0,75)$ & 42 & 29,4 & 53 & 46,5 \\
\hline$[0,25-0,5)$ & 54 & 37,8 & 42 & 36,8 \\
\hline$(0-0,25)$ & 17 & 11,9 & 0 & 0 \\
\hline TOTAL & 143 & 100 & 114 & 100 \\
\hline Média & \multicolumn{2}{|c|}{0,53} & \multicolumn{2}{|c|}{0,58} \\
\hline Coeficiente de Variação (\%) & \multicolumn{2}{|c|}{45,32} & \multicolumn{2}{|c|}{31,73} \\
\hline Máximo & \multicolumn{2}{|c|}{1,00} & \multicolumn{2}{|c|}{1,00} \\
\hline Mínimo & \multicolumn{2}{|c|}{0,11} & \multicolumn{2}{|c|}{0,29} \\
\hline
\end{tabular}

Fonte: Resultados da pesquisa.

Para a amostra Minas Gerais, 10 produtores $(8,8 \%$ ) não violaram a hipótese de eficiência. Na classe violação fraca, há 9 produtores e violação moderada, 53 produtores. Na classe violação forte, situa-se cerca de $36,8 \%$ da amostra. Não se observou nenhum produtor operando na classe da violação muito forte para a amostra Minas Gerais; já, para a amostra Brasil, 17 produtores estão nesta faixa, o que representa cerca de $12 \%$ da amostra.

Para os produtores que não violaram a hipótese de eficiência, a renda líquida mensal igualou-se a $\mathrm{R} \$ 8.234,90$, para a amostra Brasil. Na classe 0,75 - 0,9, a renda líquida média equivaleu-se a R\$ 1.357,32; nas classes 0,75 - 0,5 e 0,5 - 0,25 as médias corresponderam a R \$ 1.014,69 e R \$ 197,64, respectivamente. Os produtores da classe de eficiência técnica menor que 0,25 , em número de 17 , apresentaram renda líquida negativa. 
A renda líquida média mensal, da classe igual ou maior que 0,9 , da amostra Minas Gerais, foi de $\mathrm{R} \$ 3.633,14$. Da classe 0,75 - 0,9, a média igualou-se a $\mathrm{R} \$ 3.357,57$. Os 53 produtores da classe 0,5 - 0,75 tiveram renda líquida média mensal de $\mathrm{R} \$ 515,77$. Na classe de eficiência técnica menor que 0,5 , o valor encontrado foi de $\mathrm{R} \$ 55,52$ Dos 42 produtores da classe, 25 tiveram renda líquida negativa.

A medida de eficiência econômica total (EE) ou eficiência custo, é dada pela razão entre o custo mínimo (custo calculado) e o custo observado.

O coeficiente de eficiência custo importa no quociente de duas medidas: primeiramente, mede-se a distância entre o ponto que o vetor (insumos) do produtor corta a isoquanta e a origem. Esta é a primeira medida. A segunda é a própria distância do vetor em relação à origem. A medida é igual a 1 quando o produtor se localiza exatamente no ponto correto da fronteira. A decomposição da eficiência custo é dada por: Efic. Custo = Efic. Preço (alocativa) * Efic. Técnica.

Os resultados encontrados estão apresentados na Tabela 26. Os índices de eficiência foram gerados pelo modelo com retornos constantes à escala.

A hipótese de eficiência de Schultz pode ser reinterpretada. Em vez de se supor que os produtores tenham os índices de eficiência ao redor de 1, pode-se supor que estejam concentrados em poucas classes de violação. As classes violação moderada $(0,5$ - 0,75) e violação forte $(0,5$ - 0,25) concentram 101 observações. Ou seja, 70,7 \% da amostra Brasil. Para a amostra Minas Gerais, 100 observações das 114 estão concentradas nas classes violação moderada e violação forte, que representa $87,8 \%$ do total.

Já para a eficiência preço, na amostra Brasil as classes violação fraca $(0,75$ - 0,9) e violação moderada $(0,5$ - 0,75), concentram 100 observações $(70 \%$ da amostra), enquanto que para a amostra Minas Gerais cerca de $60 \%$ da amostra está concentrada nas classes violação fraca e moderada.

Com relação à eficiência custo, para a amostra Brasil a média igualou-se a 0,42 e para a amostra Minas Gerais a 0,44. Para a amostra Brasil, a classe 0,25 - 0,5 concentrou 64 observações o que representa 44,6 \% do total. Já para a amostra Minas Gerais, a mesma classe de eficiência, concentrou 72 observações (63,2\%) (Tabela 26). 
Tabela 26. Eficiência preço e custo para as amostras Brasil e Minas Gerais.

\begin{tabular}{|c|c|c|c|c|c|c|c|c|}
\hline \multirow{2}{*}{$\begin{array}{l}\text { Classe de } \\
\text { eficiência }\end{array}$} & \multicolumn{4}{|c|}{ Brasil } & \multicolumn{4}{|c|}{ Minas Gerais } \\
\hline & $\begin{array}{c}\text { Eficiência } \\
\text { preço } \\
\left(n^{\mathbf{0}}\right)\end{array}$ & $(\%)$ & $\begin{array}{c}\text { Eficiência } \\
\text { custo } \\
\left(\mathrm{n}^{\mathbf{O}}\right)\end{array}$ & $(\%)$ & $\begin{array}{c}\text { Eficiência } \\
\text { preço } \\
\left(\mathrm{n}^{\mathbf{0}}\right)\end{array}$ & $(\%)$ & $\begin{array}{c}\text { Eficiência } \\
\text { custo } \\
\left(\mathrm{n}^{\mathbf{O}}\right)\end{array}$ & $(\%)$ \\
\hline 1 & 3 & 2,1 & 1 & 0,7 & 2 & 1,8 & 1 & 0,9 \\
\hline$[0,9-1)$ & 39 & 27,3 & 2 & 1,4 & 35 & 30,7 & 1 & 0,9 \\
\hline$[0,75-0,9)$ & 61 & 42,7 & 5 & 3,5 & 33 & 28,9 & 3 & 2,6 \\
\hline$[0,5-0,75)$ & 28 & 19,6 & 37 & 25,9 & 35 & 30,7 & 28 & 24,6 \\
\hline$[0,25-0,5)$ & 12 & 8,4 & 64 & 44,8 & 9 & 7,9 & 72 & 63,2 \\
\hline$(0-0,25)$ & 0 & 0 & 34 & 23,8 & 0 & 0 & 9 & 7,9 \\
\hline TOTAL & 143 & 100 & 143 & 100 & 114 & 100 & 114 & 100 \\
\hline Média & 0,80 & & 0,42 & & 0,78 & & 0,44 & \\
\hline $\begin{array}{l}\text { Coeficiente } \\
\text { Variação }(\%)\end{array}$ & 20,68 & & 46,60 & & 21,99 & & 34,22 & \\
\hline Máximo & 1,00 & & 1,00 & & 1,00 & & 1,00 & \\
\hline Mínimo & 0,26 & & 0,08 & & 0,29 & & 0,14 & \\
\hline
\end{tabular}

Fonte: Resultados da pesquisa.

Na Tabela 27, estudou-se o comportamento da média de curral (vacas em lactação/litros/dia), vacas em lactação (unidade animal), produção (litros/dia) e a renda líquida mensal (renda líquida anual/12). Destaca-se, para cada classe, o mínimo, a média e o máximo. Observa-se que para ambas as amostras, os produtores que não violaram estritamente a hipótese de eficiência, a média de curral foi em torno de 18 litros/vaca em lactação/dia, o tamanho ficou em torno de 60 animais e a produção diária cerca de 1000 litros/dia.

O produtor com o maior número de animais produzindo, para a amostra Brasil, pertence à classe não violaram e para a amostra Minas Gerais pertence à classe violação moderada. Com relação à média de curral, o produtor com maior valor pertence à classe não violaram para a amostra Minas Gerais, e violação forte para a amostra Brasil. Para a 
amostra Brasil, os índices de correlação entre eficiência custo, média de curral, produção diária e número de vacas em lactação foram, 0,36, 0,44 e 0,36, respectivamente. As correlações foram significativas no nível de $1 \%$ de probabilidade.

Por sua vez, para a amostra Minas Gerais, a correlação entre a eficiência custo e média de curral e produção diária foi igual a 0,49 e 0,38 , respectivamente, e foram significantes no nível de $1 \%$ de probabilidade. A correlação do número de vacas em lactação e a eficiência custo igualoutse a 0,20, e foi significante no nível de $2 \%$ de probabilidade. Assim, existem indicações de associação entre ficiência custo, tamanho e média de curral.

Com relação à renda líquida, observou-se que, a partir da classe violação fraca, aparece pelo menos um produtor com renda líquida negativa. Para a amostra Brasil, na classe violação fraca, foi observado um produtor com renda líquida negativa. Na classe violação moderada, há 9 produtores com renda líquida negativa. O número de produtores com renda líquida negativa equivaleu a 26 e 32, respectivamente, para as classes violação forte e muito forte. Para a amostra Minas Gerais observou-se a mesma tendência, conforme se reduz a eficiência custo, o número de produtores com renda líquida negativa aumenta. Nas classes correspondentes às violações fraca, moderada, forte e muito forte, há, respectivamente, 1, 5,29 e 8 produtores com renda líquida negativa.

Considerando apenas os produtores com renda líquida não negativa, que foram de número 75, para a amostra Brasil, a eficiência custo média foi de 0,51, com os valores variando de 1,00 a 0,21 (máximo e mínimo). Já para os produtores com renda líquida negativa a média encontrada foi de 0,31 , com o máximo de 0,81 e o mínimo de 0,1.

Para os produtores da amostra Minas Gerais, a média encontrada para os 71 produtores com renda líquida não negativa foi 0,48 sendo o valor máximo de 1,00 e o mínimo 0,25. Entre os produtores com renda líquida negativa, que representam cerca de $38 \%$ da amostra, os valores de máximo e mínimo foram, 0,81 e 0,14, respectivamente, e a média igual a 0,36 .

A correlações entre a renda líquida e eficiência custo foram iguais a 0,60 e 0,42, diferentes de zero, no nível de $1 \%$ de probabilidade, para as amostras Brasil e Minas Gerais, respectivamente. 
Tabela 27. Mínimo, médio e máximo da média de curral, vacas em lactação, produção diária e renda líquida mensal para diversas classes de violações. Amostras Brasil e Minas Gerais.

\begin{tabular}{|c|c|c|c|c|c|c|}
\hline \multirow{2}{*}{ Itens } & \multicolumn{3}{|c|}{ Brasil } & \multicolumn{3}{|c|}{ Minas Gerais } \\
\hline & Mínimo & Média & Máximo & Mínimo & Média & Máximo \\
\hline Produtores (total) & & 143 & & & 114 & \\
\hline Média de curral (litros/vaca/dia) & 5,67 & 15,20 & 29,21 & 25,91 & 13,76 & 4,08 \\
\hline Vacas em Lactação (num) & 12 & 55 & 300 & 10 & 82 & 500 \\
\hline Produção (litros/dia) & 191 & 858 & 5954 & 93 & 1132 & 6504 \\
\hline Renda líquida (R \$/mês) & $-8.889,07$ & $1.010,56$ & $35.946,43$ & $-9.680,98$ & 825,59 & $16.225,30$ \\
\hline Não violaram estritamente [1] & \multicolumn{3}{|c|}{$1(0,7 \%)^{1}$} & \multicolumn{3}{|c|}{$1(0,9 \%)^{1}$} \\
\hline Média de curral (litros/vaca/dia) & \multicolumn{3}{|c|}{17,82} & \multicolumn{3}{|c|}{18,46} \\
\hline Vacas em Lactação (num.) & \multicolumn{3}{|c|}{60} & \multicolumn{3}{|c|}{55} \\
\hline Produção (litros/dia) & \multicolumn{3}{|c|}{1069} & \multicolumn{3}{|c|}{1015} \\
\hline Renda líquida ( $\mathrm{R} \$ / \mathrm{mês})$ & \multicolumn{3}{|c|}{$9.048,10$} & \multicolumn{3}{|c|}{$2.836,27$} \\
\hline Não violaram $[0,9-1)$ & \multicolumn{3}{|c|}{$2(1,4 \%)^{1}$} & \multicolumn{3}{|c|}{$1(0,9 \%)^{1}$} \\
\hline Média de curral (litros/vaca/dia) & 17,45 & 23,23 & 29,01 & \multicolumn{3}{|c|}{24,00} \\
\hline Vacas em Lactação (num.) & 135 & 217 & 300 & \multicolumn{3}{|c|}{100} \\
\hline Produção (litros/dia) & 3916 & 4576 & 5236 & \multicolumn{3}{|c|}{2400} \\
\hline Renda líquida ( $\mathrm{R} \$$ mês) & $19.133,95$ & $24.813,82$ & $30.493,68$ & \multicolumn{3}{|c|}{$3.827,50$} \\
\hline Violação fraca $[0,75-0,9)$ & \multicolumn{3}{|c|}{$5(3,5 \%)^{1}$} & \multicolumn{3}{|c|}{$3(2,6 \%)^{1}$} \\
\hline Média de curral (litros/vaca/dia) & 14,50 & 16,72 & 20,59 & 16,13 & 18,27 & 20,03 \\
\hline Vacas em Lactação (num.) & 30 & 92 & 165 & 51 & 116 & 243 \\
\hline Produção (litros/dia) & 435 & 1613 & 3053 & 887 & 2236 & 4868 \\
\hline Renda líquida (R \$/mês) & $-138,08$ & $2.340,50$ & $6.465,70$ & $-658,17$ & $3.082,76$ & $8.019,83$ \\
\hline Violação moderada $[0,5-0,75)$ & \multicolumn{3}{|c|}{$37(25,9 \%)^{1}$} & \multicolumn{3}{|c|}{$28(24,6 \%)^{1}$} \\
\hline Média de curral (litros/vaca/dia) & 9,98 & 17,17 & 28,38 & 6,77 & 15,70 & 24,44 \\
\hline Vacas em Lactação (num.) & 12 & 63 & 250 & 18 & 108 & 500 \\
\hline Produção (litros/dia) & 191 & 1090 & 5954 & 239 & 1721 & 6504 \\
\hline Renda líquida (R \$/mês) & $-2.718,03$ & $2.516,18$ & $35.946,43$ & $-2.270,65$ & $2.242,01$ & $16.225,30$ \\
\hline Violação forte $[0,25-0,5)$ & \multicolumn{3}{|c|}{$64(44,8 \%)^{1}$} & \multicolumn{3}{|c|}{$72(63,2 \%)^{1}$} \\
\hline Média de curral (litros/vaca/dia) & 7,00 & 14,64 & 29,21 & 5,89 & 13,29 & 25,91 \\
\hline Vacas em Lactação (num.) & 15 & 51 & 235 & 10 & 73 & 265 \\
\hline Produção (litros/dia) & 192 & 746 & 5641 & 93 & 934 & 4113 \\
\hline Renda líquida ( $\mathrm{R} \$ / \mathrm{mês})$ & $-3.749,51$ & 642,49 & $11.107,84$ & $-9.680,98$ & 239,07 & $8.407,46$ \\
\hline Violação muito forte $(0-0,25)$ & \multicolumn{3}{|c|}{$34(23,8 \%)^{1}$} & \multicolumn{3}{|c|}{$9(7,9 \%)^{1}$} \\
\hline Média de curral (litros/vaca/dia) & 5,67 & 13,35 & 22,61 & 4,08 & 8,28 & 18,70 \\
\hline Vacas em Lactação (num.) & 14 & 38 & 110 & 14 & 62 & 230 \\
\hline Produção (litros/dia) & 208 & 478 & 1319 & 180 & 391 & 942 \\
\hline Renda líquida (R\$/mês) & $-8.889,08$ & $-1.799,88$ & 2.854 & $-1.353,25$ & $-198,20$ & $4.638,63$ \\
\hline
\end{tabular}

Fonte: Resultados da pesquisa.

${ }^{1}$ Número de produtores e a porcentagem em relação ao total. 


\subsection{Análise envoltória de dados (DEA): orientação produto}

Reformuloutse o problema de programação linear para orientação produto. Os vetores de produto e de insumo foram os mesmos utilizados na análise DEA, com orientação insumo.

Os índices de eficiência técnica, quando se admitem retornos constantes à escala, estão resumidos na Tabela 28. Para a amostra Brasil a média foi de 0,41 e para a amostra Minas Gerais foi de 0,52. Observa-se uma distribuição assimétrica em torno da média, com os índices concentrados nas classes $0,5-0,75$ e 0,25 - 0,5, para ambas as amostras.

Dos 143 produtores da amostra Brasil, cerca de $8 \%$ (11 produtores) estão na fronteira de eficiência do modelo de retornos constantes à escala. Na amostra Minas Gerais, 8 produtores dos 114 da amostra estão na fronteira de eficiência de retornos constantes. Utilizando a classificação adaptada de Ray et al. (1993), para a amostra Brasil os produtores se concentraram nas classes violação moderada e forte, somando cerca de $67 \%$ da amostra. Já para a amostra Minas Gerais 95 produtores dos 114, estão nas classes violação moderada e forte.

Entre os produtores com renda líquida não negativa, em número de 75 para a amostra Brasil, a média da eficiência técnica, com orientação produto, foi 0,64 , com o máximo sendo 1,00 e o mínimo 0,30. Já para os produtores de renda líquida negativa (47\% da amostra) a média foi de 0,40 e os extremos 1,00 e 0,11 (máximo e mínimo). Dos 114 produtores da amostra Minas Gerais, a média da eficiência técnica, retornos constantes à escala, foi 0,62 , com o máximo 1,00 e o mínimo 0,29. Para os 43 produtores com renda líquida negativa, os valores da média, máximo e mínimo equivaleram-se a 0,50, 1,00 e 0,28, respectivamente. 
Tabela 28. Eficiência técnica, retornos constantes à escala, para as amostras Brasil e Minas Gerais, orientação produto.

\begin{tabular}{|c|c|c|c|c|}
\hline \multirow{2}{*}{ Classe de eficiência } & \multicolumn{2}{|c|}{ Brasil } & \multicolumn{2}{|c|}{ Minas Gerais } \\
\hline & $\begin{array}{l}\text { Observações } \\
\text { (número) }\end{array}$ & $(\%)$ & $\begin{array}{l}\text { Observações } \\
\text { (número) }\end{array}$ & $(\%)$ \\
\hline 1 & 11 & 7,7 & 8 & 7,0 \\
\hline$[0,9-1)$ & 5 & 3,5 & 2 & 1,8 \\
\hline$[0,75-0,9)$ & 14 & 9,8 & 9 & 7,9 \\
\hline$[0,5-0,75)$ & 42 & 29,4 & 53 & 46,5 \\
\hline$[0,25-0,5)$ & 54 & 37,8 & 42 & 36,8 \\
\hline$(0-0,25)$ & 17 & 11,9 & 0 & 0 \\
\hline TOTAL & 143 & 100 & 114 & 100 \\
\hline Média & \multicolumn{2}{|c|}{0,41} & \multicolumn{2}{|c|}{0,52} \\
\hline Coeficiente de Variação (\%) & \multicolumn{2}{|c|}{45,32} & \multicolumn{2}{|c|}{31,73} \\
\hline Máximo & \multicolumn{2}{|c|}{1,00} & \multicolumn{2}{|c|}{1,00} \\
\hline Mínimo & \multicolumn{2}{|c|}{0,11} & \multicolumn{2}{|c|}{0,29} \\
\hline
\end{tabular}

Fonte: Resultados da pesquisa.

Souza (2003) propôs um teste de hipótese. Seja $y_{i}$ a produção observada da observação $i$ e $\theta_{i}$ o respectivo resultado do DEA, orientação produto. O desvio $d_{\mathrm{i}}$ é dado por $d_{\mathrm{i}}=y_{\mathrm{i}}-\theta_{1} * y_{\mathrm{i} .}$. A hipótese é que tenham a mesma distribuição. Assim, foi possível testar as hipóteses de distribuição meio-normal ou exponencial.

Se os $d_{i}$ são iid (independente e identicamente distribuídos) com densidade comum exponencial, então, $2 \sum_{1}^{n} d_{i} / s$, em que $n$ é número de observações da amostra e $s$ o desvio padrão dos $d_{i}$, tem aproximadamente distribuição qui-quadrado com $2 n$ graus de liberdade. 
Se os $d_{\text {i }}$ são iid, com densidade comum meio-normal, então, $(1-2 / \pi) \sum_{i}^{n} d_{i}^{2} / s^{2}$ tem, aproximadamente, distribuição qui-quadrado com $n$ graus de liberdade.

Pela Tabela 29, a hipótese de distribuição exponencial foi rejeitada no nível de $10 \%$ de probabilidade. $\mathrm{E}$ as evidências não foram suficientes para rejeitar a meionormal. Embora os resultados não sejam reproduzidos, a conclusão foi semelhante para retorno variável. Com estes resultados, foi possível construir intervalo de confiança para os índices de eficiência.

Tabela 29. Ajustamento das distribuições exponencial e meio-normal (truncada em zero), retornos constantes à escala.

\begin{tabular}{lcccccc}
\hline \multirow{2}{*}{ Distribuição } & \multicolumn{3}{c}{ Brasil } & \multicolumn{3}{c}{ Minas Gerais } \\
\cline { 2 - 7 } & $\begin{array}{c}\text { Graus de } \\
\text { liberdade }\end{array}$ & $\begin{array}{c}\text { Qui- } \\
\text { quadrado }\end{array}$ & Prob. & $\begin{array}{c}\text { Graus de } \\
\text { liberdade }\end{array}$ & $\begin{array}{c}\text { Qui- } \\
\text { quadrado }\end{array}$ & Prob. \\
\hline Exponencial & 228 & 323,93 & 0,06 & 286 & 256,85 & 0,09 \\
Meio-normal & 114 & 118,26 & 0,93 & 143 & 93,64 & 0,99 \\
\hline
\end{tabular}

Fonte: Resultados da pesquisa.

Sob as hipóteses do DEA, orientação produto, quando apenas um produto é produzido, foi possível ainda testar a hipótese de retornos constantes (c) versus retornos variáveis (v) (Souza, 2003), Então, $\sum_{1}^{n}\left(d_{i}^{c}\right)^{2} / \sum_{1}^{n}\left(d_{i}^{v}\right)^{2}$ tem distribuição $\mathrm{F}$ com $n$ graus de liberdade para o numerador e $n$ graus de liberdade para o denominador, no caso da distribuição meio-normal. Para Minas Gerais, encontrout se $\mathrm{F}_{(114,114)}=1,19 \mathrm{e} \mathrm{p}=0,18$. Para o Brasil, $F_{(143,143)}=1,20$ e p = 0,14. Não houve, assim, evidências para se rejeitar a hipótese de retornos constantes. 
No caso do DEA com orientação produto, foi possível construir intervalos de confiança para as medidas de eficiência, quando somente um produto é produzido (Souza, 2003). A descrição do procedimento encontram-se no ANEXO A.

No caso do Brasil, a eficiência técnica média igualourse a 0,41 , sendo o correspondente intervalo de confiança igual a 0,24 - 0,41. Há 38 observações neste intervalo, cerca de 26,6 \% da amostra. Em Minas Gerais, a eficiência técnica média resultou igual a 0,52 , com um intervalo de confiança de 0,31 - 0,52. Nele estão 49 observações, cerca de $43,4 \%$ da amostra.

Uma questão que se discutiu é se os agricultores são eficientes. No caso, os índices de eficiência técnica deveriam concentrar-se, em torno de um. Na realidade, mesmo para as observações com o índice igual a um, o intervalo de confiança varia de observação para observação. Dois intervalos, de mesmo índice de eficiência, somente são iguais se as rendas brutas forem iguais, detalhes sobre o cálculo estão no ANEXO A.

Dependendo da observação, o intervalo pode conter grande parte da amostra. Para observação 27, amostra Brasil, de índice um, o intervalo iguala-se a 0,17 - 1,00, e contêm 138 observações, cerca de 96,5 \% das observações, que não divergem de um. Ainda para a amostra Brasil, o menor intervalo corresponde a 0,82 - 1,00, e ele abriga 22 observações, cerca de 15,4\% da amostra. O maior intervalo para Minas Gerais corresponde a 0,38 - 1, com 103 observações, cerca de 90,3 \% das unidades de decisão. O menor daquele estado equivale a 0,81 - 1,00, com 16 observações, $14 \%$. Estes resultados questionam o tipo de escala que se usou, quando foi grande a dispersão da produção, pois, uma unidade de decisão pode não divergir de um, quanto à eficiência técnica, dependendo do intervalo de confiança a que pertença, e que contém um, como limite superior (Tabela 30).

Pode-se optar pela média da renda bruta das unidades de decisão que têm eficiência técnica igual a um. Para o Brasil, o intervalo de confiança corresponde a 0,60 - 1,00, com 50 observações, cerca de 34,9 \% da amostra. Minas Gerais: 0,67 - 1,00, com 27 unidades de decisão, cerca de $23,6 \%$ da amostra.

Na Tabela 30, que retrata o intervalo de confiança das observações de índices de eficiência iguais a um, há oito das 114 observações de Minas Gerais e 11 das 143 da amostra Brasil, que alcançaram o índice um. As observações encontram-se ordenadas da menor para 
a maior renda bruta. $\mathrm{E}$ a amplitude do intervalo foi inversamente proporcional à renda bruta. De fato ela foi dada pelo índice de eficiência mais $z^{13}$ dividido pela renda bruta.

Assim, embora se tenha constatado que as observações rejeitaram a hipótese de Schultz na ótica do DEA, esta rejeição pode ser questionada, observando-se que alguns intervalos de confiança de limite superior igual a 1 contém grande parte da amostra. Mas, outros intervalos também de limite superior igual 1, contém um fração bem menor da amostra. Logo, não se tem uma conclusão clara.

Tabela 30. Número da observação, limite inferior do intervalo de confiança das observações de índices de eficiência técnica igual a um, que é o limite superior, e número de observações que pertencem ao intervalo de confiança, amostras Minas Gerais e Brasil.

\begin{tabular}{cccccc}
\hline \multicolumn{3}{c}{ Minas Gerais } & \multicolumn{3}{c}{ Brasil } \\
\hline $\begin{array}{c}\text { Número da } \\
\text { Observação }\end{array}$ & $\begin{array}{c}\text { Limite } \\
\text { inferior }\end{array}$ & $\begin{array}{c}\text { Observações } \\
\text { do intervalo }\end{array}$ & $\begin{array}{c}\text { Número da } \\
\text { Observação }\end{array}$ & $\begin{array}{c}\text { Limite } \\
\text { inferior }\end{array}$ & $\begin{array}{c}\text { Observações } \\
\text { do intervalo }\end{array}$ \\
\hline 68 & 0,38 & 103 & 27 & 0,17 & 138 \\
69 & 0,38 & 103 & 89 & 0,35 & 104 \\
73 & 0,39 & 102 & 117 & 0,47 & 78 \\
104 & 0,60 & 37 & 123 & 0,48 & 77 \\
109 & 0,71 & 23 & 129 & 0,53 & 67 \\
111 & 0,74 & 20 & 131 & 0,54 & 66 \\
112 & 0,76 & 18 & 132 & 0,54 & 66 \\
114 & 0,81 & 16 & 136 & 0,62 & 44 \\
& & & 138 & 0,69 & 35 \\
& & & 139 & 0,70 & 33 \\
\end{tabular}

Fonte: Resultados da pesquisa.

${ }^{13}$ No ANEXO A estão os detalhes para o calculado de $z$. 


\subsection{Comparação dos métodos}

$\mathrm{Na}$ metodologia, foram apresentados os métodos de Varian, DEA e fronteira estocástica. Eles provocam mudanças dos valores observados de modo a satisfazer determinados objetivos. O critério de avaliação dos métodos foi baseado na soma de quadrados dos desvios do valor calculado em relação ao observado. Também se analisou como se comportou a renda líquida dos produtores. Deseja-se o maior crescimento da renda líquida, se possível, sem renda líquida negativa, e com a menor perturbação dos dados, esta medida pela soma dos quadrados dos desvios.

Como se constatou, o método de Varian procura perturbar os insumos de modo tal que quem produziu mais não gaste menos do que quem produziu menos. Explicitamente, minimiza a soma dos desvios, observando-se a restrição mencionada. $\mathrm{O}$ método pode perturbar o produto, fixando-se o custo como referência ${ }^{14}$. Neste caso, temse a orientação produto.

O DEA, orientação insumo, reduz, radialmente, a combinação de insumos observada, nunca diminuindo a produção observada. $\mathrm{O}$ modelo orientado para produto, aumenta o produto, mantendo-se a combinação observada de insumos.

No caso da fronteira estocástica, pode-se derivar e estimar a demanda de insumos, e, pela função estimada, prevê-se a demanda dos insumos, e daí obtém-se a soma de quadrados entre o previsto menos observado.

Teve-se o cuidado, para cada caso, de fazer a soma de quadrado compatível com o procedimento de Varian: $\left(x_{\mathrm{o}} / x_{\mathrm{obs}}-1\right)^{2}, x_{\mathrm{o}}$ é o valor calculado pelo programa e $x_{\text {obs }}$ é o valor observado.

Como regra geral, a menor perturbação trouxe o menor incremento da renda líquida e menor redução do número de produtores com renda líquida negativa. $\mathrm{O}$ método Varian, quanto à menor perturbação, somente perde para fronteira estocástica, com orientação produto, e tem uma bom desempemho, quanto àrenda líquida (Tabela 31).

\footnotetext{
${ }^{14}$ No caso, introduziu-se a restrição de manter, pelo menos, o nível de produção observado.
} 
A finalidade do DEA: orientação insumo, é reduzir, radialmente, o consumo de insumos, pelo menos, mantendo-se a produção. Assim, é natural que perturbe, com maior intensidade, os insumos, com o objetivo de reduzir custos. Por isto, seu efeito sobre a renda líquida deve ser maior. Quando a orientação é produto, expande-se radialmente a produção para a fronteira, obedecendo-se a restrição de insumos: não gastar mais do que o dispêndio observado. Por isto, perturba-se a produção, no sentido de incrementá-la, sem aumentar os dispêndios. Deste modo, tanto na orientação de insumos, quanto àquela de produtos, o DEA tende a incrementar a soma de quadrados, a renda líquida e a reduzir o número de agricultores com renda líquida negativa. A Tabela 31 mostra que isto realmente aconteceu.

A fronteira estocástica procura ajustar uma curva que minimiza a soma dos quadrados das diferenças entre os valores preditos e observados, se o método for mínimos quadrados ordinários e, aproxima-se deste objetivo, quando o método é o de máxima verossimilhança. Mas, não aduz nenhuma restrição, quanto aos insumos, no sentido de reduzir ou incrementar o dispêndio. Se o ajuste da regressão for muito bom, espera-se pequena perturbação. Nenhuma previsão pode ser feita, em relação à renda líquida. A Tabela 31: orientação produto, confirma estas observações para Minas Gerais. Observa-se um efeito negativo sobre a renda líquida: diminuição da renda e aumento de observações com renda líquida negativa.

Quando a orientação é insumo, o método da fronteira estocástica nada tem, diretamente, a dizer, pois não se modificam os insumos. Apenas a produção prevista pelo modelo costuma ser diferente da observada. No caso da função de produção Cobb-Douglas, pode se estimar, para cada insumo, a função de demanda condicionada no nível de produção ${ }^{15}$, sob a hipótese de que os produtores maximizam a renda líquida. Designando-se o valor predito da regressão por $x_{\mathrm{p}}$ e o observado por $x_{\mathrm{obs}}$, a soma de quadrados compatível com Varian foi dada por $\left(x_{\mathrm{p}} / x_{\mathrm{obs}}-1\right)^{2}$, quando $x$ varia nos insumos e nos produtores. Verifica-se que a perturbação dos insumos foi bem maior do que no método Varian. Novamente, as discrepâncias foram maiores para a amostra Brasil.

\footnotetext{
${ }^{15}$ Maior detalhes sobre a estimativa da soma do quadrado dos desvios, para demanda de fatores, estão no ANEXO B.
} 
Tabela 31. Comparação de três métodos, pelos critérios da soma de quadrados dos desvios (calculado menos observado) e da renda líquida. Renda liquida não negativa observada, Minas Gerais 71 observações em 114, Brasil 75 observações em 143. DEA com retornos constantes (RC) e com retornos variáveis $(\mathrm{RV})$.

\begin{tabular}{|c|c|c|c|c|c|c|}
\hline \multirow[b]{2}{*}{ Métodos } & \multicolumn{3}{|c|}{ Orientação insumo } & \multicolumn{3}{|c|}{ Orientação produto } \\
\hline & $\begin{array}{c}\text { Soma do } \\
\text { Quadrado } \\
\text { desvio }\end{array}$ & $\begin{array}{c}\text { Incremento } \\
\text { Renda líquida } \\
(\%)\end{array}$ & $\begin{array}{l}\text { Produtores } \\
\text { Renda líquida } \\
\text { não negat iva } \\
\text { (número) }\end{array}$ & $\begin{array}{c}\text { Soma do } \\
\text { Quadrado } \\
\text { desvio }\end{array}$ & $\begin{array}{c}\text { Incremento } \\
\text { Renda líquida } \\
(\%)\end{array}$ & $\begin{array}{l}\text { Produtores } \\
\text { Renda líquida } \\
\text { não negat iva } \\
\text { (número) }\end{array}$ \\
\hline $\begin{array}{l}\text { Varian } \\
\text { MG }\end{array}$ & 7,25 & 261,21 & 108 & 3,95 & 179,3 & 109 \\
\hline DEA & $\mathrm{RC}=97,1$ & $\mathrm{RC}=613,8$ & $\mathrm{RC}=112$ & $\mathrm{RC}=130,9$ & $\mathrm{RC}=1241,1$ & $\mathrm{RC}=112$ \\
\hline MG & $\mathrm{RV}=48,1$ & $\mathrm{RV}=475,8$ & $\mathrm{RV}=101$ & $\mathrm{RV}=90,95$ & $\mathrm{RV}=1055,4$ & $\mathrm{RV}=105$ \\
\hline $\begin{array}{c}\text { Fronteira } \\
\text { MG }\end{array}$ & 82,46 & 49,2 & 114 & 1,04 & $-17,6$ & 67 \\
\hline $\begin{array}{l}\text { Varian } \\
\text { Brasil }\end{array}$ & 51,19 & 256,38 & 142 & 104,9 & 404,9 & 143 \\
\hline DEA & $\mathrm{RC}=158,0$ & $\mathrm{RC}=325,5$ & $\mathrm{RC}=141$ & $\mathrm{RC}=586,8$ & $\mathrm{RC}=794,9$ & $\mathrm{RC}=141$ \\
\hline Brasil & $\mathrm{RV}=88,5$ & $\mathrm{RV}=225,0$ & $\mathrm{RV}=126$ & $\mathrm{RV}=509,6$ & $\mathrm{RV}=703,8$ & $\mathrm{RV}=131$ \\
\hline $\begin{array}{c}\text { Fronteira } \\
\text { Brasil }\end{array}$ & 160,01 & 113,74 & 143 & 6,21 & 69,4 & 75 \\
\hline
\end{tabular}

Fonte: Resultados da pesquisa.

Em resumo, o método Varian teve um bom desempenho na indução de provocar menor perturbação nos insumos para que se obedeça à regra de racionalização dos dados e, ainda contribuiu para diminuir o número de observações de renda líquida negativa e aumentar esta expressivamente. Suas recomendações são factíveis. No caso de um agricultor produzir menos e gastar mais, recomenda-se que, pelo menos, ajuste o gasto em nível do que gastou menos. $\mathrm{O}$ método prescinde do conceito de uma fronteira, e tem como base a escolha de uma ordenação dos custos de modo que se obedeça a regra de racionalização dos dados. É, assim, um método muito conveniente para orientar grupo de produtores, porque está muito próximo do que fazem, no sentido de imitar uns aos outros. É também adequado 
para testar a hipótese de Schultz, pela qual os produtores são racionais. Como não se rejeitou a hipótese de c-racionalização, também não se rejeita a hipótese de que os produtores minimizam os custos, uma das formas de se expressar Schultz.

De forma geral, os índices de eficiência obtidos pelo modelo fronteira estocástica foram maiores que os obtidos pelo método de Varian e estes superiores ao modelo DEA (retornos constantes a escala), tanto para orientação insumo como para orientação produto ${ }^{16}$. Estes resultados estão em consonância com os obtidos por Sarafidis (2002). Segundo o autor, isto ocorre devido ao método não paramétrico tratar o resíduo como medida da eficiência relativa. Na prática, a parte residual é devido a ineficiência e ao ruído estatístico. O modelo estocástico gera índices maiores que os modelos DEA e de Varian, por separar o resíduo em ruído estatístico e ineficiência.

Para o modelo estocástico, a forma funcional Cobb-Douglas ajustou-se muito bem aos dados, ou seja, uma curva. O modelo DEA, gera implicitamente uma função de produção (Souza, 2003), lógico que feita de segmentos lineares. De forma que esta seja uma aproximação pobre da verdadeira superfície. Daí a magnitude dos índices de eficiência obtidos pelo modelo DEA, retornos constantes à escala, serem bem menores do que os do modelo de fronteira estocástica, principalmente, para a orientação produto.

O coeficiente de correlação entre os resultados do modelo de fronteira estocástica e do modelo DEA (retornos constantes à escala), ambos orientação produto, foi igual a 0,50 para a amostra Brasil e 0,54 para a amostra Minas Gerias, ambos estatisticamente significante no nível de $1 \%$ de probabilidade.

\footnotetext{
${ }^{16}$ As tabelas com os resultados podem ser encontradas no APÊNDICE.
} 
$\mathrm{Na}$ comparação entre os resultados do modelo DEA (retornos constantes à escala) e do modelo Varian, ambos orientação produto, o coeficiente de correlação entre os índices de eficiência foi de 0,60 para a amostra Brasil, significante no nível de $1 \%$ de probabilidade. Já para a amostra Minas Gerias foi 0,35 , também significante no nível de $1 \%$ de probabilidade. $\mathrm{O}$ coeficiente de correlação entre os índices de eficiência do modelo fronteira estocástica e do método Varian, orientação produto, igualou-se a 0,42 e 0,28 para a amostra Brasil e Minas Gerais, respectivamente, ambos estatisticamente significante no nível de $1 \%$ de probabilidade.

O coeficiente de correlação entre os índices de eficiência, DEA (retornos constante à escala), orientação insumo, e os índices do método Varian, também orientação insumo, foi igual a 0,53 para a amostra Brasil, estatisticamente significante no nível de $1 \%$ de probabilidade. E para a amostra Minas Gerais foi 0,13, no nível de $14 \%$ de probabilidade. 


\section{CONCLUSÕES}

A análise de métodos paramétricos e não paramétricos se torna uma ferramenta útil para escolhas de referências (benchmarks) para as empresas menos eficientes. Entretanto, a escolha entre os métodos não é trivial, porque são técnicas fundamentalmente distintas, gerando, assim, resultados diferentes.

O modelo não paramétrico DEA (data envelopment analysis), não propõe uma função; porém, implicitamente, gera uma função de produção, via programação linear. São menos estruturados que a fronteira estocástica e mais exigentes que o procedimento de Varian, no sentido de que este não pressupõe qualquer fronteira, explícita, como o método da fronteira estocástica, ou fronteira implícita, como o DEA. Este e o procedimento de Varian são deterministas, visto não se associar aos modelos qualquer estrutura de probabilidade. A fronteira estocástica explicitamente associa ao modelo uma estrutura de probabilidade, pela forma que se define o termo do erro da regressão, por isto, é mais rica em testes de hipótese. Desenvolvimentos recentes, em parte, remediaram este problema para o DEA.

Os métodos geram mudanças nos insumos ou no produto para atingirem determinados objetivos: diretamente, o DEA e o procedimento de Varian, e, indiretamente, a fronteira estocástica. A questão a saber é qual método atinge o objetivo com o menor distúrbio nos insumos ou nos produtos. O distúrbio foi medido pela soma dos quadrados dos desvios do "ótimo" em relação ao observado. Aí está o primeiro critério e o método de aferi-lo.

Como a renda líquida mede a remuneração do empreendedor pelo risco que incorreu, o método que gerar o maior incremento da renda líquida é, neste sentido, preferido. Assim, aplicourse o critério de incremento da renda líquida, que foi o segundo 
critério, sem se preocupar em maximizá-la. Pela própria natureza, o DEA produziu melhores resultados, e não poderia ser diferente: é semelhante ao de Varian que produz a máxima redução do vetor insumos, sem reduzir a produção, ou então, produz a máxima expansão da produção sem aumentar os custos.

De fato o método de Varian foi o que produziu menos distúrbios, em relação aos insumos ou produto. Incrementou mais a renda líquida que a fronteira estocástica e menos que o DEA. Mas, sua solução fica mais próxima daquilo que é factível para cada produtor fazer. $\mathrm{O}$ método prescinde do conceito de uma fronteira, reordenam-se os custos em relação aos produtores que produziram mais e gastaram menos, embora o procedimento de reordenamento requeira programação quadrática. Na prática, um bom começo é sentar com os produtores e ordená-los pela renda bruta. Em seguida, verificar os custos. Identificar quem gastou menos e produziu mais. E discutir o que pode ser feito com quem fugiu ao padrão de racionalização de custos.

Portanto, é um método muito conveniente de gestão. A fronteira estocástica não objetiva nem aumentar a renda líquida e nem reduzir custos. Seu efeito sobre a renda líquida foi até negativo e produziu um maior distúrbios nos insumos e muito pequeno no produto, o que sempre ocorrerá, quando a função de produção apresenta bom ajustamento aos dados.

Cabe, ainda ressaltar, que o método Varian é mais apropriado para testar a hipótese de que os produtores, por tentativa e erro, acabam-se localizando na fronteira eficiente, no ponto que minimiza o custo. Pois somente exige que os agricultores racionalizem os custos, no sentido de se obedecer à regra de racionalização, e passa ao largo da dinâmica de mercado, pela qual os produtores convergem para o custo mínimo, o que pode demandar muito tempo, em função de restrições, inclusive de emprego em outros setores da economia. Com os dados de um ano ou de alguns anos, quando não se pode captar o movimento de convergência, o DEA e a maximização da renda líquida são procedimentos inadequados para testar a hipótese de Schultz. Pelo procedimento de Varian, os dados das duas amostras não proveram evidências para sua rejeição.

Dada as características da amostra em estudo, pode-se preferir um método ao outro na determinação de índices relativos de eficiência. Quando a forma funcional 
empregada para a construção da fronteira for subjacente a "verdadeira" tecnologia adotada pelo grupo de comparação, o método estocástico é preferível ao modelo DEA. Entretanto quando a forma funcional se torna um problema, dado o grau de correlação entre os parâmetros estimados e os índices de ineficiência, deve-se optar pelos métodos não paramétricos. Além disso, nos casos onde o ruído estatístico for relevante, o método estocástico deve ser escolhido.

O método Varian não requer a construção de uma fronteira, entretanto utiliza programação quadrática, assim, esbarra na capacidade dos hardwares e no desenvolvimento de novos algoritmos adequados ao problema.

Em muitos casos práticos, entretanto, a amostra pode ser demasiadamente pequena para se fazer inferência sobre a escolha da técnica correta. A melhor escolha seria a combinação dos métodos dado as condições de não se optar por um único índice para quantificar a ineficiência das firmas, mas devido a construção de intervalos de confiança.

Cabe assim chamar atenção para as seguintes conclusões:

1) Para as condições estabelecidas pela pesquisa como período de levantamento dos dados (2001 e 2002), amostras relativamente pequenas, problemas advindos de entrevistas, não se pode extrapolar os resultados. Portanto, diante destas condições constatou-se que os produtores analisados são minimizadores de custos e não rejeitaram a hipótese de racionalização dos dados, ou seja, os produtores mesmo que intuitivamente, trabalham de forma racional, e, por tentativa e erro, comportam-se como se fossem minimizadores de custo.

2) O método Varian apresenta bom desempenho pela condição de provocar menos perturbações nos insumos para que se obedeça à regra de racionalização dos dados e, ainda contribui para diminuir o número de observações de renda líquida negativa e aumentar esta expressivamente. Assim é um método muito conveniente para orientar grupo de produtores, porque está muito próximo do que fazem, no sentido de imitar uns aos outros. 
3) Foi elevado o número de produtores com renda líquida negativa. Não conseguem remunerar, em conjunto, a terra, benfeitorias, máquinas, equipamentos e animais. Permanecendo na situação em que se encontram, não terão como repor o desgaste do capital. Ou reformulam o empreendimento ou terão que fechá-lo. Estes produtores tiverem menores índices de eficiência.

4) Finalizando, a concorrência acirrada e a forte competitividade que se estabelece em inúmeros setores da economia e gestão do agronegócio, onde a busca da eficiência e eficácia são constantes e a otimização dos custos de produção e os de transação se torna meta no setor produtivo, o estudo evidencia que a estimação de parâmetro de produtividade dos fatores de produção e de rentabilidade encontram nos dias de hoje um instrumental analítico com intensa riqueza de opções metodológicas comprovada pelos ajustamentos simplificadores e aderência ao mundo real. Denota-se ainda que, a complexidade do mundo real aguça a curiosidade dos pesquisadores em perseguir na investigação e descoberta de novas ferramentas metodológicas que venham a suprir e diminuir as limitações existentes. 
ANEXOS 
ANEXO A - Cálculo do intervalo de confiança para o modelo DEA: orientação produto.

Apresenta-se o cálculo para o intervalo de confiança: DEA orientação de produto $^{17}$. A proposição 4 de Souza (2003) foi base do cálculo do intervalo de confiança. Está, assim, enunciada: Sob as hipótese do teorema 2 seja $q_{i}$ tal que $P\left\{\varepsilon_{n i} \leq q_{i}\right\}=1-\alpha . O$ intervalo $\left[g_{n}\left(x_{i}\right), g_{n}\left(x_{i}\right)+q_{i}\right]$ tem, aproximadamente, nível, pelo menos, 1- $\alpha$ para $g\left(x_{i}\right)$.

O significado dos símbolos é o seguinte: $n$ é o número de observações da amostra, $i$ é o índice da observação número $i, g(x)$ é a função de produção que dá para cada $x$ o máximo de produção, e $x$ pertence a um conjunto compacto $K$. Note que se tem somente um produto e $x$ é um vetor de dimensão fixa e finita. $\mathrm{O}$ nível de probabilidade escolhido foi $\alpha$, por exemplo, $5 \%$. E os $\varepsilon$ 's e q's serão explicados abaixo.

Os intervalos de confiança foram obtidos para retorno constante. Neste caso, a definição de $K$ é a seguinte, quando $x_{j}$ é uma componente do vetor $x$.

$$
K=\left\{x \in K ; x \geq \sum_{j=1}^{n} \lambda_{j} x_{j}, \lambda_{j} \geq 0\right\}
$$

E segue-se que $g_{n}(x)=\operatorname{Max}\left\{\sum_{j=1}^{n} \lambda_{j} y_{j}, \lambda_{j} \geq 0\right\}$, em que $y_{j}$ é a produção da unidade de decisão $j$, e o vetor de insumos que produz $y$ pertence ao conjunto $K$. Se $g(x)$ é definida em $K$, demonstra-se que $g_{n}(x) \leq g(x)$, e que é uma função de produção com retornos cons tantes, detalhes estão em Souza (2003), e ela pode ser usada para estimar $g(x)$.

Define-se $\varepsilon_{j}=\kappa_{j} y_{j}-y_{j}$, em que $\kappa_{j}$ é o índice de eficiência técnica, retorno constante, orientação produto, da unidade de decisão $j$. Como $\kappa_{j} \geq 1$, segue-se que $\varepsilon_{j} \geq 0$ Admite-se que os $\varepsilon_{j}$ são idêntica e independentemente distribuídos, com distribuição meia normal.

\footnotetext{
${ }^{17}$ Reproduzido de Souza (2003). O método de cálculo foi, pessoalmente, sugerido pelo autor.
} 
O intervalo de confiança é da função de produção "estimada" $g_{n}\left(x_{j}\right)$, e $g(x)$ pertence ao mesmo. Como $g_{n}\left(x_{j}\right)=\kappa_{j} y_{j}$, uma vez obtidos os q's dividem-se os mesmos pela respectiva produção observada, e adiciona-se o índice de eficiência técnica para se obter o limite superior do intervalo de confiança. Para unidade de decisão $j$, é dado por $\kappa_{j}+q / y_{j}$. Como, de hábito, trabalha-se com o recíproco da eficiência técnica, toma-se o recíproco do limite superior, e, assim, obtém-se o limite inferior, sendo o índice de eficiência técnica o limite superior.

Resta explicar como se obtém o q. A hipótese é da distribuição meio normal, truncada em zero. A média, $\mu$, é da meia normal, bem com o desvio padrão, $\sigma$.

$$
1-\alpha=\frac{((1 / \sqrt{2 \pi}) / \sigma) \int_{0}^{z} e^{-((x-\mu) \sigma)^{2}} d x}{P(x \geq 0)}
$$

O numerador da expressão (23) dá a probabilidade dos casos favoráveis do intervalo $[0, z]$ e denominador fornece a probabilidade do intervalo $x \geq 0$, ou seja, de todos os casos possíveis.

Desdobra-se o numerador em termos de $\mathrm{N}(0,1)$, normal com média zero e desvio padrão um.

O numerador corresponde a $\mathrm{P}(x \leq z)-\mathrm{P}(x \leq 0)$, em $\mathrm{N}(\mu, \sigma)$. Em termos de desvio da média dividido pelo desvio padrão, portanto, uma transformação de variável, sendo: $\mathrm{P}((\mathrm{x}$ $\mu) / \sigma \leq(z-u) / \sigma)-\mathrm{P}((x-\mu) / \sigma \leq-\mu / \sigma)$. O primeiro termo da diferença dá a probabilidade, na distribuição $\mathrm{N}(0,1)$, do intervalo com limite superior $(z-u) / \sigma$. No segundo termo, o limite superior é $-\mu / \sigma$. Simbolicamente, representamos o numerador por, $\mathrm{R}((z-\mu) / \sigma)-\mathrm{R}(-\mu / \sigma)$, com o entendimento de que os argumentos das duas funções representam limites superiores de integração da $\mathrm{N}(0,1)$.

Cuidemos do denominador. Com a mesma transformação de variável, segue-se que $\mathrm{P}(\mathrm{x} \geq 0)=P((x-\mu) / \sigma \geq-\mu / \sigma)=P((x-\mu) / \sigma \leq \mu / \sigma)=\mathrm{R}(\mu / \sigma)$. A penúltima igualdade segue-se da simetria da distribuição normal. 
Desdobrando-se (23), vem depois de se coletar os termos:

$$
(1-\alpha) R(\mu / \sigma)+R(-\mu / \sigma)=R((z-u) / \sigma) \text {. }
$$

$\mathrm{Na}$ distribuição normal, $\mathrm{N}(0,1)$, obtêm-se as probabilidades, considerando-se os dois argumentos de $\mathrm{R}($.$) . E efetuam-se as operações indicadas do lado esquerdo da$ igualdade, e obtém-se o valor k, que é uma probabilidade. Procura-se, na $\mathrm{N}(0,1)$ que $\mathrm{x}$ dá aquela probabilidade. Designemo-lo por Probit(k). Obviamente, $q$ é igual a $z$, e:

$$
q=z=\mu+\sigma \text { Probit }(K) .
$$

Os resultados encontrados para os z's foram 256919,71 e 200318,94, para a amostra Minas Gerais e Brasil, respectivamente. 
ANEXO B - Estimação das demandas de fatores.

Descreve-se a metodologia utilizada para a estimação das demandas dos fatores (insumos) proposta por Klein (1953) e Nerlove (1965). A demanda estimada foi condiciona a y. Nos autores referidos, a demanda do insumo é estimada em função do preço do próprio insumo, dos preços dos produtos e dos outros insumos. A função estimada foi a Cobb-Douglas.

Pelos dados disponíveis, os preços dos insumos e dos produtos são iguais a um. A equação da renda líquida, admitindo-se uma função de produção Cobb-Douglas é dada por,

$$
L=a x_{1}^{b_{1}} x_{2}^{b_{2}} x_{3}^{b_{3}} x_{4}^{b_{4}}(\exp )^{i d}-x_{1}-x_{2}-x_{3}-x_{4}
$$

Derivando-se $L$ em relação aos $x$ 's, igualando-se a zero, tem-se um sistema de quatro equações, e id iguala-se a 1 quando a renda líquida é não negativa e a zero se negativa.

$$
\frac{\delta L}{\delta x_{i}}=\frac{b_{i} a x_{1}^{b_{1}} x_{2}^{b_{2}} x_{3}^{b_{3}} x_{4}^{b_{4}}}{x_{i}}=1 \quad i=1,2,3,4
$$

Como $y=a x_{1}^{b_{1}} x_{2}^{b_{2}} x_{3}^{b_{3}} x_{4}^{b_{4}}$, segue-se que,

$$
x_{i}=b_{i} * y \quad i=1,2, \ldots, 4 \text {. }
$$

Tem-se um sistema de quatro equações, uma para cada insumo. Cada equação, é a demanda condicionada ao valor de $y$ (produto), visto que os preços são iguais a um, portanto, constantes.

Em (28), há um sistema de quatro equações. Cada equação pode ser, separadamente, estimada, adicionando-se o termo do erro, com as propriedades usuais. É preciso notar que o intercepto não se encontra presente.

O interesse recai no termo do erro. Se há $n$ observações, há $n$ resíduos. No conjunto das quatro equações, $4 * n$ resíduos, que equivalem, em número, à proposta de 
Varian (1985). Obter-se-á a soma de quadrados dos mesmos, a qual será confrontada com a obtida pelo procedimento não paramétrico de Varian, depois de uma transformação simples.

Se, $e=x_{p}-x_{o b}$. Para ser coerente com o método não paramétrico de Varian, foi preciso dividir-se ambos lados por $x_{o b}$. E virá, $e / x_{o b}=x_{p} / x_{o b}-1$. Então, obter-se-á a soma dos quadrados de $\frac{e}{x_{o b}}$. 


\section{REFERÊNCIAS BIBLIOGRÁFICAS}

AFRIAT, S.N. Efficiency estimation of production function. International Economics Review, v.13, n.3, p.568-598, Oct. 1972.

AFRIAT, S.N. The construction of a utility function from expenditure data. International Economics Review, v.8, p.67-77, 1967.

AIGNER, D.J.; CHU, S.F. On estimating the industry production function. American Economic Review, v.58, n.4, p.826-839, Sept. 1968.

AIGNER, D.J.; LOVELL, C.A.K.; SCHMIDT, P. Formulation and estimation of stochastic frontier production function models. Journal of Econometrics, v.6, n.1, p.21-37, July 1977.

AKRIDGE, J.T. Measuring productive efficiency in mutiple product agribusiness firms: a dual approach. American Journal of Agricultural Econometrics, v.71, n.1, p.116-125, Feb. 1989.

ALVES, E. Teoria da produção: métodos não paramétricos. Brasília: Embrapa, 2000. $65 \mathrm{p}$.

ALVES, E.; GOMES, A.P. Medidas de eficiência na produção de leite. Revista Brasileira de Economia, v.52, n.1, p.145-167, 1998. 
ARAÚJO, L.A. Fronteira de eficiência econômica sob condições de risco: uma análise da convergência econômica entre empresas do sul de Santa Catarina. Piracicaba, 1997. 150p. Dissertação (Mestrado) - Escola Superior de Agricultura "Luiz de Queiroz”, Universidade de São Paulo.

BANKER, R.D.; CHARMES, H.; COOPER, W.W. Some models for estimating technical and scale inefficiencies in data envelopment analysis. Management Science, v.30, n.9, p.1078-1092, 1984.

BATTESE, G.E. Frontier production functions and technical efficiency: a survey of empirical applications in agricultural economics. Agricultural Economics, v.7, n.3/4, p.185-208, Oct. 1992.

BATTESE, G.E.; CORRA, G.S. Estimation of a production frontier model: with application to the Pastoral Zone Eastern Australia. Australian Journal of Agricultural Economics, v.21, n.3, p.169-179, Dec. 1977.

BATTESE, G.E.; COELLI, T.J. Prediction of firm-level technical efficiencies with a generalized frontier production function for panel data. Journal of Econometrics, v.38, n.3, p.387-399, July 1988.

BAUER, P.W. Recent developments en the econometrics estimation of frontiers. Journal of Econometrics, v.46, n.1/2, p.29-56, Oct./Nov. 1990.

BRAVO-URETA, B.E. Technical efficiency measures for dairy farms based on a probabilistic frontier function model. Canadian Journal of Agricultural Economics, v.34, n.3, p.399-415, Nov. 1986.

BRAVO-URETA, B.E.; RIEGER, L. Dairy farm efficiency measurement using stochastic frontiers and neoclassical duality. American Journal of Agricultural Economics, v.73, n.2, p.421-428, May 1991. 
CHARNES, A.; COOPER W.W.; RHODES, E. Measuring the efficiency of decision making units. European Journal of Operational Research, v.2, n.6, p.429-444, 1978.

COELLI, T.J. Estimators and hypothesis tests for a stochastic frontier function: a Monte Carlo analysis. Journal of Productivity Analysis, v.51, p.247-268, 1995.

COELLI, T.J.; RAO, D.S.P.; BATTESE, G.E. An introduction to efficiency and productivity analysis. Norwell: Kluner Academic, 1998. 275p.

COELLI, T.J. A guide to DEAP version 2.1: a data envelopment analysis program. Armidale: University of New England, 1996. 49p. (CEPA Working Papers, 8)

COELLI, T.J.; BATTESE, G.E. Identification of factors wish influence the technical inefficiency of indian farmers. Australian Journal of Agricultural Economics, v.40, p.109-128, 1996.

CONCEIÇÃO, J.C.P.R. Fronteira de produção estocástica e eficiência técnica na agricultura. Piracicaba, 1998. 108p. Tese (Doutorado) - Escola Superior de Agricultura “Luiz de Queiroz”, Universidade de São Paulo.

CONFERAÇÃO NACIONAL DA AGRICULTURA. Indicadores rurais, v.5, n.33, 51p., jul./ago. 2001.

DESAI, A.; VOSTI, S.A. Efficiency among output-diversified farmers in Brazil's Zona da Mata: a multiple-output application of DEA. /Apresentado a Conference on New Uses do DEA in Management, Austin, 1989/

DYSON, R.G.; THANASSOULIS, E., BOUSSOFIANE, A. A data envelopment analysis tutorial. Birmingham: Operational Research Society, 1990. 14p. (Tutorial Papers in Operational Research)

FÄRE, R.; GROSSKOPF, S.; LOVELL, C.A.K. Production frontiers. New York: Cambridge University Press, 1994. 269p. 
FARREL, M.J. The measurement of production efficiency. Journal of the Royal Statistical Socie ty, Series A, part III, p.253-290, 1957.

FERREIRA, A.H. Eficiência de sistemas de produção de leite: uma aplicação da análise envoltória de dados na tomada de decisão. Viçosa, 2002. 120p. Dissertação (Mestrado) - Universidade Federal de Viçosa.

FØRSUND, F.R.; HJALMARSSON, L. Generalized Farrel measures of efficiency: an application to milk processing in swedish dairy plants. Economic Journal, v.89, p.274-315, 1979.

FØRSUND, F.R.; JANSEN, E.S. On estimating average and best practice homothetic productions via cost functions. International Economic Review, v.18, n.2, p.463476, 1977.

FØRSUND, F.R.; LOVELL, C.A.K.; SCHMIDT, P. A survey of production functions and their relationship to efficiency measurement. Journal of Econometrics, v.13, n.1, p.5-25, 1980.

FRIED, H.; LOVELL, C.A.K.; SCHMIDT, P. Measurement of productive efficiency: techniques and applications. New York: Oxford University, 1993. 426p.

GOLANY, R.; ROLL, Y. An application procedure for DEA. Omega, v.17, n.3, p.237250, 1989.

GOMES, A.P. Impactos das transformações da produção de leite no número de produtores e requerimento da mão-de-obra e capital. Viçosa, 1999. 161p. Tese (Doutorado) - Universidade Federal de Viçosa.

GOMES, S.T. Diagnóstico e perspectivas da produção de leite no Brasil. In: VILELA, D.; BRESSAN, M.; CUNHA, A.S. (Eds.). Restrições técnicas, econômicas e institucionais ao desenvolvimento da cadeia produtiva do leite no Brasil. Brasília: MCT/CNPq/PADCT; Juiz de Fora: Embrapa, CNPGL, 1999. p.19-35. 
GOMES, S.T. Evolução recente e perspectivas da produção de leite no Brasil. In: GOMES, A.T.; LEITE, J.L.B.; CARNEIRO, A.V. (Eds.). O agronegócio do leite no Brasil. Juiz de Fora: Embrapa, CNPGL, 2001. p.49-61.

GREENE, W.H. Maximum likelihood estimation of econometrics frontier function. Journal of Econometrics, v.13, n.1, p.27-56, May 1980a.

GREENE, W.H. On the estimation of flexible frontier production model. Journal of Econometrics, v.13, n.1, p.101-115, May 1980b.

GREENE, W.H. A gamma-distributed stochastic frontier model. Journal of Econometrics, v.46, n.1/2, p.141-163, Oct./Nov. 1990.

GREENE, W.H. The econometric approach to efficiency analysis. In: The measurement of productive efficiency. New York: Oxford University Press, 1993. p.68-119.

INSTITUTO BRASILEIRO DE GEOGRAFIA E ESTATÍSTICA - IBGE. Banco de dados. http:/www.sidra.ibge.gov.org/ (19 out. 2002)

JØNDROW, J.; LOVELL, C.A.K.; MATEROV, I.S.; SCHMIDT, P. On the estimation of technical inefficiency in the stochastic frontier production function model. Journal of Econometrics, v.19, n.2/3, p.233-238, Aug. 1982.

KALIRAJAN, K. On measuring yield potential of the high yielding varieties technology at farm level. Journal of Agricultural Economics, v.33, n.2, p.227-236, May 1982.

KLEIN, L.R. A text book of econometrics. Evanston: Row Peterson and Company, 1953. 120p.

KOOP, R.J. The measurement of productive efficiency: a reconsideration. The Quarterly Journal of Econometrics, v.96, n.3, p.477-503, Aug. 1981. 
KOOP, R.J.; DIEWERT, W.E. The decomposition of frontier cost function deviations into measures of technical and allocative efficiency. Journal of Econometrics, v.19, n.2/3, p.319-33, Aug. 1982.

KUMBHAKAR, S.C. The specification of technical and allocative inefficiency in stochastic production and profit frontiers. Journal of Econometrics, v.34, n.3, p.335-348, Mar. 1987.

KUMBHAKAR, S.C.; BISWAS, B.; BAILEY, D.V. A study of economic efficiency of Utah dairy farmers: a system approach. The Review of Economics and Statistics, v.71, n.4, p.595-604, Nov. 1989.

LEE, L.F.; TYLER, W.G. The stochastic frontier production and average efficiency: an empirical analysis. Journal of Econometrics, v.7, n.3, p.385-389, June 1978.

LEMBERG, B.; WONGCHARUPAN, M. Nonparametric analysis of cost minimization and efficiency. Texas: A\&M University, 1998. 14p.

LOVELL, K.C.A. Production frontiers and productive efficiency. In: The measurement of productive efficiency: techniques and applications. New York: Oxford University Press, 1993. 25p.

LOVELL, K.C.A., SCHMIDT, P. A comparison of alternative approaches to the measurement of productive efficiency. In: Applications of modern production theory. Boston: Kluwer Academic Publishers, 1988. p.3-32.

MEEUSEN, W.; VAN DEN BROECK, J. Efficiency estimation from Cobb-Douglas production functions with composed error. International Economic Review, v.18, n.2, p.435-444, June 1977.

MOITA, M.H.V. Medindo a eficiência relativa de escolas municipais da cidade do Rio Grande - RS usando a abordagem DEA (data envelopment analysis). Florianópolis, 1995. 105p. Dissertação (Mestrado) - Universidade Federal de Santa Catarina. 
MULLER, J. On sources of measured technical efficiency: the impact of information. American Journal of Agricultural Economics, v.56, n.4, p.730-738, Nov. 1974.

NERLOVE, M. Estimation and identification of Cobb-Douglas production functions. New York: Rand McNally and Company, 1965. 75p.

OLSON, J.A.; SCHMIDT, P.; WALDMAN, D.M. A Monte Carlo study of estimators of stochastic frontier productions functions. Journal of Econometrics, v.13, n.1, p.6782, May 1980.

PEREIRA FILHO, C.A. Eficiência econômica da pequena produção familiar no Recôncavo do Estado da Bahia: uma análise não-paramétrica de fronteiras de produção multi-produto. Piracicaba, 2000. 122p. Tese (Doutorado) - Escola Superior de Agricultura “Luiz de Queiroz”, Universidade de São Paulo.

PERELMAN, S.; COELLI, T.J. A comparison of parametric and non-parametric distance functions: with application to European railways. European Journal of Operational Research, v.117, p.326-339, 1999.

RAY, S.C.; BHADRA, D. Nonparametric test of cost minimizing behavior: a study of indian farms. American Journal of Agricultural Economics, v.75, n.4, p.990-999, 1993.

RICHMOND, J. Estimating the efficiency of production. International Economic Review, v.15, n.2, p.515-521, 1974.

SARAFIDIS, V. An assessment of comparative efficiency measurement techniques. Europe Economics. London, 2002. 21p. (Occasional paper, 2) http://www.europeeconomics.com (10 Nov. 2002)

SCHMIDT, P.; LOVELL, C.A.K. Estimating stochastic production and cost frontiers when technical and allocative inefficiency are correlated. Journal of Econometrics, v.13, n.1, p.83-100, May 1980. 
SCHMIDT, P.; LOVELL, C.A.K. Estimating technical and allocative inefficiency relative to stochastic production and cost frontiers. Journal of Econometrics, v.9, n.3, p.343-366, Feb. 1979.

SCHULTZ, T.W. Transforming traditional agriculture. New Haven: Yale University Press, 1964. 53p.

SEIFORD, L.M.; THRALL, R.M. Recent developments in DEA: the mathematical programming approach to frontier analysis Journal of Econometrics, v.46, n.1/2, p.7-38, Oct./Nov. 1990.

SEIFORD, L.M.; ZHU, J. An investigation of returns to scale in data envelopment analysis. Omega: The Journal of Management Science, v.27, n.1, p.1-11, 1999.

SHARMA, K.R.; LEUNG, P.; ZALESKI, H.M. Technical, allocative and economic efficiencies in swine production in Hawaii: a comparation of parametric and nonparametric approaches. Agricultural Economics, v.20, n.1, p.23-35, 1999.

SOUZA, D.P.H. Análise da estrutura de custo e preço de sobrevivência dos principais sistemas de produção de leite. Viçosa, 2000. 96p. Dissertação (Mestrado) Universidade Federal de Viçosa.

SOUZA, G.S. Funções de produção: uma abordagem estatística com o uso de modelos de encapsulamento de dados. Brasília: Embrapa, Informação Tecnológica, 2003. 49p. (Texto para discussão, 17)

TAYLOR, T.G.; DRUMMOND, H.E.; GOMES, A.T. Agricultural credit programs and production efficiency: an analysis of traditional farming in southeastern Minas Gerais, Brazil. American Journal of Agricultural Economics, v.68, n.1, p.110119, Feb. 1986.

TIMMER, C.P. Using a probabilistic frontier production to measure technical efficiency. Journal of Political Economy, v.79, n.4, p.776-794, July/Aug. 1971. 
TORESON, L.; LANZER, E.A. Avaliação da eficiência relativa das propriedades agrícolas típicas de Santa Catarina. In: CONGRESSO BRASILEIRO DE ECONOMIA E SOCIOLOGIA RURAL, 33., Curitiba, 1995. Anais. Brasília: Sober, 1995. p.559-565.

TUPY, O. Fronteira estocástica, dualidade neoclássica e eficiência econômica na produção de frangos de corte. Piracicaba, 1996. 91p. Tese (Doutorado) - Escola Superior de Agricultura “Luiz de Queiroz”, Universidade de São Paulo.

TUPY, O.; YAMAGUCHI, L.C.T. Eficiência e produtividade: conceitos e medição. Agricultura em São Paulo, v.45, n.2, p.39-51, 1998.

TUPY, O; YAMAGUCHI, L.C.T. Identificando benchmarks na produção de leite. Revista de Economia Rural, v.40, n.1, p.81-96, 2002.

VAN DEN BROECK, J.; FØRSUND, F.R.; HJALMARSSON, L.; MEEUSEN, W. On the estimation of deterministic and stochastic frontier production function: a comparison. Journal of Econometrics, v.13, n.1, p.117-138, May 1980.

VARIAN, H.R. Non-parametric analysis of optimizing behavior with measurement error. Journal of Econometrics, v.30, p.445-458, 1985. 
APÊNDICE 
Tabela 32. Resultados do modelo Varian, amostra Brasil, orientação insumo.

Observações ordenadas pelo renda bruta de forma crescente.

\begin{tabular}{|c|c|c|c|c|c|c|c|c|}
\hline Obs. & x1 obs. & $\mathrm{x} 2$ obs. & x3 obs. & $\mathrm{x} 4$ obs. & Residual x 100 & Residual x 100 & Residual x 100 & Residual x 100 \\
\hline 1 & 4464,97 & 6234,20 & 8277,00 & 3166,00 & 0,04 & 0,08 & 0,14 & 0,02 \\
\hline 2 & 7994,15 & 7758,75 & 18906,00 & 4536,48 & 7,91 & 7,46 & 44,27 & 2,55 \\
\hline 3 & 7817,80 & 10220,00 & 11505,00 & 1580,00 & 6,24 & 10,66 & 13,51 & 0,25 \\
\hline 4 & 10295,98 & 4562,50 & 16314,30 & 2320,00 & 9,57 & 1,88 & 24,02 & 0,49 \\
\hline 5 & 5041,51 & 4998,68 & 22263,50 & 2596,00 & 1,49 & 1,46 & 29,02 & 0,39 \\
\hline 6 & 11397,29 & 7391,25 & 14271,00 & 4902,75 & 20,65 & 8,69 & 32,38 & 3,82 \\
\hline 7 & 8655,02 & 5184,00 & 15308,07 & 3370,00 & 7,50 & 2,69 & 23,45 & 1,14 \\
\hline 8 & 8515,96 & 2400,00 & 14303,30 & 2610,00 & 3,44 & 0,27 & 9,69 & 0,32 \\
\hline 9 & 9454,16 & 9250,00 & 15902,00 & 3501,00 & 12,69 & 12,15 & 35,91 & 1,74 \\
\hline 10 & 8662,96 & 7270,80 & 12959,10 & 3530,00 & 9,38 & 6,61 & 20,98 & 1,56 \\
\hline 11 & 3082,80 & 7665,00 & 15768,20 & 1625,00 & 0,41 & 2,52 & 10,66 & 0,11 \\
\hline 12 & 2906,31 & 4653,75 & 11910,50 & 2054,00 & 0,00 & 0,00 & 0,00 & 0,00 \\
\hline 13 & 30121,64 & 9936,00 & 10650,95 & 9020,00 & 82,26 & 8,95 & 10,28 & 7,38 \\
\hline 14 & 3795,03 & 8400,00 & 17800,02 & 2540,00 & 0,69 & 3,40 & 15,27 & 0,31 \\
\hline 15 & 8584,91 & 5475,00 & 6328,50 & 3300,00 & 0,00 & 0,00 & 0,00 & 0,00 \\
\hline 16 & 8511,96 & 3850,75 & 17995,50 & 1835,00 & 3,13 & 0,64 & 14,01 & 0,15 \\
\hline 17 & 5152,24 & 6842,00 & 18689,31 & 2765,00 & 1,40 & 2,47 & 18,40 & 0,40 \\
\hline 18 & 15301,03 & 4355,00 & 24450,00 & 10710,00 & 24,51 & 1,99 & 62,59 & 12,01 \\
\hline 19 & 14893,52 & 5990,63 & 31481,20 & 3200,00 & 14,32 & 2,32 & 64,00 & 0,66 \\
\hline 20 & 5895,26 & 3186,00 & 26651,00 & 4120,00 & 1,55 & 0,45 & 31,58 & 0,75 \\
\hline 21 & 8406,41 & 11972,00 & 20624,63 & 4336,12 & 7,73 & 15,68 & 46,53 & 2,06 \\
\hline 22 & 5180,59 & 5256,00 & 31306,04 & 2700,57 & 1,08 & 1,11 & 39,33 & 0,29 \\
\hline 23 & 5378,04 & 9417,00 & 23872,24 & 2601,00 & 1,88 & 5,76 & 37,03 & 0,44 \\
\hline 24 & 14197,65 & 7117,50 & 23974,00 & 4361,43 & 19,15 & 4,81 & 54,62 & 1,81 \\
\hline 25 & 6749,10 & 11862,50 & 14463,00 & 3696,00 & 4,74 & 14,65 & 21,77 & 1,42 \\
\hline 26 & 12364,29 & 23360,00 & 22252,42 & 2051,00 & 14,16 & 50,54 & 45,86 & 0,39 \\
\hline 27 & 3591,81 & 5931,25 & 10160,00 & 3888,48 & 0,00 & 0,00 & 0,00 & 0,00 \\
\hline 28 & 11524,09 & 6843,75 & 19647,60 & 7350,00 & 4,41 & 1,56 & 12,83 & 1,80 \\
\hline 29 & 15308,45 & 10320,00 & 16620,50 & 3190,00 & 7,70 & 3,50 & 9,08 & 0,33 \\
\hline 30 & 8333,61 & 4790,63 & 20849,38 & 5300,00 & 0,61 & 0,20 & 3,82 & 0,25 \\
\hline 31 & 15755,23 & 2574,25 & 31769,23 & 10295,00 & 9,16 & 0,24 & 37,26 & 3,91 \\
\hline 32 & 21685,88 & 11761,50 & 23647,00 & 8390,00 & 30,28 & 8,91 & 36,00 & 4,53 \\
\hline 33 & 14502,64 & 7500,00 & 20760,00 & 3039,00 & 5,80 & 1,55 & 11,88 & 0,25 \\
\hline 34 & 8078,49 & 5361,85 & 20162,00 & 3792,00 & 0,27 & 0,12 & 1,70 & 0,06 \\
\hline 35 & 32032,95 & 22174,85 & 50111,80 & 9435,00 & 38,42 & 18,41 & 94,03 & 3,33 \\
\hline 36 & 55089,69 & 9600,00 & 13260,00 & 6250,00 & 68,29 & 2,07 & 3,96 & 0,88 \\
\hline 37 & 10710,96 & 10080,00 & 15342,39 & 3260,00 & 1,52 & 1,35 & 3,12 & 0,14 \\
\hline 38 & 18887,82 & 8361,60 & 20901,25 & 4915,00 & 16,34 & 3,20 & 20,01 & 1,11 \\
\hline 39 & 13758,17 & 4824,00 & 34347,00 & 3180,00 & 4,68 & 0,57 & 29,14 & 0,25 \\
\hline 40 & 12700,72 & 9600,00 & 6860,00 & 6500,00 & 0,35 & 0,20 & 0,10 & 0,09 \\
\hline 41 & 12070,90 & 6696,00 & 19234,40 & 3050,00 & 2,19 & 0,67 & 5,56 & 0,14 \\
\hline 42 & 25391,09 & 14125,50 & 31730,70 & 7634,00 & 35,52 & 10,99 & 55,47 & 3,21 \\
\hline 43 & 11026,20 & 15330,00 & 41140,70 & 4119,00 & 4,02 & 7,76 & 55,90 & 0,56 \\
\hline 44 & 19812,79 & 20352,00 & 17070,00 & 3370,00 & 22,46 & 23,70 & 16,67 & 0,65 \\
\hline 45 & 12972,79 & 8066,40 & 26763,50 & 10393,00 & 8,76 & 3,39 & 37,28 & 5,62 \\
\hline 46 & 7806,29 & 10026,00 & 16633,50 & 6920,00 & 1,38 & 2,28 & 6,27 & 1,09 \\
\hline 47 & 17301,09 & 5840,00 & 25296,00 & 8031,00 & 13,95 & 1,59 & 29,81 & 3,00 \\
\hline 48 & 13912,99 & 14965,00 & 17179,50 & 3483,00 & 8,82 & 10,21 & 13,45 & 0,55 \\
\hline 49 & 16881,02 & 16020,00 & 11451,60 & 9156,00 & 18,82 & 16,95 & 8,66 & 5,54 \\
\hline 50 & 5450,92 & 5400,00 & 32048,00 & 3700,00 & 0,39 & 0,38 & 13,34 & 0,18 \\
\hline
\end{tabular}


Tabela 32. Resultados do modelo Varian, amostra Brasil, orientação insumo.

Observações ordenadas pelo renda bruta de forma crescente.

\begin{tabular}{|c|c|c|c|c|c|c|c|c|}
\hline Obs. & x1 obs. & $\mathrm{x} 2$ obs. & $\mathrm{x} 3$ obs. & $\mathrm{x} 4$ obs. & Residual x 100 & Residual x 100 & Residual x 100 & Residual x 100 \\
\hline 51 & 18252,93 & 9633,00 & 30155,30 & 4070,00 & 14,34 & 3,99 & 39,13 & 0,71 \\
\hline 52 & 17465,52 & 5550,00 & 27612,00 & 5290,00 & 11,48 & 1,16 & 28,70 & 1,05 \\
\hline 53 & 10830,29 & 6241,50 & 25887,90 & 6970,00 & 3,85 & 1,28 & 22,02 & 1,60 \\
\hline 54 & 17908,80 & 8316,00 & 15295,10 & 3920,00 & 10,15 & 2,19 & 7,40 & 0,49 \\
\hline 55 & 10305,14 & 7470,00 & 32083,00 & 5570,00 & 3,24 & 1,70 & 31,44 & 0,95 \\
\hline 56 & 10223,03 & 5475,00 & 32103,00 & 10103,87 & 3,70 & 1,06 & 36,47 & 3,61 \\
\hline 57 & 14666,89 & 5520,00 & 44621,78 & 8040,00 & 6,11 & 0,87 & 56,54 & 1,84 \\
\hline 58 & 21398,59 & 8602,40 & 51524,72 & 6490,00 & 12,78 & 2,07 & 74,11 & 1,18 \\
\hline 59 & 7109,05 & 4800,00 & 17738,00 & 4420,00 & 0,00 & 0,00 & 0,00 & 0,00 \\
\hline 60 & 12912,89 & 5986,00 & 41278,75 & 4982,00 & 1,98 & 0,43 & 20,27 & 0,30 \\
\hline 61 & 13883,02 & 7680,00 & 33484,00 & 4950,00 & 2,50 & 0,76 & 14,52 & 0,32 \\
\hline 62 & 10469,22 & 10258,33 & 55263,38 & 7691,00 & 1,55 & 1,49 & 43,22 & 0,84 \\
\hline 63 & 7035,56 & 12600,00 & 29583,58 & 3860,00 & 0,33 & 1,06 & 5,86 & 0,10 \\
\hline 64 & 7247,17 & 5994,00 & 27142,20 & 3710,00 & 0,00 & 0,00 & 0,00 & 0,00 \\
\hline 65 & 9311,43 & 9307,50 & 30698,00 & 4703,00 & 0,33 & 0,33 & 3,62 & 0,09 \\
\hline 66 & 7258,23 & 17653,59 & 25501,80 & 3288,00 & 0,23 & 1,35 & 2,81 & 0,05 \\
\hline 67 & 43833,46 & 15202,50 & 34558,25 & 9872,00 & 51,71 & 6,22 & 32,14 & 2,62 \\
\hline 68 & 14235,45 & 8760,00 & 21953,70 & 2015,00 & 0,00 & 0,00 & 0,00 & 0,00 \\
\hline 69 & 12530,49 & 8325,25 & 33327,50 & 9530,00 & 1,52 & 0,67 & 10,72 & 0,88 \\
\hline 70 & 21942,16 & 5871,94 & 36908,10 & 4110,00 & 4,92 & 0,35 & 13,91 & 0,17 \\
\hline 71 & 25915,15 & 14460,00 & 40657,84 & 16224,00 & 19,43 & 6,05 & 47,82 & 7,61 \\
\hline 72 & 11044,95 & 9168,00 & 48484,54 & 14090,00 & 1,76 & 1,21 & 33,93 & 2,87 \\
\hline 73 & 12260,09 & 10785,75 & 34378,50 & 7800,00 & 1,59 & 1,23 & 12,53 & 0,64 \\
\hline 74 & 8910,44 & 9382,50 & 24874,00 & 7045,00 & 0,00 & 0,00 & 0,02 & 0,00 \\
\hline 75 & 26862,02 & 23030,40 & 84951,44 & 8480,00 & 8,67 & 6,38 & 86,75 & 0,86 \\
\hline 76 & 30764,00 & 9120,00 & 41250,00 & 11400,00 & 21,23 & 1,87 & 38,17 & 2,91 \\
\hline 77 & 13852,28 & 6600,00 & 24452,00 & 4780,00 & 0,00 & 0,00 & 0,00 & 0,00 \\
\hline 78 & 39957,04 & 17406,00 & 38250,51 & 14830,00 & 29,13 & 5,53 & 26,70 & 4,01 \\
\hline 79 & 16695,03 & 11880,00 & 80760,00 & 3930,00 & 1,51 & 0,76 & 35,34 & 0,08 \\
\hline 80 & 11789,80 & 5911,50 & 42369,98 & 18154,50 & 0,69 & 0,17 & 8,89 & 1,63 \\
\hline 81 & 40783,64 & 8635,90 & 42634,48 & 9550,00 & 19,57 & 0,88 & 21,39 & 1,07 \\
\hline 82 & 9891,87 & 10560,00 & 37197,60 & 8090,00 & 0,05 & 0,06 & 0,69 & 0,03 \\
\hline 83 & 13610,19 & 15696,00 & 61540,00 & 8136,87 & 1,38 & 1,83 & 28,14 & 0,49 \\
\hline 84 & 24244,27 & 10920,00 & 43298,00 & 9210,00 & 5,43 & 1,10 & 17,31 & 0,78 \\
\hline 85 & 15229,28 & 10080,00 & 60456,00 & 6630,00 & 1,31 & 0,58 & 20,70 & 0,25 \\
\hline 86 & 16997,19 & 12300,00 & 44853,50 & 14267,00 & 2,85 & 1,49 & 19,84 & 2,01 \\
\hline 87 & 52330,86 & 26400,00 & 118436,80 & 9420,00 & 18,57 & 4,73 & 95,13 & 0,60 \\
\hline 88 & 71018,44 & 7968,00 & 29266,50 & 13950,00 & 48,12 & 0,61 & 8,17 & 1,86 \\
\hline 89 & 23327,01 & 7200,00 & 20277,83 & 12835,00 & 0,10 & 0,01 & 0,08 & 0,03 \\
\hline 90 & 18535,88 & 13794,00 & 65190,70 & 10185,00 & 3,00 & 1,66 & 37,09 & 0,91 \\
\hline 91 & 42868,13 & 15120,00 & 28590,00 & 16916,00 & 31,42 & 3,91 & 13,97 & 4,89 \\
\hline 92 & 26557,67 & 51792,00 & 41400,00 & 38050,00 & 15,08 & 57,33 & 36,63 & 30,94 \\
\hline 93 & 22880,62 & 25104,00 & 44396,57 & 17490,00 & 10,17 & 12,25 & 38,30 & 5,94 \\
\hline 94 & 16261,27 & 22110,00 & 59451,00 & 14380,00 & 3,29 & 6,09 & 44,01 & 2,58 \\
\hline 95 & 15764,17 & 11760,00 & 51562,00 & 5120,00 & 1,29 & 0,72 & 13,83 & 0,14 \\
\hline 96 & 17385,28 & 10402,50 & 86160,00 & 13224,00 & 2,00 & 0,72 & 49,08 & 1,16 \\
\hline 97 & 37409,05 & 18780,00 & 41875,17 & 5740,00 & 19,49 & 4,91 & 24,42 & 0,46 \\
\hline 98 & 27468,50 & 21188,25 & 54414,80 & 3470,00 & 8,56 & 5,09 & 33,60 & 0,14 \\
\hline 99 & 22319,23 & 3870,00 & 112944,98 & 6320,00 & 1,96 & 0,06 & 50,09 & 0,16 \\
\hline 100 & 14856,49 & 11280,00 & 70364,00 & 9490,89 & 1,47 & 0,85 & 32,92 & 0,60 \\
\hline 101 & 30298,86 & 4756,00 & 61837,00 & 9597,00 & 7,69 & 0,19 & 32,02 & 0,77 \\
\hline 102 & 17595,30 & 19218,00 & 14495,00 & 10740,00 & 0,00 & 0,00 & 0,00 & 0,00 \\
\hline 103 & 21382,17 & 15002,00 & 23231,25 & 15902,50 & 0,81 & 0,40 & 0,96 & 0,45 \\
\hline 104 & 30308,58 & 15600,00 & 77142,50 & 12550,00 & 7,64 & 2,02 & 49,48 & 1,31 \\
\hline 105 & 26551,55 & 11315,00 & 80688,00 & 15871,00 & 5,18 & 0,94 & 47,86 & 1,85 \\
\hline 106 & 46614,57 & 13158,00 & 72830,00 & 9130,00 & 19,06 & 1,52 & 46,52 & 0,73 \\
\hline 107 & 37251,14 & 14190,47 & 77854,40 & 3640,00 & 9,57 & 1,39 & 41,79 & 0,09 \\
\hline
\end{tabular}


Tabela 32. Resultados do modelo Varian, amostra Brasil, orientação insumo.

Observações ordenadas pelo renda bruta de forma crescente.

\begin{tabular}{|c|c|c|c|c|c|c|c|c|}
\hline Obs. & x1 obs. & $\mathrm{x} 2$ obs. & x 3 obs. & $\mathrm{x} 4$ obs. & Residual x 100 & Residual x 100 & Residual x 100 & Residual x 100 \\
\hline 108 & 43457,79 & 19851,75 & 66212,00 & 2840,00 & 16,86 & 3,52 & 39,13 & 0,07 \\
\hline 109 & 22897,66 & 17028,00 & 119080,00 & 22550,00 & 2,75 & 1,52 & 74,34 & 2,67 \\
\hline 110 & 23277,51 & 10056,00 & 62630,00 & 11400,00 & 3,56 & 0,66 & 25,77 & 0,85 \\
\hline 111 & 25684,81 & 12318,75 & 63605,78 & 7255,00 & 4,28 & 0,99 & 26,27 & 0,34 \\
\hline 112 & 24873,49 & 16560,00 & 95560,00 & 9410,00 & 3,60 & 1,59 & 53,07 & 0,51 \\
\hline 113 & 23073,22 & 19584,00 & 104358,00 & 21243,00 & 3,47 & 2,50 & 70,97 & 2,94 \\
\hline 114 & 29698,48 & 7161,60 & 68361,00 & 8534,00 & 5,40 & 0,31 & 28,63 & 0,45 \\
\hline 115 & 18521,67 & 10224,00 & 87150,00 & 7640,00 & 1,54 & 0,47 & 34,04 & 0,26 \\
\hline 116 & 46800,79 & 16485,00 & 44960,83 & 12645,00 & 27,03 & 3,35 & 24,95 & 1,97 \\
\hline 117 & 15077,11 & 6000,00 & 40710,00 & 7517,00 & 0,00 & 0,00 & 0,00 & 0,00 \\
\hline 118 & 16720,65 & 23139,00 & 101836,00 & 23148,00 & 0,75 & 1,43 & 27,78 & 1,44 \\
\hline 119 & 24010,09 & 24075,00 & 138352,50 & 25410,00 & 1,52 & 1,53 & 50,59 & 1,71 \\
\hline 120 & 24485,49 & 12480,00 & 104480,00 & 24155,00 & 1,51 & 0,39 & 27,42 & 1,47 \\
\hline 121 & 18507,84 & 15075,00 & 62448,78 & 8150,00 & 0,00 & 0,00 & 0,00 & 0,00 \\
\hline 122 & 81449,35 & 11100,00 & 35115,50 & 20340,00 & 0,33 & 0,01 & 0,06 & 0,02 \\
\hline 123 & 23042,00 & 19200,00 & 91511,00 & 8360,00 & 0,00 & 0,00 & 0,00 & 0,00 \\
\hline 124 & 35549,86 & 15390,00 & 129023,65 & 15400,00 & 0,70 & 0,13 & 9,18 & 0,13 \\
\hline 125 & 56216,59 & 8755,20 & 129789,25 & 8186,00 & 2,01 & 0,05 & 10,69 & 0,04 \\
\hline 126 & 32299,96 & 27770,40 & 145500,00 & 50080,00 & 1,72 & 1,27 & 34,87 & 4,13 \\
\hline 127 & 124364,81 & 8280,00 & 104588,00 & 5900,00 & 18,21 & 0,08 & 12,88 & 0,04 \\
\hline 128 & 39035,34 & 21983,75 & 90151,43 & 17754,20 & 0,39 & 0,12 & 2,09 & 0,08 \\
\hline 129 & 21565,41 & 24022,80 & 53565,80 & 60300,00 & 0,04 & 0,05 & 0,27 & 0,34 \\
\hline 130 & 75725,14 & 24037,56 & 33608,00 & 18813,78 & 0,00 & 0,00 & 0,00 & 0,00 \\
\hline 131 & 37148,37 & 5224,80 & 89656,10 & 22460,00 & 0,00 & 0,00 & 0,00 & 0,00 \\
\hline 132 & 37949,00 & 22664,45 & 152955,93 & 18190,00 & 0,01 & 0,00 & 0,17 & 0,00 \\
\hline 133 & 37623,43 & 27096,96 & 93551,13 & 66550,00 & 0,00 & 0,00 & 0,00 & 0,00 \\
\hline 134 & 44580,46 & 24896,00 & 157980,00 & 17000,00 & 0,00 & 0,00 & 0,00 & 0,00 \\
\hline 135 & 40246,64 & 21096,00 & 188263,50 & 23640,00 & 0,00 & 0,00 & 0,00 & 0,00 \\
\hline 136 & 29623,99 & 23289,00 & 189860,00 & 40215,00 & 0,00 & 0,00 & 0,00 & 0,00 \\
\hline 137 & 56622,53 & 17280,00 & 206472,75 & 28940,00 & 0,00 & 0,00 & 0,00 & 0,00 \\
\hline 138 & 47856,55 & 12912,00 & 365255,00 & 30308,42 & 0,12 & 0,01 & 6,72 & 0,05 \\
\hline 139 & 106204,26 & 24000,00 & 340844,39 & 19890,00 & 1,19 & 0,06 & 12,22 & 0,04 \\
\hline 140 & 51381,88 & 43200,00 & 227238,45 & 37400,00 & 0,00 & 0,00 & 0,00 & 0,00 \\
\hline 141 & 128539,33 & 42300,00 & 347422,84 & 46700,00 & 2,26 & 0,25 & 16,53 & 0,30 \\
\hline 142 & 68465,97 & 61920,00 & 243500,00 & 25854,67 & 0,00 & 0,00 & 0,00 & 0,00 \\
\hline \multirow[t]{3}{*}{143} & 102572,82 & 31500,00 & 281846,21 & 38500,00 & 0,00 & 0,00 & 0,00 & 0,00 \\
\hline & & & & SOMA & 11,19 & 4,69 & 33,36 & 1,95 \\
\hline & & & & TOTAL & & & & 51,20 \\
\hline
\end{tabular}

Fonte: Resultados da pesquisa. 
Tabela 33. Resultados do modelo Varian, amostra Brasil, renda líquida não negativa, orientação insumo. Observações ordenadas pelo renda bruta de forma crescente.

\begin{tabular}{|c|c|c|c|c|c|c|c|c|}
\hline Obs. & x1 obs. & $\mathrm{x} 2$ obs. & x3 obs. & $\mathrm{x} 4$ obs. & Residual x 100 & Residual x 100 & Residual x 100 & Residual x 100 \\
\hline 1 & 3082,80 & 7665,00 & 15768,20 & 1625,00 & 0,41 & 2,52 & 10,66 & 0,11 \\
\hline 2 & 2906,31 & 4653,75 & 11910,50 & 2054,00 & 0,00 & 0,00 & 0,00 & 0,00 \\
\hline 3 & 8584,91 & 5475,00 & 6328,50 & 3300,00 & 0,00 & 0,00 & 0,00 & 0,00 \\
\hline 4 & 8511,96 & 3850,75 & 17995,50 & 1835,00 & 3,13 & 0,64 & 14,01 & 0,15 \\
\hline 5 & 6749,10 & 11862,50 & 14463,00 & 3696,00 & 4,74 & 14,65 & 21,77 & 1,42 \\
\hline 6 & 3591,81 & 5931,25 & 10160,00 & 3888,48 & 0,00 & 0,00 & 0,00 & 0,00 \\
\hline 7 & 8333,61 & 4790,63 & 20849,38 & 5300,00 & 0,61 & 0,20 & 3,82 & 0,25 \\
\hline 8 & 8078,49 & 5361,85 & 20162,00 & 3792,00 & 0,27 & 0,12 & 1,70 & 0,06 \\
\hline 9 & 10710,96 & 10080,00 & 15342,39 & 3260,00 & 1,52 & 1,35 & 3,12 & 0,14 \\
\hline 10 & 12700,72 & 9600,00 & 6860,00 & 6500,00 & 0,35 & 0,20 & 0,10 & 0,09 \\
\hline 11 & 12070,90 & 6696,00 & 19234,40 & 3050,00 & 2,19 & 0,67 & 5,56 & 0,14 \\
\hline 12 & 7806,29 & 10026,00 & 16633,50 & 6920,00 & 1,38 & 2,28 & 6,27 & 1,09 \\
\hline 13 & 13912,99 & 14965,00 & 17179,50 & 3483,00 & 8,82 & 10,21 & 13,45 & 0,55 \\
\hline 14 & 5450,92 & 5400,00 & 32048,00 & 3700,00 & 0,39 & 0,38 & 13,34 & 0,18 \\
\hline 15 & 10830,29 & 6241,50 & 25887,90 & 6970,00 & 3,85 & 1,28 & 22,02 & 1,60 \\
\hline 16 & 17908,80 & 8316,00 & 15295,10 & 3920,00 & 10,15 & 2,19 & 7,40 & 0,49 \\
\hline 17 & 10305,14 & 7470,00 & 32083,00 & 5570,00 & 3,24 & 1,70 & 31,44 & 0,95 \\
\hline 18 & 7109,05 & 4800,00 & 17738,00 & 4420,00 & 0,00 & 0,00 & 0,00 & 0,00 \\
\hline 19 & 13883,02 & 7680,00 & 33484,00 & 4950,00 & 2,50 & 0,76 & 14,52 & 0,32 \\
\hline 20 & 7035,56 & 12600,00 & 29583,58 & 3860,00 & 0,33 & 1,06 & 5,86 & 0,10 \\
\hline 21 & 7247,17 & 5994,00 & 27142,20 & 3710,00 & 0,00 & 0,00 & 0,00 & 0,00 \\
\hline 22 & 9311,43 & 9307,50 & 30698,00 & 4703,00 & 0,33 & 0,33 & 3,62 & 0,09 \\
\hline 23 & 7258,23 & 17653,59 & 25501,80 & 3288,00 & 0,23 & 1,35 & 2,81 & 0,05 \\
\hline 24 & 14235,45 & 8760,00 & 21953,70 & 2015,00 & 0,00 & 0,00 & 0,00 & 0,00 \\
\hline 25 & 12530,49 & 8325,25 & 33327,50 & 9530,00 & 1,52 & 0,67 & 10,72 & 0,88 \\
\hline 26 & 12260,09 & 10785,75 & 34378,50 & 7800,00 & 1,59 & 1,23 & 12,53 & 0,64 \\
\hline 27 & 8910,44 & 9382,50 & 24874,00 & 7045,00 & 0,00 & 0,00 & 0,02 & 0,00 \\
\hline 28 & 13852,28 & 6600,00 & 24452,00 & 4780,00 & 0,00 & 0,00 & 0,00 & 0,00 \\
\hline 29 & 11789,80 & 5911,50 & 42369,98 & 18154,50 & 0,69 & 0,17 & 8,89 & 1,63 \\
\hline 30 & 9891,87 & 10560,00 & 37197,60 & 8090,00 & 0,05 & 0,06 & 0,69 & 0,03 \\
\hline 31 & 24244,27 & 10920,00 & 43298,00 & 9210,00 & 5,43 & 1,10 & 17,31 & 0,78 \\
\hline 32 & 15229,28 & 10080,00 & 60456,00 & 6630,00 & 1,31 & 0,58 & 20,70 & 0,25 \\
\hline 33 & 16997,19 & 12300,00 & 44853,50 & 14267,00 & 2,85 & 1,49 & 19,84 & 2,01 \\
\hline 34 & 23327,01 & 7200,00 & 20277,83 & 12835,00 & 0,10 & 0,01 & 0,08 & 0,03 \\
\hline 35 & 18535,88 & 13794,00 & 65190,70 & 10185,00 & 3,00 & 1,66 & 37,09 & 0,91 \\
\hline 36 & 42868,13 & 15120,00 & 28590,00 & 16916,00 & 31,42 & 3,91 & 13,97 & 4,89 \\
\hline 37 & 22880,62 & 25104,00 & 44396,57 & 17490,00 & 10,17 & 12,25 & 38,30 & 5,94 \\
\hline 38 & 16261,27 & 22110,00 & 59451,00 & 14380,00 & 3,29 & 6,09 & 44,01 & 2,58 \\
\hline 39 & 15764,17 & 11760,00 & 51562,00 & 5120,00 & 1,29 & 0,72 & 13,83 & 0,14 \\
\hline 40 & 37409,05 & 18780,00 & 41875,17 & 5740,00 & 19,49 & 4,91 & 24,42 & 0,46 \\
\hline 41 & 27468,50 & 21188,25 & 54414,80 & 3470,00 & 8,56 & 5,09 & 33,60 & 0,14 \\
\hline 42 & 14856,49 & 11280,00 & 70364,00 & 9490,89 & 1,47 & 0,85 & 32,92 & 0,60 \\
\hline 43 & 30298,86 & 4756,00 & 61837,00 & 9597,00 & 7,69 & 0,19 & 32,02 & 0,77 \\
\hline 44 & 17595,30 & 19218,00 & 14495,00 & 10740,00 & 0,00 & 0,00 & 0,00 & 0,00 \\
\hline 45 & 21382,17 & 15002,00 & 23231,25 & 15902,50 & 0,81 & 0,40 & 0,96 & 0,45 \\
\hline 46 & 30308,58 & 15600,00 & 77142,50 & 12550,00 & 7,64 & 2,02 & 49,48 & 1,31 \\
\hline 47 & 26551,55 & 11315,00 & 80688,00 & 15871,00 & 5,18 & 0,94 & 47,86 & 1,85 \\
\hline 48 & 37251,14 & 14190,47 & 77854,40 & 3640,00 & 9,57 & 1,39 & 41,79 & 0,09 \\
\hline 49 & 43457,79 & 19851,75 & 66212,00 & 2840,00 & 16,86 & 3,52 & 39,13 & 0,07 \\
\hline 50 & 23277,51 & 10056,00 & 62630,00 & 11400,00 & 3,56 & 0,66 & 25,77 & 0,85 \\
\hline
\end{tabular}


Tabela 33. Resultados do modelo Varian, amostra Brasil, renda líquida não negativa, orientação insumo. Observações ordenadas pelo renda bruta de forma crescente.

\begin{tabular}{|c|c|c|c|c|c|c|c|c|}
\hline Obs. & x1 obs. & x 2 obs. & x3 obs. & $\mathrm{x} 4$ obs. & Residual x 100 & Residual x 100 & Residual x 100 & Residual x 100 \\
\hline 51 & 25684,81 & 12318,75 & 63605,78 & 7255,00 & 4,28 & 0,99 & 26,27 & 0,34 \\
\hline 52 & 24873,49 & 16560,00 & 95560,00 & 9410,00 & 3,60 & 1,59 & 53,07 & 0,51 \\
\hline 53 & 29698,48 & 7161,60 & 68361,00 & 8534,00 & 5,40 & 0,31 & 28,63 & 0,45 \\
\hline 54 & 18521,67 & 10224,00 & 87150,00 & 7640,00 & 1,54 & 0,47 & 34,04 & 0,26 \\
\hline 55 & 46800,79 & 16485,00 & 44960,83 & 12645,00 & 27,03 & 3,35 & 24,95 & 1,97 \\
\hline 56 & 15077,11 & 6000,00 & 40710,00 & 7517,00 & 0,00 & 0,00 & 0,00 & 0,00 \\
\hline 57 & 16720,65 & 23139,00 & 101836,00 & 23148,00 & 0,75 & 1,43 & 27,78 & 1,44 \\
\hline 58 & 24485,49 & 12480,00 & 104480,00 & 24155,00 & 1,51 & 0,39 & 27,42 & 1,47 \\
\hline 59 & 18507,84 & 15075,00 & 62448,78 & 8150,00 & 0,00 & 0,00 & 0,00 & 0,00 \\
\hline 60 & 81449,35 & 11100,00 & 35115,50 & 20340,00 & 0,33 & 0,01 & 0,06 & 0,02 \\
\hline 61 & 23042,00 & 19200,00 & 91511,00 & 8360,00 & 0,00 & 0,00 & 0,00 & 0,00 \\
\hline 62 & 39035,34 & 21983,75 & 90151,43 & 17754,20 & 0,39 & 0,12 & 2,09 & 0,08 \\
\hline 63 & 21565,41 & 24022,80 & 53565,80 & 60300,00 & 0,04 & 0,05 & 0,27 & 0,34 \\
\hline 64 & 75725,14 & 24037,56 & 33608,00 & 18813,78 & 0,00 & 0,00 & 0,00 & 0,00 \\
\hline 65 & 37148,37 & 5224,80 & 89656,10 & 22460,00 & 0,00 & 0,00 & 0,00 & 0,00 \\
\hline 66 & 37949,00 & 22664,45 & 152955,93 & 18190,00 & 0,01 & 0,00 & 0,17 & 0,00 \\
\hline 67 & 37623,43 & 27096,96 & 93551,13 & 66550,00 & 0,00 & 0,00 & 0,00 & 0,00 \\
\hline 68 & 44580,46 & 24896,00 & 157980,00 & 17000,00 & 0,00 & 0,00 & 0,00 & 0,00 \\
\hline 69 & 40246,64 & 21096,00 & 188263,50 & 23640,00 & 0,00 & 0,00 & 0,00 & 0,00 \\
\hline 70 & 29623,99 & 23289,00 & 189860,00 & 40215,00 & 0,00 & 0,00 & 0,00 & 0,00 \\
\hline 71 & 56622,53 & 17280,00 & 206472,75 & 28940,00 & 0,00 & 0,00 & 0,00 & 0,00 \\
\hline 72 & 51381,88 & 43200,00 & 227238,45 & 37400,00 & 0,00 & 0,00 & 0,00 & 0,00 \\
\hline 73 & 128539,33 & 42300,00 & 347422,84 & 46700,00 & 2,26 & 0,25 & 16,53 & 0,30 \\
\hline 74 & 68465,97 & 61920,00 & 243500,00 & 25854,67 & 0,00 & 0,00 & 0,00 & 0,00 \\
\hline \multirow[t]{3}{*}{75} & 102572,82 & 31500,00 & 281846,21 & 38500,00 & 0,00 & 0,00 & 0,00 & 0,00 \\
\hline & & & & SOMA & 2,35 & 1,01 & 9,89 & 0,42 \\
\hline & & & & TOTAL & & & & 13,67 \\
\hline
\end{tabular}

Fonte: Resultados da pesquisa. 
Tabela 34. Resultados do modelo Varian, amostra Minas Gerais, orientação insumo.

Observações ordenadas pelo renda bruta de forma crescente.

\begin{tabular}{|c|c|c|c|c|c|c|c|c|}
\hline Obs. & x1 obs. & $\mathrm{x} 2$ obs. & x 3 obs. & $\mathrm{x} 4$ obs. & Residual x 100 & Residual x 100 & Residual x 100 & Residual x 100 \\
\hline 1 & 4173,54 & 2587,84 & 6414,78 & 1689,91 & 0,00 & 0,00 & 0,00 & 0,00 \\
\hline 2 & 3537,32 & 6207,95 & 6017,65 & 2134,98 & 0,00 & 0,00 & 0,00 & 0,00 \\
\hline 3 & 4559,60 & 6326,95 & 17790,16 & 2746,47 & 0,26 & 0,55 & 4,24 & 0,10 \\
\hline 4 & 12036,67 & 5036,77 & 14146,17 & 1937,86 & 3,93 & 0,65 & 5,44 & 0,25 \\
\hline 5 & 7016,78 & 6391,40 & 10867,77 & 2694,53 & 0,00 & 0,00 & 0,00 & 0,00 \\
\hline 6 & 4559,49 & 6683,37 & 22743,60 & 1623,57 & 0,00 & 0,00 & 0,00 & 0,00 \\
\hline 7 & 8600,60 & 10800,00 & 18304,00 & 2720,00 & 0,26 & 0,43 & 1,30 & 0,17 \\
\hline 8 & 15750,17 & 10173,54 & 19027,30 & 2358,00 & 5,04 & 2,11 & 7,35 & 0,09 \\
\hline 9 & 6504,27 & 18291,00 & 8323,61 & 3950,00 & 0,00 & 0,00 & 0,00 & 0,00 \\
\hline 10 & 6191,82 & 5020,53 & 26222,86 & 1929,18 & 0,00 & 0,00 & 0,06 & 0,00 \\
\hline 11 & 4263,71 & 8567,33 & 34028,71 & 2293,29 & 0,08 & 0,52 & 8,12 & 0,11 \\
\hline 12 & 10174,09 & 9467,27 & 19725,44 & 1894,30 & 0,20 & 0,17 & 0,77 & 0,09 \\
\hline 13 & 6457,97 & 10237,57 & 19889,85 & 2920,13 & 0,01 & 0,02 & 0,10 & 0,01 \\
\hline 14 & 12068,13 & 7721,33 & 20304,65 & 8144,69 & 2,87 & 1,17 & 8,12 & 1,31 \\
\hline 15 & 9605,85 & 11053,92 & 16812,44 & 1169,75 & 0,00 & 0,00 & 0,00 & 0,00 \\
\hline 16 & 10449,33 & 8847,31 & 29225,23 & 2843,17 & 0,00 & 0,00 & 0,00 & 0,00 \\
\hline 17 & 33906,67 & 14074,00 & 17420,00 & 4463,62 & 14,24 & 2,45 & 3,76 & 0,25 \\
\hline 18 & 10877,20 & 11215,10 & 38349,57 & 6178,70 & 0,91 & 0,97 & 11,29 & 0,28 \\
\hline 19 & 4502,25 & 11180,32 & 25466,32 & 10116,32 & 0,00 & 0,00 & 0,00 & 0,00 \\
\hline 20 & 8580,37 & 13997,17 & 28429,23 & 4599,19 & 0,00 & 0,00 & 0,00 & 0,00 \\
\hline 21 & 14659,72 & 13378,07 & 39301,41 & 4418,78 & 0,75 & 0,63 & 5,40 & 0,07 \\
\hline 22 & 6987,67 & 15988,00 & 35632,12 & 1571,60 & 0,00 & 0,00 & 0,00 & 0,00 \\
\hline 23 & 35583,67 & 14574,00 & 20799,40 & 5620,00 & 5,36 & 0,90 & 1,83 & 0,13 \\
\hline 24 & 8800,63 & 15729,95 & 35816,93 & 7612,07 & 0,05 & 0,14 & 0,75 & 0,03 \\
\hline 25 & 35309,33 & 16074,00 & 19540,62 & 5650,00 & 5,41 & 1,12 & 1,66 & 0,14 \\
\hline 26 & 26797,24 & 30285,00 & 24712,99 & 7862,82 & 8,92 & 11,39 & 7,59 & 0,77 \\
\hline 27 & 14039,09 & 7403,37 & 40227,61 & 7702,97 & 0,16 & 0,04 & 1,29 & 0,05 \\
\hline 28 & 21055,43 & 15828,90 & 43184,91 & 8911,31 & 3,99 & 2,26 & 16,81 & 0,72 \\
\hline 29 & 16583,85 & 14150,00 & 28678,52 & 4522,00 & 0,00 & 0,00 & 0,00 & 0,00 \\
\hline 30 & 10883,17 & 16428,20 & 44483,03 & 3140,32 & 0,00 & 0,00 & 0,00 & 0,00 \\
\hline 31 & 20904,33 & 15316,97 & 43437,00 & 5259,07 & 0,25 & 0,13 & 1,07 & 0,01 \\
\hline 32 & 18727,00 & 11481,90 & 43455,50 & 8562,96 & 0,07 & 0,03 & 0,38 & 0,01 \\
\hline 33 & 10679,67 & 22301,18 & 42168,71 & 6722,72 & 0,02 & 0,08 & 0,29 & 0,01 \\
\hline 34 & 10798,66 & 28800,00 & 37476,00 & 4200,00 & 0,01 & 0,09 & 0,16 & 0,00 \\
\hline 35 & 26112,39 & 24174,11 & 24178,10 & 7484,36 & 0,19 & 0,16 & 0,16 & 0,02 \\
\hline 36 & 11499,74 & 31850,48 & 47198,42 & 4885,52 & 0,32 & 2,44 & 5,36 & 0,06 \\
\hline 37 & 9488,49 & 19881,83 & 46157,54 & 9723,63 & 0,05 & 0,23 & 1,22 & 0,05 \\
\hline 38 & 16791,81 & 14132,98 & 41282,28 & 7612,42 & 0,01 & 0,00 & 0,04 & 0,00 \\
\hline 39 & 30604,00 & 17952,00 & 42422,60 & 12384,00 & 5,49 & 1,89 & 10,55 & 0,90 \\
\hline 40 & 14230,64 & 20128,00 & 41805,04 & 7290,60 & 0,08 & 0,15 & 0,66 & 0,02 \\
\hline 41 & 21564,67 & 37996,00 & 49998,60 & 9353,00 & 3,71 & 11,51 & 19,93 & 0,70 \\
\hline 42 & 28522,83 & 26002,80 & 37212,00 & 8001,83 & 4,14 & 3,44 & 7,05 & 0,33 \\
\hline 43 & 13279,19 & 19681,16 & 43079,07 & 3634,31 & 0,00 & 0,01 & 0,03 & 0,00 \\
\hline 44 & 17457,06 & 15553,97 & 46952,87 & 5371,97 & 0,17 & 0,13 & 1,23 & 0,02 \\
\hline 45 & 9180,04 & 15330,00 & 48830,91 & 5428,00 & 0,00 & 0,00 & 0,00 & 0,00 \\
\hline 46 & 14490,86 & 29352,54 & 49669,60 & 4234,47 & 0,03 & 0,11 & 0,32 & 0,00 \\
\hline 47 & 14646,43 & 20069,00 & 50331,97 & 10425,08 & 0,01 & 0,01 & 0,08 & 0,00 \\
\hline 48 & 13695,56 & 22630,63 & 59212,41 & 6630,61 & 0,07 & 0,20 & 1,40 & 0,02 \\
\hline 49 & 16380,93 & 22255,91 & 53426,80 & 3860,35 & 0,01 & 0,02 & 0,11 & 0,00 \\
\hline 50 & 17848,67 & 23088,13 & 81634,65 & 7229,80 & 0,73 & 1,21 & 15,17 & 0,12 \\
\hline 51 & 21721,86 & 21561,02 & 48837,00 & 7220,00 & 0,13 & 0,13 & 0,67 & 0,01 \\
\hline
\end{tabular}


Tabela 34. Resultados do modelo Varian, amostra Minas Gerais, orientação insumo.

Observações ordenadas pelo renda bruta de forma crescente.

\begin{tabular}{|c|c|c|c|c|c|c|c|c|}
\hline Obs. & x1 obs. & $\mathrm{x} 2$ obs. & x 3 obs. & $\mathrm{x} 4$ obs. & Residual x 100 & Residual x 100 & Residual x 100 & Residual x 100 \\
\hline 52 & 16687,13 & 19049,92 & 71456,75 & 14339,69 & 0,61 & 0,79 & 11,17 & 0,45 \\
\hline 53 & 19059,50 & 14680,00 & 67512,20 & 10017,16 & 0,41 & 0,24 & 5,14 & 0,11 \\
\hline 54 & 15751,34 & 19255,00 & 51800,60 & 6880,00 & 0,00 & 0,00 & 0,00 & 0,00 \\
\hline 55 & 19988,33 & 15830,00 & 81224,97 & 9768,76 & 0,12 & 0,08 & 1,98 & 0,03 \\
\hline 56 & 12183,45 & 12827,37 & 78838,99 & 10240,36 & 0,00 & 0,00 & 0,00 & 0,00 \\
\hline 57 & 15614,92 & 22727,37 & 83771,15 & 8077,31 & 0,08 & 0,17 & 2,25 & 0,02 \\
\hline 58 & 19311,33 & 27030,70 & 80134,09 & 12936,61 & 0,34 & 0,67 & 5,88 & 0,15 \\
\hline 59 & 19865,73 & 27030,70 & 80134,09 & 12936,61 & 0,38 & 0,70 & 6,13 & 0,16 \\
\hline 60 & 25233,00 & 24600,00 & 101760,00 & 16200,00 & 1,21 & 1,15 & 19,65 & 0,50 \\
\hline 61 & 25507,70 & 31383,55 & 57967,15 & 6425,98 & 0,07 & 0,10 & 0,35 & 0,00 \\
\hline 62 & 28206,00 & 26340,35 & 65674,40 & 7650,99 & 0,32 & 0,28 & 1,73 & 0,02 \\
\hline 63 & 34043,75 & 23057,52 & 78437,00 & 11565,51 & 1,75 & 0,80 & 9,27 & 0,20 \\
\hline 64 & 20452,50 & 47317,45 & 67626,85 & 15473,44 & 0,90 & 4,84 & 9,89 & 0,52 \\
\hline 65 & 22160,20 & 24569,84 & 61323,23 & 16511,51 & 0,13 & 0,16 & 1,02 & 0,07 \\
\hline 66 & 36749,30 & 42174,67 & 48996,36 & 7470,48 & 1,61 & 2,11 & 2,85 & 0,07 \\
\hline 67 & 20924,71 & 34658,24 & 90898,72 & 17721,24 & 0,97 & 2,66 & 18,29 & 0,69 \\
\hline 68 & 12063,87 & 13253,63 & 134618,06 & 4367,56 & 0,10 & 0,12 & 12,34 & 0,01 \\
\hline 69 & 22369,00 & 16648,20 & 70638,70 & 6478,29 & 0,00 & 0,00 & 0,00 & 0,00 \\
\hline 70 & 23041,38 & 38817,23 & 90430,53 & 16285,05 & 0,61 & 1,74 & 9,47 & 0,31 \\
\hline 71 & 20912,40 & 15921,00 & 94076,08 & 10448,16 & 0,03 & 0,02 & 0,68 & 0,01 \\
\hline 72 & 37757,21 & 21242,57 & 97998,48 & 15204,20 & 1,60 & 0,51 & 10,81 & 0,26 \\
\hline 73 & 10012,84 & 24794,00 & 91240,95 & 6864,50 & 0,00 & 0,00 & 0,00 & 0,00 \\
\hline 74 & 19677,87 & 48029,13 & 97162,67 & 12017,43 & 0,32 & 1,92 & 7,87 & 0,12 \\
\hline 75 & 32322,55 & 45282,98 & 110362,26 & 23444,05 & 2,04 & 4,01 & 23,81 & 1,07 \\
\hline 76 & 32073,89 & 38558,30 & 126835,88 & 9346,45 & 1,26 & 1,82 & 19,68 & 0,11 \\
\hline 77 & 28154,17 & 24148,94 & 117478,43 & 12445,58 & 0,56 & 0,41 & 9,77 & 0,11 \\
\hline 78 & 26294,60 & 27103,18 & 74022,57 & 14021,71 & 0,00 & 0,00 & 0,00 & 0,00 \\
\hline 79 & 36440,00 & 55846,72 & 117491,79 & 18857,20 & 2,63 & 6,17 & 27,33 & 0,70 \\
\hline 80 & 32537,42 & 29818,75 & 113785,16 & 14311,91 & 0,92 & 0,78 & 11,30 & 0,18 \\
\hline 81 & 35456,30 & 58508,52 & 96968,16 & 8755,55 & 1,82 & 4,95 & 13,59 & 0,11 \\
\hline 82 & 44745,52 & 32030,00 & 62676,00 & 6400,00 & 0,00 & 0,00 & 0,00 & 0,00 \\
\hline 83 & 25448,23 & 43788,12 & 98873,50 & 22885,71 & 0,00 & 0,00 & 0,00 & 0,00 \\
\hline 84 & 43742,00 & 28355,66 & 108116,61 & 13456,56 & 0,00 & 0,00 & 0,00 & 0,00 \\
\hline 85 & 43805,64 & 32685,00 & 133280,82 & 17681,56 & 0,00 & 0,00 & 0,02 & 0,00 \\
\hline 86 & 34491,18 & 64423,68 & 103759,64 & 23479,72 & 0,00 & 0,00 & 0,00 & 0,00 \\
\hline 87 & 30003,67 & 45585,25 & 141110,08 & 18328,16 & 0,02 & 0,04 & 0,37 & 0,01 \\
\hline 88 & 44123,54 & 44388,08 & 117106,36 & 25046,12 & 0,02 & 0,02 & 0,13 & 0,01 \\
\hline 89 & 41135,46 & 30018,27 & 145434,94 & 29119,93 & 0,12 & 0,06 & 1,50 & 0,06 \\
\hline 90 & 29657,88 & 72806,90 & 156625,77 & 26979,72 & 0,33 & 2,00 & 9,25 & 0,27 \\
\hline 91 & 42516,01 & 51310,24 & 131077,51 & 20331,32 & 0,15 & 0,22 & 1,45 & 0,03 \\
\hline 92 & 39381,91 & 38973,51 & 118828,00 & 27838,00 & 0,00 & 0,00 & 0,00 & 0,00 \\
\hline 93 & 77649,66 & 23863,83 & 175938,95 & 24896,30 & 0,42 & 0,04 & 2,18 & 0,04 \\
\hline 94 & 47046,34 & 51434,29 & 170403,64 & 18707,54 & 0,06 & 0,07 & 0,74 & 0,01 \\
\hline 95 & 70224,73 & 64573,18 & 122290,74 & 31396,29 & 0,26 & 0,22 & 0,78 & 0,05 \\
\hline 96 & 39396,67 & 40007,00 & 185859,26 & 11912,71 & 0,01 & 0,01 & 0,11 & 0,00 \\
\hline 97 & 38993,57 & 51332,40 & 182817,65 & 17622,68 & 0,04 & 0,08 & 0,97 & 0,01 \\
\hline 98 & 35896,67 & 41890,00 & 173073,96 & 19482,72 & 0,00 & 0,00 & 0,00 & 0,00 \\
\hline 99 & 48589,67 & 48416,00 & 157550,66 & 46838,00 & 0,01 & 0,01 & 0,10 & 0,01 \\
\hline 100 & 53203,50 & 83244,00 & 132452,00 & 26063,50 & 0,00 & 0,00 & 0,00 & 0,00 \\
\hline 101 & 56707,66 & 49290,44 & 178325,11 & 35504,55 & 0,11 & 0,08 & 1,11 & 0,04 \\
\hline 102 & 132358,06 & 87092,41 & 46167,33 & 31329,59 & 0,00 & 0,00 & 0,00 & 0,00 \\
\hline 103 & 49267,03 & 43695,23 & 234903,69 & 28890,30 & 0,03 & 0,02 & 0,72 & 0,01 \\
\hline 104 & 27150,27 & 35608,07 & 238586,18 & 33637,29 & 0,00 & 0,00 & 0,00 & 0,00 \\
\hline 105 & 92200,00 & 66420,00 & 188972,90 & 11825,00 & 0,02 & 0,01 & 0,08 & 0,00 \\
\hline 106 & 55118,00 & 48509,28 & 212282,87 & 36323,59 & 0,00 & 0,00 & 0,00 & 0,00 \\
\hline 107 & 84857,66 & 83625,99 & 269241,93 & 47454,06 & 0,22 & 0,21 & 2,31 & 0,07 \\
\hline 108 & 95363,71 & 60980,00 & 232686,00 & 46169,44 & 0,00 & 0,00 & 0,00 & 0,00 \\
\hline
\end{tabular}


Tabela 34. Resultados do modelo Varian, amostra Minas Gerais, orientação insumo. Observações ordenadas pelo renda bruta de forma crescente.

\begin{tabular}{|c|c|c|c|c|c|c|c|c|}
\hline Obs. & x1 obs. & x2 obs. & x3 obs. & $\mathrm{x} 4$ obs. & Residual x 100 & Residual x 100 & Residual x 100 & Residual x 100 \\
\hline 109 & 66831,33 & 73471,95 & 409685,42 & 34142,91 & 0,00 & 0,00 & 5,26 & 0,00 \\
\hline 110 & 98673,34 & 163049,11 & 480496,81 & 81038,41 & 0,13 & 0,40 & 31,23 & 0,08 \\
\hline 111 & 94058,00 & 99243,00 & 447915,17 & 37216,61 & 0,00 & 0,00 & 9,75 & 0,00 \\
\hline 112 & 56743,34 & 99530,90 & 508177,01 & 43933,11 & 0,00 & 0,00 & 11,16 & 0,00 \\
\hline 113 & 129671,35 & 100818,60 & 530911,47 & 53167,52 & 0,02 & 0,01 & 26,44 & 0,00 \\
\hline \multirow[t]{3}{*}{114} & 111072,00 & 89587,80 & 742845,00 & 24864,86 & 0,00 & 0,00 & 33,46 & 0,00 \\
\hline & & & & SOMA & 0,91 & 0,88 & 5,33 & 0,14 \\
\hline & & & & TOTAL & & & & 7,26 \\
\hline
\end{tabular}

Fonte: Resultados da pesquisa.

Tabela 35. Resultados do modelo Varian, amostra Minas Gerais, renda líquida não negativa, orientação insumo. Observações ordenadas pelo renda bruta de forma crescente.

\begin{tabular}{ccccccccc}
\hline Obs. & x1 obs. & x2 obs. & x3 obs. & x4 obs. & Residual x 100 & Residual x 100 & Residual x 100 & Residual x 100 \\
\hline 1 & 7016,78 & 6391,40 & 10867,77 & 2694,53 & 0,00 & 0,00 & 0,00 & 0,00 \\
2 & 4559,49 & 6683,37 & 22743,60 & 1623,57 & 0,00 & 0,00 & 0,00 & 0,00 \\
3 & 6504,27 & 18291,00 & 8323,61 & 3950,00 & 0,00 & 0,00 & 0,00 & 0,00 \\
4 & 6191,82 & 5020,53 & 26222,86 & 1929,18 & 0,00 & 0,00 & 0,06 & 0,05 \\
5 & 10174,09 & 9467,27 & 19725,44 & 1894,30 & 0,21 & 0,18 & 0,78 & 0,01 \\
6 & 6457,97 & 10237,57 & 19889,85 & 2920,13 & 0,01 & 0,03 & 0,10 & 0,00 \\
7 & 12068,13 & 7721,33 & 20304,65 & 8144,69 & 2,87 & 1,18 & 8,12 & 1,30 \\
8 & 9605,85 & 11053,92 & 16812,44 & 1169,75 & 0,00 & 0,00 & 0,00 & 0,00 \\
9 & 4502,25 & 11180,32 & 25466,32 & 10116,32 & 0,00 & 0,00 & 0,00 & 0,00 \\
10 & 8580,37 & 13997,17 & 28429,23 & 4599,19 & 0,00 & 0,00 & 0,00 & 0,00 \\
11 & 6987,67 & 15988,00 & 35632,12 & 1571,60 & 0,00 & 0,00 & 0,00 & 0,00 \\
12 & 8800,63 & 15729,95 & 35816,93 & 7612,07 & 0,05 & 0,14 & 0,75 & 0,03 \\
13 & 14039,09 & 7403,37 & 40227,61 & 7702,97 & 0,16 & 0,04 & 1,29 & 0,05 \\
14 & 16583,85 & 14150,00 & 28678,52 & 4522,00 & 0,00 & 0,00 & 0,00 & 0,00 \\
15 & 10883,17 & 16428,20 & 44483,03 & 3140,32 & 0,00 & 0,00 & 0,00 & 0,00 \\
16 & 10679,67 & 22301,18 & 42168,71 & 6722,72 & 0,02 & 0,08 & 0,29 & 0,01 \\
17 & 10798,66 & 28800,00 & 37476,00 & 4200,00 & 0,01 & 0,09 & 0,16 & 0,00 \\
18 & 26112,39 & 24174,11 & 24178,10 & 7484,36 & 0,19 & 0,16 & 0,16 & 0,02 \\
19 & 9488,49 & 19881,83 & 46157,54 & 9723,63 & 0,05 & 0,23 & 1,22 & 0,05 \\
20 & 16791,81 & 14132,98 & 41282,28 & 7612,42 & 0,00 & 0,00 & 0,04 & 0,01 \\
21 & 14230,64 & 20128,00 & 41805,04 & 7290,60 & 0,07 & 0,15 & 0,66 & 0,02 \\
22 & 13279,19 & 19681,16 & 43079,07 & 3634,31 & 0,00 & 0,01 & 0,03 & 0,00 \\
23 & 17457,06 & 15553,97 & 46952,87 & 5371,97 & 0,17 & 0,13 & 1,23 & 0,02 \\
24 & 9180,04 & 15330,00 & 48830,91 & 5428,00 & 0,00 & 0,00 & 0,00 & 0,00 \\
25 & 14646,43 & 20069,00 & 50331,97 & 10425,08 & 0,01 & 0,01 & 0,08 & 0,00 \\
26 & 13695,56 & 22630,63 & 59212,41 & 6630,61 & 0,07 & 0,20 & 1,40 & 0,02
\end{tabular}


Tabela 35. Resultados do modelo Varian, amostra Minas Gerais, renda líquida não negativa, orientação insumo. Observações ordenadas pelo renda bruta de forma crescente.

\begin{tabular}{|c|c|c|c|c|c|c|c|c|}
\hline Obs. & x1 obs. & x2 obs. & x3 obs. & x4 obs. & Residual x 100 & Residual x 100 & Residual x 100 & Residual x 100 \\
\hline 27 & 16380,93 & 22255,91 & 53426,80 & 3860,35 & 0,01 & 0,02 & 0,11 & 0,00 \\
\hline 28 & 21721,86 & 21561,02 & 48837,00 & 7220,00 & 0,13 & 0,12 & 0,66 & 0,04 \\
\hline 29 & 16687,13 & 19049,92 & 71456,75 & 14339,69 & 0,61 & 0,79 & 11,17 & 0,45 \\
\hline 30 & 19059,50 & 14680,00 & 67512,20 & 10017,16 & 0,41 & 0,24 & 5,14 & 0,11 \\
\hline 31 & 15751,34 & 19255,00 & 51800,60 & 6880,00 & 0,00 & 0,00 & 0,00 & 0,00 \\
\hline 32 & 19988,33 & 15830,00 & 81224,97 & 9768,76 & 0,12 & 0,08 & 1,98 & 0,03 \\
\hline 33 & 12183,45 & 12827,37 & 78838,99 & 10240,36 & 0,00 & 0,00 & 0,00 & 0,00 \\
\hline 34 & 15614,92 & 22727,37 & 83771,15 & 8077,31 & 0,08 & 0,17 & 2,25 & 0,02 \\
\hline 35 & 25507,70 & 31383,55 & 57967,15 & 6425,98 & 0,07 & 0,10 & 0,35 & 0,00 \\
\hline 36 & 28206,00 & 26340,35 & 65674,40 & 7650,99 & 0,33 & 0,29 & 1,74 & 0,00 \\
\hline 37 & 20452,50 & 47317,45 & 67626,85 & 15473,44 & 0,90 & 4,84 & 9,89 & 0,52 \\
\hline 38 & 22160,20 & 24569,84 & 61323,23 & 16511,51 & 0,13 & 0,16 & 1,02 & 0,07 \\
\hline 39 & 36749,30 & 42174,67 & 48996,36 & 7470,48 & 1,60 & 2,11 & 2,85 & 0,07 \\
\hline 40 & 22369,00 & 16648,20 & 70638,70 & 6478,29 & 0,00 & 0,00 & 0,00 & 0,00 \\
\hline 41 & 20912,40 & 15921,00 & 94076,08 & 10448,16 & 0,03 & 0,02 & 0,68 & 0,01 \\
\hline 42 & 10012,84 & 24794,00 & 91240,95 & 6864,50 & 0,00 & 0,00 & 0,00 & 0,00 \\
\hline 43 & 28154,17 & 24148,94 & 117478,43 & 12445,58 & 0,56 & 0,41 & 9,77 & 0,11 \\
\hline 44 & 26294,60 & 27103,18 & 74022,57 & 14021,71 & 0,00 & 0,00 & 0,00 & 0,00 \\
\hline 45 & 32537,42 & 29818,75 & 113785,16 & 14311,91 & 0,92 & 0,78 & 11,30 & 0,18 \\
\hline 46 & 44745,52 & 32030,00 & 62676,00 & 6400,00 & 0,00 & 0,00 & 0,00 & 0,00 \\
\hline 47 & 25448,23 & 43788,12 & 98873,50 & 22885,71 & 0,00 & 0,00 & 0,00 & 0,00 \\
\hline 48 & 43742,00 & 28355,66 & 108116,61 & 13456,56 & 0,00 & 0,00 & 0,00 & 0,00 \\
\hline 49 & 44123,54 & 44388,08 & 117106,36 & 25046,12 & 0,02 & 0,02 & 0,13 & 0,01 \\
\hline 50 & 41135,46 & 30018,27 & 145434,94 & 29119,93 & 0,12 & 0,06 & 1,50 & 0,06 \\
\hline 51 & 42516,01 & 51310,24 & 131077,51 & 20331,32 & 0,15 & 0,22 & 1,45 & 0,03 \\
\hline 52 & 39381,91 & 38973,51 & 118828,00 & 27838,00 & 0,00 & 0,00 & 0,00 & 0,00 \\
\hline 53 & 47046,34 & 51434,29 & 170403,64 & 18707,54 & 0,06 & 0,07 & 0,74 & 0,01 \\
\hline 54 & 70224,73 & 64573,18 & 122290,74 & 31396,29 & 0,26 & 0,22 & 0,79 & 0,05 \\
\hline 55 & 39396,67 & 40007,00 & 185859,26 & 11912,71 & 0,01 & 0,01 & 0,11 & 0,00 \\
\hline 56 & 38993,57 & 51332,40 & 182817,65 & 17622,68 & 0,04 & 0,08 & 0,97 & 0,01 \\
\hline 57 & 35896,67 & 41890,00 & 173073,96 & 19482,72 & 0,00 & 0,00 & 0,00 & 0,00 \\
\hline 58 & 48589,67 & 48416,00 & 157550,66 & 46838,00 & 0,01 & 0,01 & 0,10 & 0,01 \\
\hline 59 & 53203,50 & 83244,00 & 132452,00 & 26063,50 & 0,00 & 0,00 & 0,00 & 0,00 \\
\hline 60 & 56707,66 & 49290,44 & 178325,11 & 35504,55 & 0,11 & 0,08 & 1,11 & 0,04 \\
\hline 61 & 132358,06 & 87092,41 & 46167,33 & 31329,59 & 0,00 & 0,00 & 0,00 & 0,00 \\
\hline 62 & 49267,03 & 43695,23 & 234903,69 & 28890,30 & 0,01 & 0,01 & 2,00 & 0,00 \\
\hline 63 & 27150,27 & 35608,07 & 238586,18 & 33637,29 & 0,00 & 0,00 & 0,27 & 0,00 \\
\hline 64 & 92200,00 & 66420,00 & 188972,90 & 11825,00 & 0,01 & 0,01 & 0,64 & 0,00 \\
\hline 65 & 55118,00 & 48509,28 & 212282,87 & 36323,59 & 0,00 & 0,00 & 0,20 & 0,00 \\
\hline 66 & 95363,71 & 60980,00 & 232686,00 & 46169,44 & 0,00 & 0,00 & 3,31 & 0,00 \\
\hline 67 & 66831,33 & 73471,95 & 409685,42 & 34142,91 & 0,00 & 0,00 & 20,97 & 0,00 \\
\hline 68 & 94058,00 & 99243,00 & 447915,17 & 37216,61 & 0,01 & 0,01 & 37,84 & 0,00 \\
\hline 69 & 56743,34 & 99530,90 & 508177,01 & 43933,11 & 0,00 & 0,00 & 36,65 & 0,00 \\
\hline 70 & 129671,35 & 100818,60 & 530911,47 & 53167,52 & 0,15 & 0,07 & 55,26 & 0,02 \\
\hline \multirow[t]{3}{*}{71} & 111072,00 & 89587,80 & 742845,00 & 24864,86 & 0,00 & 0,00 & 56,22 & 0,00 \\
\hline & & & & SOMA & 0,11 & 0,14 & 2,96 & 0,03 \\
\hline & & & & TOTAL & & & & 3,23 \\
\hline
\end{tabular}

Fonte: Resultados da pesquisa. 
Tabela 36. Resultados do modelo Varian, amostras Brasil e Minas, orientação produto. Observações ordenadas pelo custo de forma crescente.

\begin{tabular}{|c|c|c|c|c|c|}
\hline \multicolumn{3}{|c|}{ Brasil } & \multicolumn{3}{|c|}{ Minas Gerais } \\
\hline Observação & $Y$ observado & Residual x 100 & Observação & $Y$ obs ervado & Residual x 100 \\
\hline 1 & 30574,50 & 0,00 & 1 & 14192,44 & 0,00 \\
\hline 2 & 21231,75 & 19,37 & 2 & 16979,42 & 0,00 \\
\hline 3 & 40644,00 & 0,00 & 3 & 28061,85 & 0,00 \\
\hline 4 & 31536,00 & 8,34 & 4 & 26844,85 & 0,21 \\
\hline 5 & 27010,00 & 25,48 & 5 & 27020,28 & 0,15 \\
\hline 6 & 30506,56 & 11,04 & 6 & 39010,32 & 0,00 \\
\hline 7 & 24359,25 & 44,69 & 7 & 41902,00 & 0,00 \\
\hline 8 & 33131,25 & 5,14 & 8 & 50405,99 & 0,00 \\
\hline 9 & 28203,50 & 19,46 & 9 & 44369,77 & 1,85 \\
\hline 10 & 26718,00 & 27,17 & 10 & 48458,49 & 0,16 \\
\hline 11 & 31072,50 & 9,49 & 11 & 39617,30 & 7,42 \\
\hline 12 & 33358,00 & 4,77 & 12 & 45621,73 & 1,10 \\
\hline 13 & 25683,39 & 33,93 & 13 & 41359,27 & 4,78 \\
\hline 14 & 59130,00 & 0,00 & 14 & 49137,60 & 0,07 \\
\hline 15 & 25866,76 & 165,37 & 15 & 45022,85 & 1,43 \\
\hline 16 & 47892,50 & 5,51 & 16 & 56428,19 & 0,00 \\
\hline 17 & 39250,00 & 25,65 & 17 & 50642,27 & 1,31 \\
\hline 18 & 43610,50 & 12,66 & 18 & 60819,18 & 0,00 \\
\hline 19 & 26623,43 & 149,08 & 19 & 64347,47 & 0,00 \\
\hline 20 & 27440,33 & 133,37 & 20 & 76126,76 & 0,00 \\
\hline 21 & 21836,88 & 291,66 & 21 & 54950,25 & 14,85 \\
\hline 22 & 42220,00 & 16,04 & 22 & 72155,04 & 0,30 \\
\hline 23 & 45518,75 & 8,94 & 23 & 73843,58 & 0,10 \\
\hline 24 & 36208,00 & 40,08 & 24 & 54481,00 & 15,79 \\
\hline 25 & 49822,50 & 3,49 & 25 & 63715,30 & 3,79 \\
\hline 26 & 38095,35 & 30,49 & 26 & 79858,24 & 0,00 \\
\hline 27 & 51751,75 & 2,03 & 27 & 72202,50 & 1,12 \\
\hline 28 & 64402,30 & 0,00 & 28 & 70880,50 & 1,60 \\
\hline 29 & 37774,00 & 49,69 & 29 & 93538,50 & 0,00 \\
\hline 30 & 36783,95 & 56,37 & 30 & 92194,96 & 0,02 \\
\hline 31 & 41101,20 & 32,14 & 31 & 87542,26 & 0,47 \\
\hline 32 & 41276,03 & 31,39 & 32 & 82968,77 & 1,62 \\
\hline 33 & 54756,00 & 3,10 & 33 & 82266,27 & 1,88 \\
\hline 34 & 43444,13 & 23,27 & 34 & 84390,82 & 1,18 \\
\hline 35 & 52560,00 & 5,08 & 35 & 80605,98 & 2,57 \\
\hline
\end{tabular}


Tabela 36. Resultados do modelo Varian, amostras Brasil e Minas, orientação produto. Observações ordenadas pelo custo de forma crescente.

\begin{tabular}{|c|c|c|c|c|c|}
\hline \multicolumn{3}{|c|}{ Brasil } & \multicolumn{3}{|c|}{ Minas Gerais } \\
\hline Observação & $Y$ observado & Residual x 100 & Observação & $Y$ observado & Residual x 100 \\
\hline 36 & 67105,00 & 0,00 & 36 & 91338,95 & 0,06 \\
\hline 37 & 52369,48 & 7,92 & 37 & 80219,26 & 2,76 \\
\hline 38 & 38343,75 & 56,26 & 38 & 87480,33 & 0,48 \\
\hline 39 & 80000,00 & 0,00 & 39 & 92828,20 & 0,01 \\
\hline 40 & 54681,25 & 21,44 & 40 & 75787,76 & 5,49 \\
\hline 41 & 74914,50 & 0,46 & 41 & 73419,02 & 7,51 \\
\hline 42 & 47158,00 & 48,50 & 42 & 128984,50 & 0,00 \\
\hline 43 & 64237,50 & 6,02 & 43 & 85763,41 & 25,40 \\
\hline 44 & 52558,00 & 27,26 & 44 & 102865,87 & 6,45 \\
\hline 45 & 66334,19 & 4,24 & 45 & 106138,03 & 4,63 \\
\hline 46 & 66068,15 & 4,45 & 46 & 94031,48 & 13,82 \\
\hline 47 & 35549,74 & 156,34 & 47 & 120387,45 & 0,51 \\
\hline 48 & 57487,50 & 15,34 & 48 & 91791,96 & 16,42 \\
\hline 49 & 35897,50 & 150,94 & 49 & 105733,25 & 4,84 \\
\hline 50 & 54604,00 & 21,63 & 50 & 88018,00 & 21,66 \\
\hline 51 & 47520,00 & 46,72 & 51 & 126851,04 & 0,03 \\
\hline 52 & 52168,13 & 28,46 & 52 & 136729,53 & 0,00 \\
\hline 53 & 57700,46 & 14,94 & 53 & 157254,00 & 0,00 \\
\hline 54 & 51347,20 & 31,14 & 54 & 91784,64 & 50,88 \\
\hline 55 & 31048,00 & 248,58 & 55 & 145238,99 & 0,68 \\
\hline 56 & 63769,40 & 6,48 & 56 & 123338,70 & 7,56 \\
\hline 57 & 40047,50 & 99,53 & 57 & 154373,36 & 0,03 \\
\hline 58 & 42796,25 & 75,57 & 58 & 133041,67 & 3,31 \\
\hline 59 & 51322,50 & 31,22 & 59 & 146057,44 & 0,59 \\
\hline 60 & 127332,88 & 0,00 & 60 & 111330,41 & 17,02 \\
\hline 61 & 53757,00 & 187,33 & 61 & 138422,52 & 1,85 \\
\hline 62 & 108496,25 & 3,01 & 62 & 166947,47 & 0,00 \\
\hline 63 & 67847,50 & 76,87 & 63 & 154465,25 & 0,65 \\
\hline 64 & 63324,25 & 102,17 & 64 & 139085,24 & 4,01 \\
\hline 65 & 70851,25 & 63,55 & 65 & 139085,24 & 4,01 \\
\hline 66 & 42911,00 & 387,06 & 66 & 164692,10 & 0,02 \\
\hline 67 & 93100,00 & 13,52 & 67 & 185618,94 & 0,00 \\
\hline 68 & 67993,75 & 76,16 & 68 & 196322,50 & 0,00 \\
\hline 69 & 177881,25 & 0,00 & 69 & 146334,60 & 11,67 \\
\hline 70 & 51016,66 & 618,38 & 70 & 152667,39 & 8,18 \\
\hline 71 & 58400,00 & 418,57 & 71 & 156104,27 & 6,64 \\
\hline 72 & 130080,00 & 13,50 & 72 & 156405,13 & 6,51 \\
\hline 73 & 89227,74 & 98,72 & 73 & 140700,00 & 15,63 \\
\hline 74 & 50803,44 & 625,68 & 74 & 161661,55 & 4,60 \\
\hline
\end{tabular}


Tabela 36. Resultados do modelo Varian, amostras Brasil e Minas, orientação produto. Observações ordenadas pelo custo de forma crescente.

\begin{tabular}{|c|c|c|c|c|c|}
\hline \multicolumn{3}{|c|}{ Brasil } & \multicolumn{3}{|c|}{ Minas Gerais } \\
\hline Observação & $Y$ observado & Residual x 100 & Observação & $Y$ observado & Residual x 100 \\
\hline 75 & 70080,00 & 236,62 & 75 & 166122,71 & 3,30 \\
\hline 76 & 63829,75 & 319,27 & 76 & 167954,75 & 2,85 \\
\hline 77 & 45390,00 & 852,03 & 77 & 184982,67 & 0,38 \\
\hline 78 & 116241,25 & 28,12 & 78 & 191122,28 & 0,07 \\
\hline 79 & 96618,75 & 70,74 & 79 & 203670,37 & 0,00 \\
\hline 80 & 58622,50 & 413,86 & 80 & 208775,10 & 0,00 \\
\hline 81 & 97889,38 & 66,78 & 81 & 194831,92 & 0,51 \\
\hline 82 & 97318,13 & 68,53 & 82 & 172352,63 & 4,47 \\
\hline 83 & 77181,75 & 170,22 & 83 & 171576,10 & 4,70 \\
\hline 84 & 69350,00 & 244,91 & 84 & 266876,34 & 0,00 \\
\hline 85 & 95785,31 & 73,46 & 85 & 224128,49 & 3,64 \\
\hline 86 & 91647,50 & 88,53 & 86 & 219979,08 & 4,54 \\
\hline 87 & 66766,25 & 276,97 & 87 & 185775,10 & 19,06 \\
\hline 88 & 109780,00 & 38,48 & 88 & 245743,31 & 0,74 \\
\hline 89 & 117983,13 & 25,77 & 89 & 234525,57 & 1,90 \\
\hline 90 & 181770,00 & 0,00 & 90 & 263338,42 & 0,02 \\
\hline 91 & 123100,00 & 22,72 & 91 & 254883,85 & 0,22 \\
\hline 92 & 125421,50 & 20,18 & 92 & 309144,64 & 0,00 \\
\hline 93 & 118560,00 & 28,42 & 93 & 297403,62 & 0,16 \\
\hline 94 & 150350,00 & 4,37 & 94 & 258822,45 & 3,78 \\
\hline 95 & 108646,07 & 45,30 & 95 & 289547,89 & 0,46 \\
\hline 96 & 153947,50 & 3,27 & 96 & 293529,47 & 0,28 \\
\hline 97 & 110827,22 & 40,98 & 97 & 308599,87 & 0,00 \\
\hline 98 & 81030,00 & 154,57 & 98 & 335800,00 & 0,00 \\
\hline 99 & 112742,19 & 37,49 & 99 & 352610,90 & 0,00 \\
\hline 100 & 88375,63 & 111,68 & 100 & 329997,84 & 0,47 \\
\hline 101 & 43800,00 & 992,25 & 101 & 289414,62 & 4,77 \\
\hline 102 & 159060,00 & 2,04 & 102 & 336463,45 & 0,23 \\
\hline 103 & 160757,50 & 1,71 & 103 & 380911,79 & 0,00 \\
\hline 104 & 106251,50 & 50,52 & 104 & 411157,95 & 0,00 \\
\hline 105 & 160070,00 & 1,84 & 105 & 372158,81 & 1,10 \\
\hline 106 & 117535,60 & 29,87 & 106 & 410695,02 & 0,00 \\
\hline 107 & 149439,50 & 4,68 & 107 & 536088,70 & 0,00 \\
\hline 108 & 140525,00 & 8,61 & 108 & 480087,43 & 1,36 \\
\hline 109 & 136892,50 & 10,75 & 109 & 634186,06 & 0,00 \\
\hline 110 & 136875,00 & 10,76 & 110 & 713408,00 & 0,00 \\
\hline 111 & 138100,00 & 10,00 & 111 & 804622,27 & 0,00 \\
\hline 112 & 184690,00 & 0,00 & 112 & 1009272,59 & 0,00 \\
\hline 113 & 76497,93 & 200,03 & 113 & 707085,86 & 18,26 \\
\hline
\end{tabular}


Tabela 36. Resultados do modelo Varian, amostras Brasil e Minas, orientação produto. Observações ordenadas pelo custo de forma crescente.

\begin{tabular}{|c|c|c|c|c|c|}
\hline \multicolumn{3}{|c|}{ Brasil } & \multicolumn{3}{|c|}{ Minas Gerais } \\
\hline Observação & $Y$ observado & Residual x 100 & Observação & $Y$ observado & Residual x 100 \\
\hline 114 & 120300,00 & 28,65 & 114 & 1100187,57 & 0,00 \\
\hline 115 & 154550,00 & 3,80 & SOMA & & 305 \\
\hline 116 & 182257,50 & 0,16 & DUVAA & & ה נור, \\
\hline 117 & 233321,00 & 0,00 & & & \\
\hline 118 & 234200,00 & 0,00 & & & \\
\hline 119 & 110325,00 & 126,07 & & & \\
\hline 120 & 224510,00 & 0,19 & & & \\
\hline 121 & 178469,37 & 9,75 & & & \\
\hline 122 & 180645,00 & 8,79 & & & \\
\hline 123 & 157353,82 & 23,85 & & & \\
\hline 124 & 220727,38 & 0,37 & & & \\
\hline 125 & 150142,75 & 31,34 & & & \\
\hline 126 & 187615,00 & 6,17 & & & \\
\hline 127 & 199158,41 & 3,10 & & & \\
\hline 128 & 99918,75 & 180,61 & & & \\
\hline 129 & 179231,25 & 9,41 & & & \\
\hline 130 & 269887,25 & 0,00 & & & \\
\hline 131 & 237266,40 & 1,89 & & & \\
\hline 132 & 216615,00 & 6,05 & & & \\
\hline 133 & 308640,00 & 0,00 & & & \\
\hline 134 & 210656,25 & 21,64 & & & \\
\hline 135 & 317300,38 & 0,64 & & & \\
\hline 136 & 327900,00 & 0,66 & & & \\
\hline 137 & 390400,00 & 0,75 & & & \\
\hline 138 & 588827,75 & 0,89 & & & \\
\hline 139 & 765664,80 & 0,93 & & & \\
\hline 140 & 885776,25 & 0,00 & & & \\
\hline 141 & 454675,00 & 89,90 & & & \\
\hline 142 & 466575,00 & 80,72 & & & \\
\hline 143 & 698256,25 & 7,21 & & & \\
\hline SOMA & & 104,92 & & & \\
\hline
\end{tabular}

Fonte: Resultados da pesquisa. 
Tabela 37. Resultados das eficiências técnicas para as amostra Brasil e Minas Gerais, obtidas pelo método de fronteira estocástica. Observações ordenadas pela renda bruta de forma crescente.

\begin{tabular}{|c|c|c|c|c|c|}
\hline \multicolumn{3}{|c|}{ Brasil } & \multicolumn{3}{|c|}{ Minas Gerais } \\
\hline Observações & Renda Bruta & $\begin{array}{c}\text { Eficiência } \\
\text { Técnica }\end{array}$ & Observações & Renda Bruta & $\begin{array}{c}\text { Eficiência } \\
\text { Técnica }\end{array}$ \\
\hline 1 & 21231,75 & 0,9254 & 1 & 14192,44 & 0,9759 \\
\hline 2 & 21836,88 & 0,8239 & 2 & 16979,42 & 0,9766 \\
\hline 3 & 24359,25 & 0,9143 & 3 & 26844,85 & 0,9733 \\
\hline 4 & 25683,39 & 0,8885 & 4 & 27020,28 & 0,9733 \\
\hline 5 & 25866,76 & 0,8924 & 5 & 28061,85 & 0,9774 \\
\hline 6 & 26623,43 & 0,8728 & 6 & 39010,32 & 0,9783 \\
\hline 7 & 26718,00 & 0,8957 & 7 & 39617,30 & 0,9761 \\
\hline 8 & 27010,00 & 0,9164 & 8 & 41359,27 & 0,9745 \\
\hline 9 & 27440,33 & 0,8843 & 9 & 41902,00 & 0,9815 \\
\hline 10 & 28203,50 & 0,9093 & 10 & 44369,77 & 0,9789 \\
\hline 11 & 30506,56 & 0,9010 & 11 & 45022,85 & 0,9758 \\
\hline 12 & 30574,50 & 0,9207 & 12 & 45621,73 & 0,9782 \\
\hline 13 & 31048,00 & 0,8546 & 13 & 48458,49 & 0,9799 \\
\hline 14 & 31072,50 & 0,9317 & 14 & 49137,60 & 0,9767 \\
\hline 15 & 31536,00 & 0,9153 & 15 & 50405,99 & 0,9812 \\
\hline 16 & 33131,25 & 0,8642 & 16 & 50642,27 & 0,9759 \\
\hline 17 & 33358,00 & 0,9288 & 17 & 54481,00 & 0,9753 \\
\hline 18 & 35549,74 & 0,8462 & 18 & 54950,25 & 0,9722 \\
\hline 19 & 35897,50 & 0,8598 & 19 & 56428,19 & 0,9789 \\
\hline 20 & 36208,00 & 0,9157 & 20 & 60819,18 & 0,9780 \\
\hline 21 & 36783,95 & 0,9060 & 21 & 63715,30 & 0,9736 \\
\hline 22 & 37774,00 & 0,9187 & 22 & 64347,47 & 0,9780 \\
\hline 23 & 38095,35 & 0,9275 & 23 & 70880,50 & 0,9778 \\
\hline 24 & 38343,75 & 0,8866 & 24 & 72155,04 & 0,9775 \\
\hline 25 & 39250,00 & 0,8874 & 25 & 72202,50 & 0,9783 \\
\hline 26 & 40047,50 & 0,9072 & 26 & 73419,02 & 0,9743 \\
\hline 27 & 40644,00 & 0,9373 & 27 & 73843,58 & 0,9779 \\
\hline 28 & 41101,20 & 0,9074 & 28 & 75787,76 & 0,9727 \\
\hline 29 & 41276,03 & 0,9205 & 29 & 76126,76 & 0,9793 \\
\hline 30 & 42220,00 & 0,8615 & 30 & 79858,24 & 0,9774 \\
\hline 31 & 42796,25 & 0,8674 & 31 & 80219,26 & 0,9750 \\
\hline 32 & 42911,00 & 0,8600 & 32 & 80605,98 & 0,9758 \\
\hline 33 & 43444,13 & 0,9198 & 33 & 82266,27 & 0,9766 \\
\hline 34 & 43610,50 & 0,8807 & 34 & 82968,77 & 0,9776 \\
\hline
\end{tabular}


Tabela 37. Resultados das eficiências técnicas para as amostra Brasil e Minas Gerais, obtidas pelo método de fronteira estocástica. Observações ordenadas pela renda bruta de forma crescente.

\begin{tabular}{|c|c|c|c|c|c|}
\hline \multicolumn{3}{|c|}{ Brasil } & \multicolumn{3}{|c|}{ Minas Gerais } \\
\hline Observações & Renda Bruta & $\begin{array}{l}\text { Eficiência } \\
\text { Técnica }\end{array}$ & Observações & Renda Bruta & $\begin{array}{c}\text { Eficiência } \\
\text { Técnica }\end{array}$ \\
\hline 35 & 43800,00 & 0,7340 & 35 & 84390,82 & 0,9782 \\
\hline 36 & 45390,00 & 0,8872 & 36 & 85763,41 & 0,9750 \\
\hline 37 & 45518,75 & 0,8921 & 37 & 87480,33 & 0,9771 \\
\hline 38 & 47158,00 & 0,9104 & 38 & 87542,26 & 0,9777 \\
\hline 39 & 47520,00 & 0,9067 & 39 & 88018,00 & 0,9731 \\
\hline 40 & 47892,50 & 0,9276 & 40 & 91338,95 & 0,9778 \\
\hline 41 & 49822,50 & 0,8913 & 41 & 91784,64 & 0,9711 \\
\hline 42 & 50803,44 & 0,8568 & 42 & 91791,96 & 0,9751 \\
\hline 43 & 51016,66 & 0,8927 & 43 & 92194,96 & 0,9788 \\
\hline 44 & 51322,50 & 0,9275 & 44 & 92828,20 & 0,9775 \\
\hline 45 & 51347,20 & 0,9036 & 45 & 93538,50 & 0,9795 \\
\hline 46 & 51751,75 & 0,9001 & 46 & 94031,48 & 0,9758 \\
\hline 47 & 52168,13 & 0,9083 & 47 & 102865,87 & 0,9775 \\
\hline 48 & 52369,48 & 0,8874 & 48 & 105733,25 & 0,9769 \\
\hline 49 & 52558,00 & 0,9376 & 49 & 106138,03 & 0,9779 \\
\hline 50 & 52560,00 & 0,8928 & 50 & 111330,41 & 0,9731 \\
\hline 51 & 53757,00 & 0,9081 & 51 & 120387,45 & 0,9793 \\
\hline 52 & 54604,00 & 0,9172 & 52 & 123338,70 & 0,9767 \\
\hline 53 & 54681,25 & 0,8648 & 53 & 126851,04 & 0,9787 \\
\hline 54 & 54756,00 & 0,8974 & 54 & 128984,50 & 0,9813 \\
\hline 55 & 57487,50 & 0,8611 & 55 & 133041,67 & 0,9774 \\
\hline 56 & 57700,46 & 0,9198 & 56 & 136729,53 & 0,9804 \\
\hline 57 & 58400,00 & 0,8923 & 57 & 138422,52 & 0,9776 \\
\hline 58 & 58622,50 & 0,8619 & 58 & 139085,24 & 0,9761 \\
\hline 59 & 59130,00 & 0,9306 & 59 & 139085,24 & 0,9760 \\
\hline 60 & 63324,25 & 0,9216 & 60 & 140700,00 & 0,9726 \\
\hline 61 & 63769,40 & 0,8650 & 61 & 145238,99 & 0,9793 \\
\hline 62 & 63829,75 & 0,8971 & 62 & 146057,44 & 0,9783 \\
\hline 63 & 64237,50 & 0,9061 & 63 & 146334,60 & 0,9758 \\
\hline 64 & 64402,30 & 0,9190 & 64 & 152667,39 & 0,9768 \\
\hline 65 & 66068,15 & 0,8958 & 65 & 154373,36 & 0,9796 \\
\hline 66 & 66334,19 & 0,9175 & 66 & 154465,25 & 0,9794 \\
\hline 67 & 66766,25 & 0,8643 & 67 & 156104,27 & 0,9752 \\
\hline 68 & 67105,00 & 0,9221 & 68 & 156405,13 & 0,9782 \\
\hline 69 & 67847,50 & 0,8608 & 69 & 157254,00 & 0,9811 \\
\hline 70 & 67993,75 & 0,9232 & 70 & 161661,55 & 0,9753 \\
\hline 71 & 69350,00 & 0,8691 & 71 & 164692,10 & 0,9794 \\
\hline 72 & 70080,00 & 0,9047 & 72 & 166122,71 & 0,9755 \\
\hline 73 & 70851,25 & 0,8695 & 73 & 166947,47 & 0,9811 \\
\hline 74 & 74914,50 & 0,9185 & 74 & 167954,75 & 0,9756 \\
\hline 75 & 76497,93 & 0,8261 & 75 & 171576,10 & 0,9714 \\
\hline
\end{tabular}


Tabela 37. Resultados das eficiências técnicas para as amostra Brasil e Minas Gerais, obtidas pelo método de fronteira estocástica. Observações ordenadas pela renda bruta de forma crescente.

\begin{tabular}{|c|c|c|c|c|c|}
\hline \multicolumn{3}{|c|}{ Brasil } & \multicolumn{3}{|c|}{ Minas Gerais } \\
\hline Observações & Renda Bruta & $\begin{array}{l}\text { Eficiência } \\
\text { Técnica }\end{array}$ & Observações & Renda Bruta & $\begin{array}{c}\text { Eficiência } \\
\text { Técnica }\end{array}$ \\
\hline 76 & 77181,75 & 0,8950 & 76 & 172352,63 & 0,9720 \\
\hline 77 & 80000,00 & 0,9236 & 77 & 184982,67 & 0,9766 \\
\hline 78 & 81030,00 & 0,8814 & 78 & 185618,94 & 0,9804 \\
\hline 79 & 88375,63 & 0,9126 & 79 & 185775,10 & 0,9714 \\
\hline 80 & 89227,74 & 0,8796 & 80 & 191122,28 & 0,9760 \\
\hline 81 & 91647,50 & 0,9108 & 81 & 194831,92 & 0,9757 \\
\hline 82 & 93100,00 & 0,9142 & 82 & 196322,50 & 0,9813 \\
\hline 83 & 95785,31 & 0,9263 & 83 & 203670,37 & 0,9773 \\
\hline 84 & 96618,75 & 0,8671 & 84 & 208775,10 & 0,9773 \\
\hline 85 & 97318,13 & 0,8732 & 85 & 219979,08 & 0,9753 \\
\hline 86 & 97889,38 & 0,8691 & 86 & 224128,49 & 0,9760 \\
\hline 87 & 99918,75 & 0,8015 & 87 & 234525,57 & 0,9761 \\
\hline 88 & 106251,50 & 0,9249 & 88 & 245743,31 & 0,9769 \\
\hline 89 & 108496,25 & 0,9318 & 89 & 254883,85 & 0,9770 \\
\hline 90 & 108646,07 & 0,8585 & 90 & 258822,45 & 0,9745 \\
\hline 91 & 109780,00 & 0,8759 & 91 & 263338,42 & 0,9771 \\
\hline 92 & 110325,00 & 0,9025 & 92 & 266876,34 & 0,9788 \\
\hline 93 & 110827,22 & 0,8603 & 93 & 289414,62 & 0,9762 \\
\hline 94 & 112742,19 & 0,8626 & 94 & 289547,89 & 0,9759 \\
\hline 95 & 116241,25 & 0,9147 & 95 & 293529,47 & 0,9761 \\
\hline 96 & 117535,60 & 0,9193 & 96 & 297403,62 & 0,9775 \\
\hline 97 & 117983,13 & 0,8901 & 97 & 308599,87 & 0,9772 \\
\hline 98 & 118560,00 & 0,8954 & 98 & 309144,64 & 0,9786 \\
\hline 99 & 120300,00 & 0,9225 & 99 & 329997,84 & 0,9775 \\
\hline 100 & 123100,00 & 0,8907 & 100 & 335800,00 & 0,9783 \\
\hline 101 & 125421,50 & 0,8841 & 101 & 336463,45 & 0,9768 \\
\hline 102 & 127332,88 & 0,9543 & 102 & 352610,90 & 0,9825 \\
\hline 103 & 130080,00 & 0,9354 & 103 & 372158,81 & 0,9772 \\
\hline 104 & 136875,00 & 0,8528 & 104 & 380911,79 & 0,9800 \\
\hline 105 & 136892,50 & 0,8536 & 105 & 410695,02 & 0,9781 \\
\hline 106 & 138100,00 & 0,9211 & 106 & 411157,95 & 0,9788 \\
\hline 107 & 140525,00 & 0,8861 & 107 & 480087,43 & 0,9754 \\
\hline 108 & 149439,50 & 0,9029 & 108 & 536088,70 & 0,9794 \\
\hline 109 & 150142,75 & 0,9052 & 109 & 634186,06 & 0,9781 \\
\hline 110 & 150350,00 & 0,9074 & 110 & 707085,86 & 0,9727 \\
\hline 111 & 153947,50 & 0,9132 & 111 & 713408,00 & 0,9769 \\
\hline 112 & 154550,00 & 0,8752 & 112 & 804622,27 & 0,9794 \\
\hline 113 & 157353,82 & 0,9184 & 113 & 1009272,59 & 0,9797 \\
\hline 114 & 159060,00 & 0,9106 & 114 & 1100187,57 & 0,9793 \\
\hline 115 & 160070,00 & 0,9111 & & & \\
\hline 116 & 160757,50 & 0,9046 & & & \\
\hline
\end{tabular}


Tabela 37. Resultados das eficiências técnicas para as amostra Brasil e Minas Gerais, obtidas pelo método de fronteira estocástica. Observações ordenadas pela renda bruta de forma crescente.

\begin{tabular}{|c|c|c|c|c|c|}
\hline \multicolumn{3}{|c|}{ Brasil } & \multicolumn{3}{|c|}{ Minas Gerais } \\
\hline Observações & Renda Bruta & $\begin{array}{l}\text { Eficiência } \\
\text { Técnica }\end{array}$ & Observações & Renda Bruta & $\begin{array}{l}\text { Eficiência } \\
\text { Técnica }\end{array}$ \\
\hline 117 & 177881,25 & 0,9559 & & & \\
\hline 118 & 178469,37 & 0,8833 & & & \\
\hline 119 & 179231,25 & 0,9109 & & & \\
\hline 120 & 180645,00 & 0,8730 & & & \\
\hline 121 & 181770,00 & 0,9359 & & & \\
\hline 122 & 182257,50 & 0,9113 & & & \\
\hline 123 & 184690,00 & 0,9102 & & & \\
\hline 124 & 187615,00 & 0,9217 & & & \\
\hline 125 & 199158,41 & 0,9300 & & & \\
\hline 126 & 210656,25 & 0,9022 & & & \\
\hline 127 & 216615,00 & 0,9328 & & & \\
\hline 128 & 220727,38 & 0,8977 & & & \\
\hline 129 & 224510,00 & 0,9250 & & & \\
\hline 130 & 233321,00 & 0,9352 & & & \\
\hline 131 & 234200,00 & 0,9184 & & & \\
\hline 132 & 237266,40 & 0,8666 & & & \\
\hline 133 & 269887,25 & 0,8916 & & & \\
\hline 134 & 308640,00 & 0,9015 & & & \\
\hline 135 & 317300,38 & 0,8911 & & & \\
\hline 136 & 327900,00 & 0,8937 & & & \\
\hline 137 & 390400,00 & 0,8995 & & & \\
\hline 138 & 454675,00 & 0,9402 & & & \\
\hline 139 & 466575,00 & 0,9286 & & & \\
\hline 140 & 588827,75 & 0,9309 & & & \\
\hline 141 & 698256,25 & 0,8928 & & & \\
\hline 142 & 765664,80 & 0,9447 & & & \\
\hline 143 & 885776,25 & 0,9420 & & & \\
\hline
\end{tabular}

Fonte: Resultados da pesquisa. 
Tabela 38. Resultados obtidos pelo método DEA, orientação insumo, para a amostra Brasil. Observações ordenadas pela renda bruta de forma crescente.

\begin{tabular}{|c|c|c|c|c|c|c|}
\hline Observ ações & $\begin{array}{c}\mathrm{ET} \\
\mathrm{R} \text { constante }\end{array}$ & $\begin{array}{c}\text { ET } \\
\text { R variável. }\end{array}$ & $\begin{array}{l}\text { Eficiência } \\
\text { escala }\end{array}$ & $\begin{array}{c}\text { Retornoà } \\
\text { escala }\end{array}$ & $\begin{array}{l}\text { Eficiência } \\
\text { Alocativa }\end{array}$ & $\begin{array}{l}\text { Eficiência } \\
\text { Econômica }\end{array}$ \\
\hline 1 & 0,40 & 0,72 & 0,56 & crescente & 0,75 & 0,30 \\
\hline 2 & 0,23 & 0,70 & 0,33 & crescente & 0,89 & 0,21 \\
\hline 3 & 0,26 & 0,54 & 0,49 & crescente & 0,89 & 0,24 \\
\hline 4 & 0,21 & 0,65 & 0,33 & crescente & 0,99 & 0,21 \\
\hline 5 & 0,44 & 0,81 & 0,54 & crescente & 0,94 & 0,41 \\
\hline 6 & 0,20 & 0,55 & 0,36 & crescente & 0,93 & 0,18 \\
\hline 7 & 0,42 & 1,00 & 0,42 & crescente & 0,60 & 0,25 \\
\hline 8 & 0,33 & 1,00 & 0,33 & crescente & 0,83 & 0,27 \\
\hline 9 & 0,25 & 0,60 & 0,41 & crescente & 0,90 & 0,22 \\
\hline 10 & 0,28 & 0,53 & 0,52 & crescente & 0,90 & 0,25 \\
\hline 11 & 0,84 & 0,94 & 0,89 & crescente & 0,83 & 0,70 \\
\hline 12 & 0,89 & 1,00 & 0,89 & crescente & 0,84 & 0,75 \\
\hline 13 & 0,11 & 0,35 & 0,31 & crescente & 0,86 & 0,09 \\
\hline 14 & 0,69 & 1,00 & 0,69 & crescente & 0,80 & 0,56 \\
\hline 15 & 0,35 & 0,65 & 0,53 & crescente & 0,82 & 0,28 \\
\hline 16 & 0,33 & 0,77 & 0,43 & crescente & 1,00 & 0,33 \\
\hline 17 & 0,58 & 1,00 & 0,58 & crescente & 0,83 & 0,49 \\
\hline 26 & 0,28 & 0,41 & 0,67 & crescente & 0,88 & 0,24 \\
\hline 27 & 1,00 & 1,00 & 1,00 & constante & 0,68 & 0,68 \\
\hline 28 & 0,30 & 0,68 & 0,45 & crescente & 0,94 & 0,28 \\
\hline 29 & 0,25 & 0,40 & 0,61 & crescente & 0,89 & 0,22 \\
\hline 30 & 0,49 & 0,75 & 0,65 & crescente & 0,85 & 0,41 \\
\hline 31 & 0,40 & 1,00 & 0,40 & crescente & 0,62 & 0,25 \\
\hline 32 & 0,19 & 0,30 & 0,65 & crescente & 0,84 & 0,16 \\
\hline 33 & 0,27 & 0,44 & 0,60 & crescente & 0,94 & 0,25 \\
\hline 34 & 0,46 & 0,70 & 0,65 & crescente & 0,96 & 0,44 \\
\hline 35 & 0,13 & 0,19 & 0,65 & crescente & 0,87 & 0,11 \\
\hline 36 & 0,12 & 0,35 & 0,33 & crescente & 0,66 & 0,08 \\
\hline 37 & 0,36 & 0,44 & 0,81 & crescente & 0,90 & 0,33 \\
\hline 38 & 0,25 & 0,40 & 0,63 & crescente & 0,84 & 0,21 \\
\hline 39 & 0,36 & 0,85 & 0,43 & crescente & 0,82 & 0,29 \\
\hline 40 & 0,32 & 0,43 & 0,74 & crescente & 0,80 & 0,26 \\
\hline 41 & 0,35 & 0,54 & 0,65 & crescente & 0,98 & 0,34 \\
\hline 42 & 0,21 & 0,37 & 0,58 & crescente & 0,77 & 0,16 \\
\hline 43 & 0,39 & 0,50 & 0,79 & crescente & 0,91 & 0,36 \\
\hline 44 & 0,22 & 0,29 & 0,77 & crescente & 0,90 & 0,20 \\
\hline 45 & 0,34 & 0,49 & 0,69 & crescente & 0,93 & 0,31 \\
\hline 46 & 0,56 & 0,63 & 0,89 & crescente & 0,76 & 0,43 \\
\hline 47 & 0,36 & 0,77 & 0,47 & crescente & 0,72 & 0,26 \\
\hline 48 & 0,32 & 0,38 & 0,85 & crescente & 0,89 & 0,28 \\
\hline 49 & 0,38 & 0,74 & 0,52 & crescente & 0,52 & 0,20 \\
\hline 50 & 0,87 & 1,00 & 0,87 & crescente & 0,89 & 0,77 \\
\hline 51 & 0,29 & 0,40 & 0,71 & crescente & 0,86 & 0,25 \\
\hline 52 & 0,32 & 0,59 & 0,55 & crescente & 0,83 & 0,27 \\
\hline 53 & 0,43 & 0,64 & 0,67 & crescente & 0,96 & 0,41 \\
\hline
\end{tabular}


Tabela 38. Resultados obtidos pelo método DEA, orientação insumo, para a amostra Brasil. Observações ordenadas pela renda bruta de forma crescente.

\begin{tabular}{|c|c|c|c|c|c|c|}
\hline Observ ações & $\begin{array}{c}\mathrm{ET} \\
\mathrm{R} \text { constante }\end{array}$ & $\begin{array}{c}\text { ET } \\
\text { R variável. }\end{array}$ & $\begin{array}{c}\text { Eficiência } \\
\text { escala }\end{array}$ & $\begin{array}{c}\text { Retornoà } \\
\text { escala }\end{array}$ & $\begin{array}{l}\text { Eficiência } \\
\text { Alocativa }\end{array}$ & $\begin{array}{l}\text { Eficiência } \\
\text { Econômica }\end{array}$ \\
\hline 54 & 0,30 & 0,43 & 0,70 & crescente & 0,84 & 0,26 \\
\hline 55 & 0,47 & 0,65 & 0,73 & crescente & 0,95 & 0,45 \\
\hline 56 & 0,65 & 1,00 & 0,65 & crescente & 0,71 & 0,46 \\
\hline 57 & 0,41 & 0,63 & 0,65 & crescente & 0,84 & 0,34 \\
\hline 58 & 0,23 & 0,41 & 0,57 & crescente & 1,00 & 0,23 \\
\hline 59 & 0,93 & 1,00 & 0,93 & crescente & 0,71 & 0,66 \\
\hline 60 & 0,42 & 0,61 & 0,68 & crescente & 0,99 & 0,41 \\
\hline 61 & 0,62 & 0,93 & 0,67 & crescente & 0,61 & 0,38 \\
\hline 62 & 0,52 & 0,60 & 0,86 & crescente & 0,93 & 0,48 \\
\hline 63 & 0,77 & 0,80 & 0,97 & crescente & 0,85 & 0,66 \\
\hline 64 & 0,75 & 0,90 & 0,84 & crescente & 0,95 & 0,71 \\
\hline 65 & 0,60 & 0,71 & 0,85 & crescente & 0,92 & 0,55 \\
\hline 66 & 0,78 & 0,93 & 0,84 & crescente & 0,80 & 0,62 \\
\hline 67 & 0,15 & 0,27 & 0,54 & crescente & 0,89 & 0,13 \\
\hline 68 & 0,45 & 0,56 & 0,80 & crescente & 0,88 & 0,39 \\
\hline 69 & 0,46 & 0,54 & 0,85 & crescente & 0,94 & 0,43 \\
\hline 70 & 0,36 & 0,70 & 0,51 & crescente & 0,74 & 0,27 \\
\hline 71 & 0,31 & 0,37 & 0,83 & crescente & 0,70 & 0,22 \\
\hline 72 & 0,57 & 0,65 & 0,88 & crescente & 0,84 & 0,48 \\
\hline 73 & 0,49 & 0,62 & 0,79 & crescente & 0,91 & 0,45 \\
\hline 74 & 0,71 & 0,74 & 0,97 & crescente & 0,86 & 0,61 \\
\hline 75 & 0,34 & 0,56 & 0,61 & crescente & 0,68 & 0,23 \\
\hline 76 & 0,81 & 1,00 & 0,81 & crescente & 0,27 & 0,22 \\
\hline 77 & 0,57 & 0,71 & 0,81 & crescente & 0,85 & 0,48 \\
\hline 78 & 0,40 & 0,53 & 0,75 & crescente & 0,43 & 0,17 \\
\hline 79 & 0,60 & 0,77 & 0,78 & crescente & 0,74 & 0,44 \\
\hline 80 & 0,64 & 0,76 & 0,85 & crescente & 0,96 & 0,62 \\
\hline 81 & 0,28 & 0,42 & 0,67 & crescente & 0,71 & 0,20 \\
\hline 82 & 0,85 & 0,87 & 0,98 & crescente & 0,83 & 0,70 \\
\hline 83 & 0,60 & 0,67 & 0,90 & crescente & 0,91 & 0,55 \\
\hline 84 & 0,34 & 0,44 & 0,77 & crescente & 0,99 & 0,33 \\
\hline 85 & 0,56 & 0,62 & 0,91 & crescente & 0,94 & 0,53 \\
\hline 86 & 0,49 & 0,55 & 0,89 & crescente & 0,92 & 0,45 \\
\hline 87 & 0,16 & 0,19 & 0,88 & crescente & 0,98 & 0,16 \\
\hline 88 & 0,33 & 0,48 & 0,69 & crescente & 0,43 & 0,14 \\
\hline 89 & 1,00 & 1,00 & 1,00 & constante & 0,41 & 0,41 \\
\hline 90 & 0,52 & 0,56 & 0,94 & crescente & 0,91 & 0,47 \\
\hline 91 & 0,45 & 0,52 & 0,86 & crescente & 0,50 & 0,22 \\
\hline 92 & 0,39 & 0,42 & 0,92 & crescente & 0,44 & 0,17 \\
\hline 93 & 0,42 & 0,45 & 0,94 & crescente & 0,79 & 0,33 \\
\hline 94 & 0,60 & 0,64 & 0,94 & crescente & 0,81 & 0,49 \\
\hline 95 & 0,63 & 0,68 & 0,92 & crescente & 0,97 & 0,61 \\
\hline 96 & 0,57 & 0,59 & 0,98 & crescente & 0,97 & 0,56 \\
\hline 97 & 0,49 & 0,54 & 0,91 & crescente & 0,54 & 0,26 \\
\hline 98 & 0,42 & 0,45 & 0,95 & crescente & 0,84 & 0,36 \\
\hline
\end{tabular}


Tabela 38. Resultados obtidos pelo método DEA, orientação insumo, para a amostra Brasil. Observações ordenadas pela renda bruta de forma crescente.

\begin{tabular}{|c|c|c|c|c|c|c|}
\hline Observ ações & $\begin{array}{c}\mathrm{ET} \\
\mathrm{R} \text { constante }\end{array}$ & $\begin{array}{c}\text { ET } \\
\text { R variável. }\end{array}$ & $\begin{array}{c}\text { Eficiência } \\
\text { escala }\end{array}$ & $\begin{array}{c}\text { Retornoà } \\
\text { escala }\end{array}$ & $\begin{array}{l}\text { Eficiência } \\
\text { Alocativa }\end{array}$ & $\begin{array}{l}\text { Eficiência } \\
\text { Econômica }\end{array}$ \\
\hline 99 & 0,76 & 1,00 & 0,76 & crescente & 0,61 & 0,46 \\
\hline 100 & 0,75 & 0,83 & 0,92 & crescente & 0,89 & 0,67 \\
\hline 101 & 0,62 & 0,78 & 0,79 & crescente & 0,59 & 0,36 \\
\hline 102 & 0,61 & 0,62 & 0,99 & crescente & 0,72 & 0,44 \\
\hline 103 & 0,67 & 0,69 & 0,98 & crescente & 0,66 & 0,44 \\
\hline 104 & 0,45 & 0,48 & 0,93 & crescente & 0,84 & 0,38 \\
\hline 105 & 0,44 & 0,46 & 0,94 & crescente & 1,00 & 0,44 \\
\hline 106 & 0,31 & 0,40 & 0,77 & crescente & 0,82 & 0,26 \\
\hline 107 & 0,60 & 0,64 & 0,93 & crescente & 0,54 & 0,32 \\
\hline 108 & 0,30 & 0,31 & 0,97 & crescente & 0,96 & 0,29 \\
\hline 109 & 0,56 & 0,56 & 1,00 & crescente & 0,94 & 0,52 \\
\hline 110 & 0,65 & 0,69 & 0,93 & crescente & 0,84 & 0,54 \\
\hline 111 & 0,51 & 0,51 & 1,00 & crescente & 0,99 & 0,50 \\
\hline 112 & 0,61 & 0,63 & 0,97 & crescente & 0,84 & 0,51 \\
\hline 113 & 0,58 & 0,58 & 0,99 & crescente & 0,92 & 0,53 \\
\hline 114 & 0,61 & 0,73 & 0,83 & crescente & 0,76 & 0,46 \\
\hline 115 & 0,83 & 0,88 & 0,95 & crescente & 0,87 & 0,72 \\
\hline 116 & 0,31 & 0,34 & 0,93 & crescente & 0,94 & 0,30 \\
\hline 117 & 1,00 & 1,00 & 1,00 & constante & 1,00 & 1,00 \\
\hline 118 & 0,91 & 0,91 & 1,00 & constante & 0,83 & 0,75 \\
\hline 119 & 0,75 & 0,75 & 1,00 & crescente & 0,77 & 0,57 \\
\hline 120 & 0,73 & 0,76 & 0,96 & crescente & 0,84 & 0,61 \\
\hline 121 & 0,89 & 0,91 & 0,98 & crescente & 0,89 & 0,79 \\
\hline 122 & 0,49 & 0,50 & 0,97 & crescente & 0,44 & 0,22 \\
\hline 123 & 1,00 & 1,00 & 1,00 & constante & 0,65 & 0,65 \\
\hline 124 & 0,53 & 0,55 & 0,96 & crescente & 0,84 & 0,45 \\
\hline 125 & 0,53 & 0,56 & 0,95 & crescente & 0,58 & 0,31 \\
\hline 126 & 0,57 & 0,57 & 1,00 & constante & 0,85 & 0,49 \\
\hline 127 & 0,58 & 0,60 & 0,97 & crescente & 0,26 & 0,15 \\
\hline 128 & 0,52 & 0,52 & 1,00 & constante & 0,89 & 0,47 \\
\hline 129 & 1,00 & 1,00 & 1,00 & constante & 0,57 & 0,57 \\
\hline 130 & 0,65 & 0,68 & 0,96 & crescente & 0,42 & 0,27 \\
\hline 131 & 1,00 & 1,00 & 1,00 & constante & 0,57 & 0,57 \\
\hline 132 & 1,00 & 1,00 & 1,00 & constante & 0,52 & 0,52 \\
\hline 133 & 0,68 & 0,68 & 0,99 & decrescente & 0,76 & 0,52 \\
\hline 134 & 0,74 & 0,74 & 1,00 & crescente & 0,78 & 0,58 \\
\hline 135 & 0,70 & 0,72 & 0,96 & decrescente & 0,94 & 0,66 \\
\hline 136 & 1,00 & 1,00 & 1,00 & constante & 0,87 & 0,87 \\
\hline 137 & 0,80 & 0,80 & 1,00 & crescente & 0,74 & 0,59 \\
\hline 138 & 1,00 & 1,00 & 1,00 & constante & 0,81 & 0,81 \\
\hline 139 & 1,00 & 1,00 & 1,00 & constante & 0,38 & 0,38 \\
\hline
\end{tabular}


Tabela 38. Resultados obtidos pelo método DEA, orientação insumo, para a amostra Brasil. Observações ordenadas pela renda bruta de forma crescente.

\begin{tabular}{ccccccc}
\hline Observações & $\begin{array}{c}\text { ET } \\
\text { R constante }\end{array}$ & $\begin{array}{c}\text { ET } \\
\text { R variável. }\end{array}$ & $\begin{array}{c}\text { Eficiência } \\
\text { escala }\end{array}$ & $\begin{array}{c}\text { Retornoà } \\
\text { escala }\end{array}$ & $\begin{array}{c}\text { Eficiência } \\
\text { Alocativa }\end{array}$ & $\begin{array}{c}\text { Eficiência } \\
\text { Econômica }\end{array}$ \\
\hline 140 & 0,98 & 1,00 & 0,98 & decrescente & 0,93 & 0,91 \\
141 & 0,96 & 1,00 & 0,96 & decrescente & 0,48 & 0,47 \\
142 & 0,97 & 1,00 & 0,97 & decrescente & 0,93 & 0,90 \\
143 & 1,00 & 1,00 & 1,00 & constante & 0,74 & 0,74 \\
\hline
\end{tabular}

Fonte: Resultados da pesquisa.

Tabela 39. Resultados obtidos pelo método DEA, orientação insumo, para a amostra Minas Gerais. Observações ordenadas pela renda bruta de forma crescente.

\begin{tabular}{|c|c|c|c|c|c|c|}
\hline Observações & $\begin{array}{c}\text { ET } \\
\text { R constante }\end{array}$ & $\begin{array}{c}\text { ET } \\
\mathrm{R} \text { variável }\end{array}$ & $\begin{array}{l}\text { Eficiência } \\
\text { escala }\end{array}$ & $\begin{array}{l}\text { Retornoà } \\
\text { escala }\end{array}$ & $\begin{array}{l}\text { Eficiência } \\
\text { Alocativa }\end{array}$ & $\begin{array}{l}\text { Eficiência } \\
\text { Econômica }\end{array}$ \\
\hline 1 & 0,45 & 1,00 & 0,45 & crescente & 0,63 & 0,28 \\
\hline 2 & 0,32 & 1,00 & 0,32 & crescente & 0,97 & 0,31 \\
\hline 3 & 0,42 & 0,90 & 0,46 & crescente & 0,97 & 0,40 \\
\hline 4 & 0,44 & 1,00 & 0,44 & crescente & 0,39 & 0,17 \\
\hline 5 & 0,36 & 0,67 & 0,54 & crescente & 0,85 & 0,31 \\
\hline 6 & 0,60 & 1,00 & 0,60 & crescente & 0,92 & 0,55 \\
\hline 7 & 0,34 & 0,79 & 0,42 & crescente & 0,95 & 0,32 \\
\hline 8 & 0,33 & 1,00 & 0,33 & crescente & 0,58 & 0,19 \\
\hline 9 & 0,85 & 1,00 & 0,85 & crescente & 0,38 & 0,32 \\
\hline 10 & 0,72 & 0,97 & 0,75 & crescente & 0,67 & 0,48 \\
\hline 11 & 0,68 & 1,00 & 0,68 & crescente & 0,96 & 0,65 \\
\hline 12 & 0,41 & 1,00 & 0,41 & crescente & 0,75 & 0,31 \\
\hline 13 & 0,51 & 0,76 & 0,67 & crescente & 0,97 & 0,50 \\
\hline 14 & 0,52 & 0,98 & 0,53 & crescente & 0,68 & 0,35 \\
\hline 15 & 0,40 & 0,60 & 0,66 & crescente & 0,86 & 0,34 \\
\hline 16 & 0,47 & 0,96 & 0,49 & crescente & 0,71 & 0,33 \\
\hline 17 & 0,41 & 1,00 & 0,41 & crescente & 0,34 & 0,14 \\
\hline 18 & 0,43 & 0,96 & 0,45 & crescente & 0,86 & 0,36 \\
\hline 19 & 0,80 & 1,00 & 0,80 & crescente & 0,86 & 0,68 \\
\hline 20 & 0,49 & 0,86 & 0,58 & crescente & 0,96 & 0,47 \\
\hline 21 & 0,40 & 0,69 & 0,57 & crescente & 0,77 & 0,30 \\
\hline 22 & 0,57 & 0,72 & 0,78 & crescente & 0,98 & 0,56 \\
\hline 23 & 0,40 & 0,55 & 0,72 & crescente & 0,44 & 0,17 \\
\hline 24 & 0,59 & 1,00 & 0,59 & crescente & 0,92 & 0,54 \\
\hline 25 & 0,37 & 0,60 & 0,61 & crescente & 0,49 & 0,18 \\
\hline 26 & 0,30 & 0,56 & 0,53 & crescente & 0,68 & 0,20 \\
\hline 27 & 0,81 & 1,00 & 0,81 & crescente & 0,52 & 0,42 \\
\hline
\end{tabular}


Tabela 39. Resultados obtidos pelo método DEA, orientação insumo, para a amostra Minas Gerais. Observações ordenadas pela renda bruta de forma crescente.

\begin{tabular}{|c|c|c|c|c|c|c|}
\hline Observações & $\begin{array}{c}\mathrm{ET} \\
\mathrm{R} \text { constante }\end{array}$ & $\begin{array}{c}\text { ET } \\
\text { R variável }\end{array}$ & $\begin{array}{c}\text { Eficiência } \\
\text { escala }\end{array}$ & $\begin{array}{c}\text { Retornoà } \\
\text { escala }\end{array}$ & $\begin{array}{l}\text { Eficiência } \\
\text { Alocativa }\end{array}$ & $\begin{array}{r}\text { Eficiência } \\
\text { Econômica }\end{array}$ \\
\hline 28 & 0,39 & 0,54 & 0,72 & crescente & 0,72 & 0,28 \\
\hline 29 & 0,44 & 0,55 & 0,80 & crescente & 0,76 & 0,34 \\
\hline 30 & 0,52 & 0,87 & 0,59 & crescente & 0,90 & 0,47 \\
\hline 31 & 0,43 & 0,70 & 0,61 & crescente & 0,64 & 0,28 \\
\hline 32 & 0,57 & 1,00 & 0,57 & crescente & 0,60 & 0,34 \\
\hline 33 & 0,50 & 0,62 & 0,81 & crescente & 0,96 & 0,48 \\
\hline 34 & 0,48 & 0,55 & 0,88 & crescente & 0,94 & 0,45 \\
\hline 35 & 0,29 & 0,44 & 0,67 & crescente & 0,86 & 0,25 \\
\hline 36 & 0,47 & 0,55 & 0,85 & crescente & 0,94 & 0,44 \\
\hline 37 & 0,59 & 0,69 & 0,86 & crescente & 0,98 & 0,58 \\
\hline 38 & 0,51 & 0,71 & 0,71 & crescente & 0,78 & 0,39 \\
\hline 39 & 0,52 & 0,93 & 0,56 & crescente & 0,47 & 0,24 \\
\hline 40 & 0,45 & 0,57 & 0,79 & crescente & 0,98 & 0,44 \\
\hline 41 & 0,29 & 0,36 & 0,80 & crescente & 0,98 & 0,28 \\
\hline 42 & 0,29 & 0,39 & 0,75 & crescente & 0,84 & 0,25 \\
\hline 43 & 0,49 & 0,70 & 0,70 & crescente & 0,92 & 0,45 \\
\hline 44 & 0,50 & 0,93 & 0,54 & crescente & 0,74 & 0,37 \\
\hline 45 & 0,78 & 1,00 & 0,78 & crescente & 0,84 & 0,66 \\
\hline 46 & 0,42 & 0,48 & 0,88 & crescente & 0,96 & 0,40 \\
\hline 47 & 0,50 & 0,64 & 0,77 & crescente & 1,00 & 0,50 \\
\hline 48 & 0,54 & 0,65 & 0,83 & crescente & 0,93 & 0,50 \\
\hline 49 & 0,61 & 0,80 & 0,76 & crescente & 0,68 & 0,42 \\
\hline 50 & 0,45 & 0,57 & 0,80 & crescente & 0,91 & 0,41 \\
\hline 51 & 0,47 & 0,56 & 0,84 & crescente & 0,84 & 0,40 \\
\hline 52 & 0,58 & 0,79 & 0,74 & crescente & 0,92 & 0,54 \\
\hline 53 & 0,81 & 1,00 & 0,81 & crescente & 0,60 & 0,49 \\
\hline 54 & 0,61 & 0,77 & 0,80 & crescente & 0,92 & 0,56 \\
\hline 55 & 0,68 & 0,79 & 0,87 & crescente & 0,69 & 0,47 \\
\hline 56 & 0,92 & 1,00 & 0,92 & crescente & 0,85 & 0,78 \\
\hline 57 & 0,62 & 0,66 & 0,93 & crescente & 0,94 & 0,58 \\
\hline 58 & 0,54 & 0,68 & 0,80 & crescente & 0,92 & 0,49 \\
\hline 59 & 0,52 & 0,61 & 0,85 & crescente & 0,93 & 0,48 \\
\hline 60 & 0,75 & 0,89 & 0,85 & crescente & 0,54 & 0,40 \\
\hline 61 & 0,42 & 0,49 & 0,86 & crescente & 0,91 & 0,38 \\
\hline 62 & 0,52 & 0,77 & 0,68 & crescente & 0,69 & 0,36 \\
\hline 63 & 0,52 & 0,57 & 0,91 & crescente & 0,62 & 0,32 \\
\hline 64 & 0,51 & 0,55 & 0,93 & crescente & 0,90 & 0,45 \\
\hline 65 & 0,57 & 0,72 & 0,80 & crescente & 0,91 & 0,52 \\
\hline 66 & 0,36 & 0,46 & 0,79 & crescente & 0,82 & 0,30 \\
\hline 67 & 0,53 & 0,59 & 0,89 & crescente & 0,96 & 0,50 \\
\hline 68 & 1,00 & 1,00 & 1,00 & constante & 0,81 & 0,81 \\
\hline 69 & 1,00 & 1,00 & 1,00 & constante & 0,48 & 0,48 \\
\hline 70 & 0,49 & 0,56 & 0,88 & crescente & 0,96 & 0,47 \\
\hline 71 & 0,85 & 0,98 & 0,86 & crescente & 0,66 & 0,56 \\
\hline 72 & 0,64 & 0,70 & 0,91 & crescente & 0,53 & 0,34 \\
\hline
\end{tabular}


Tabela 39. Resultados obtidos pelo método DEA, orientação insumo, para a amostra Minas Gerais. Observações ordenadas pela renda bruta de forma crescente.

\begin{tabular}{|c|c|c|c|c|c|c|}
\hline Observações & $\begin{array}{c}\text { ET } \\
\text { R constante }\end{array}$ & $\begin{array}{c}\text { ET } \\
\text { R variável }\end{array}$ & $\begin{array}{l}\text { Eficiência } \\
\text { escala }\end{array}$ & $\begin{array}{l}\text { Retornoà } \\
\text { escala }\end{array}$ & $\begin{array}{l}\text { Eficiência } \\
\text { Alocativa }\end{array}$ & $\begin{array}{l}\text { Eficiência } \\
\text { Econômica }\end{array}$ \\
\hline 73 & 1,00 & 1,00 & 1,00 & constante & 1,00 & 1,00 \\
\hline 74 & 0,55 & 0,58 & 0,96 & crescente & 0,93 & 0,51 \\
\hline 75 & 0,45 & 0,54 & 0,84 & crescente & 0,83 & 0,37 \\
\hline 76 & 0,41 & 0,46 & 0,89 & crescente & 0,86 & 0,35 \\
\hline 77 & 0,63 & 0,73 & 0,86 & crescente & 0,72 & 0,46 \\
\hline 78 & 0,59 & 0,63 & 0,94 & crescente & 0,88 & 0,52 \\
\hline 79 & 0,58 & 0,69 & 0,84 & crescente & 0,59 & 0,34 \\
\hline 80 & 0,54 & 0,63 & 0,86 & crescente & 0,77 & 0,41 \\
\hline 81 & 0,39 & 0,45 & 0,87 & crescente & 0,91 & 0,35 \\
\hline 82 & 0,50 & 0,55 & 0,90 & crescente & 0,62 & 0,31 \\
\hline 83 & 0,56 & 0,69 & 0,82 & crescente & 0,95 & 0,53 \\
\hline 84 & 0,67 & 0,73 & 0,92 & crescente & 0,52 & 0,35 \\
\hline 85 & 0,64 & 0,65 & 0,99 & crescente & 0,57 & 0,36 \\
\hline 86 & 0,48 & 0,58 & 0,82 & crescente & 0,89 & 0,42 \\
\hline 87 & 0,55 & 0,58 & 0,95 & crescente & 0,94 & 0,52 \\
\hline 88 & 0,50 & 0,55 & 0,91 & crescente & 0,84 & 0,42 \\
\hline 89 & 0,69 & 0,72 & 0,96 & crescente & 0,70 & 0,49 \\
\hline 90 & 0,59 & 0,61 & 0,97 & crescente & 0,89 & 0,53 \\
\hline 91 & 0,62 & 0,73 & 0,84 & crescente & 0,70 & 0,43 \\
\hline 92 & 0,59 & 0,62 & 0,97 & crescente & 0,86 & 0,51 \\
\hline 93 & 0,99 & 1,00 & 0,99 & crescente & 0,29 & 0,29 \\
\hline 94 & 0,50 & 0,54 & 0,94 & crescente & 0,84 & 0,42 \\
\hline 95 & 0,39 & 0,42 & 0,93 & crescente & 0,83 & 0,32 \\
\hline 96 & 0,64 & 0,66 & 0,97 & crescente & 0,77 & 0,49 \\
\hline 97 & 0,58 & 0,60 & 0,97 & crescente & 0,90 & 0,52 \\
\hline 98 & 0,68 & 0,69 & 0,98 & crescente & 0,87 & 0,58 \\
\hline 99 & 0,59 & 0,60 & 0,98 & crescente & 0,88 & 0,52 \\
\hline 100 & 0,83 & 0,84 & 0,99 & crescente & 0,52 & 0,43 \\
\hline 101 & 0,56 & 0,59 & 0,96 & crescente & 0,80 & 0,45 \\
\hline 102 & 0,33 & 0,36 & 0,92 & crescente & 0,75 & 0,25 \\
\hline 103 & 0,73 & 0,80 & 0,92 & crescente & 0,73 & 0,53 \\
\hline 104 & 1,00 & 1,00 & 1,00 & constante & 0,96 & 0,96 \\
\hline 105 & 0,65 & 0,79 & 0,82 & decrescente & 0,46 & 0,30 \\
\hline 106 & 0,75 & 0,84 & 0,90 & crescente & 0,74 & 0,55 \\
\hline 107 & 0,53 & 0,54 & 0,99 & crescente & 0,79 & 0,42 \\
\hline 108 & 0,72 & 0,72 & 0,99 & crescente & 0,62 & 0,45 \\
\hline 109 & 1,00 & 1,00 & 1,00 & constante & 0,63 & 0,63 \\
\hline 110 & 0,58 & 0,58 & 0,99 & crescente & 0,82 & 0,48 \\
\hline 111 & 1,00 & 1,00 & 1,00 & constante & 0,50 & 0,50 \\
\hline 112 & 1,00 & 1,00 & 1,00 & constante & 0,90 & 0,90 \\
\hline 113 & 0,83 & 0,84 & 0,99 & decrescente & 0,65 & 0,54 \\
\hline 114 & 1,00 & 1,00 & 1,00 & constante & 0,63 & 0,63 \\
\hline
\end{tabular}

Fonte: Resultados da pesquisa. 
Tabela 40. Renda bruta, índices de eficiência técnica e limite inferior (método DEA,

orientação produto, retorno constante à escala), para as amostras Brasil e

Minas Gerais.

\begin{tabular}{|c|c|c|c|c|c|c|c|}
\hline \multicolumn{4}{|c|}{ Brasil } & \multicolumn{4}{|c|}{ Minas Gerais } \\
\hline Obs. & $\begin{array}{l}\text { Renda bruta } \\
\text { (R\$) }\end{array}$ & $\begin{array}{l}\text { Eficiência } \\
\text { técnica }\end{array}$ & $\begin{array}{l}\text { Limite } \\
\text { inferior }\end{array}$ & Obs. & $\begin{array}{l}\text { Renda bruta } \\
\text { (R\$) }\end{array}$ & $\begin{array}{l}\text { Eficiência } \\
\text { técnica }\end{array}$ & $\begin{array}{l}\text { Limite } \\
\text { inferior }\end{array}$ \\
\hline 1 & 21231,75 & 0,40 & 0,08 & 1 & 14192,44 & 0,45 & 0,05 \\
\hline 2 & 21836,88 & 0,23 & 0,07 & 2 & 16979,42 & 0,32 & 0,05 \\
\hline 3 & 24359,25 & 0,26 & 0,08 & 3 & 26844,85 & 0,42 & 0,08 \\
\hline 4 & 25683,39 & 0,21 & 0,08 & 4 & 27020,28 & 0,44 & 0,08 \\
\hline 5 & 25866,76 & 0,44 & 0,10 & 5 & 28061,85 & 0,36 & 0,08 \\
\hline 6 & 26623,43 & 0,20 & 0,08 & 6 & 39010,32 & 0,60 & 0,12 \\
\hline 7 & 26718,00 & 0,42 & 0,10 & 7 & 39617,30 & 0,34 & 0,11 \\
\hline 8 & 27010,00 & 0,33 & 0,10 & 8 & 41359,27 & 0,33 & 0,11 \\
\hline 9 & 27440,33 & 0,25 & 0,09 & 9 & 41902,00 & 0,85 & 0,14 \\
\hline 10 & 28203,50 & 0,28 & 0,09 & 10 & 44369,77 & 0,72 & 0,14 \\
\hline 11 & 30506,56 & 0,84 & 0,13 & 11 & 45022,85 & 0,68 & 0,14 \\
\hline 12 & 30574,50 & 0,89 & 0,13 & 12 & 45621,73 & 0,41 & 0,12 \\
\hline 13 & 31048,00 & 0,11 & 0,06 & 13 & 48458,49 & 0,51 & 0,14 \\
\hline 14 & 31072,50 & 0,69 & 0,13 & 14 & 49137,60 & 0,52 & 0,14 \\
\hline 15 & 31536,00 & 0,35 & 0,11 & 15 & 50405,99 & 0,40 & 0,13 \\
\hline 16 & 33131,25 & 0,33 & 0,11 & 16 & 50642,27 & 0,47 & 0,14 \\
\hline 17 & 33358,00 & 0,58 & 0,13 & 17 & 54481,00 & 0,41 & 0,14 \\
\hline 18 & 35549,74 & 0,41 & 0,12 & 18 & 54950,25 & 0,43 & 0,14 \\
\hline 19 & 35897,50 & 0,20 & 0,10 & 19 & 56428,19 & 0,80 & 0,17 \\
\hline 20 & 36208,00 & 0,60 & 0,14 & 20 & 60819,18 & 0,49 & 0,16 \\
\hline 21 & 36783,95 & 0,37 & 0,12 & 21 & 63715,30 & 0,40 & 0,15 \\
\hline 22 & 37774,00 & 0,66 & 0,15 & 22 & 64347,47 & 0,57 & 0,17 \\
\hline 23 & 38095,35 & 0,60 & 0,14 & 23 & 70880,50 & 0,40 & 0,16 \\
\hline 24 & 38343,75 & 0,23 & 0,10 & 24 & 72155,04 & 0,59 & 0,19 \\
\hline 25 & 39250,00 & 0,59 & 0,15 & 25 & 72202,50 & 0,37 & 0,16 \\
\hline 26 & 40047,50 & 0,28 & 0,12 & 26 & 73419,02 & 0,30 & 0,15 \\
\hline 27 & 40644,00 & 1,00 & 0,17 & 27 & 73843,58 & 0,81 & 0,21 \\
\hline 28 & 41101,20 & 0,30 & 0,12 & 28 & 75787,76 & 0,39 & 0,17 \\
\hline 29 & 41276,03 & 0,25 & 0,11 & 29 & 76126,76 & 0,44 & 0,18 \\
\hline 30 & 42220,00 & 0,49 & 0,15 & 30 & 79858,24 & 0,52 & 0,19 \\
\hline 31 & 42796,25 & 0,40 & 0,14 & 31 & 80219,26 & 0,43 & 0,18 \\
\hline 32 & 42911,00 & 0,19 & 0,10 & 32 & 80605,98 & 0,57 & 0,20 \\
\hline 33 & 43444,13 & 0,27 & 0,12 & 33 & 82266,27 & 0,50 & 0,20 \\
\hline 34 & 43610,50 & 0,46 & 0,15 & 34 & 82968,77 & 0,48 & 0,19 \\
\hline 35 & 43800,00 & 0,13 & 0,08 & 35 & 84390,82 & 0,29 & 0,16 \\
\hline 36 & 45390,00 & 0,12 & 0,08 & 36 & 85763,41 & 0,47 & 0,19 \\
\hline 37 & 45518,75 & 0,36 & 0,14 & 37 & 87480,33 & 0,59 & 0,22 \\
\hline
\end{tabular}


Tabela 40. Renda bruta, índices de eficiência técnica e limite inferior (método DEA,

orientação produto, retorno constante à escala), para as amostras Brasil e

Minas Gerais.

\begin{tabular}{|c|c|c|c|c|c|c|c|}
\hline \multicolumn{4}{|c|}{ Brasil } & \multicolumn{4}{|c|}{ Minas Gerais } \\
\hline Obs. & $\begin{array}{l}\text { Renda bruta } \\
(\mathrm{R} \$)\end{array}$ & $\begin{array}{l}\text { Eficiência } \\
\text { técnica }\end{array}$ & $\begin{array}{l}\text { Limite } \\
\text { inferior }\end{array}$ & Obs. & $\begin{array}{l}\text { Renda bruta } \\
\qquad(\mathrm{R} \$)\end{array}$ & $\begin{array}{l}\text { Eficiência } \\
\text { técnica }\end{array}$ & $\begin{array}{l}\text { Limite } \\
\text { inferior }\end{array}$ \\
\hline 38 & 47158,00 & 0,25 & 0,12 & 38 & 87542,26 & 0,51 & 0,20 \\
\hline 39 & 47520,00 & 0,36 & 0,14 & 39 & 88018,00 & 0,52 & 0,21 \\
\hline 40 & 47892,50 & 0,32 & 0,14 & 40 & 91338,95 & 0,45 & 0,20 \\
\hline 41 & 49822,50 & 0,35 & 0,15 & 41 & 91784,64 & 0,29 & 0,16 \\
\hline 42 & 50803,44 & 0,21 & 0,12 & 42 & 91791,96 & 0,29 & 0,16 \\
\hline 43 & 51016,66 & 0,39 & 0,15 & 43 & 92194,96 & 0,49 & 0,21 \\
\hline 44 & 51322,50 & 0,22 & 0,12 & 44 & 92828,20 & 0,50 & 0,21 \\
\hline 45 & 51347,20 & 0,34 & 0,15 & 45 & 93538,50 & 0,78 & 0,25 \\
\hline 46 & 51751,75 & 0,56 & 0,18 & 46 & 94031,48 & 0,42 & 0,20 \\
\hline 47 & 52168,13 & 0,36 & 0,15 & 47 & 102865,87 & 0,50 & 0,22 \\
\hline 48 & 52369,48 & 0,32 & 0,14 & 48 & 105733,25 & 0,54 & 0,23 \\
\hline 49 & 52558,00 & 0,38 & 0,16 & 49 & 106138,03 & 0,61 & 0,25 \\
\hline 50 & 52560,00 & 0,87 & 0,20 & 50 & 111330,41 & 0,45 & 0,22 \\
\hline 51 & 53757,00 & 0,29 & 0,14 & 51 & 120387,45 & 0,47 & 0,23 \\
\hline 52 & 54604,00 & 0,32 & 0,15 & 52 & 123338,70 & 0,58 & 0,26 \\
\hline 53 & 54681,25 & 0,43 & 0,17 & 53 & 126851,04 & 0,81 & 0,31 \\
\hline 54 & 54756,00 & 0,30 & 0,14 & 54 & 128984,50 & 0,61 & 0,28 \\
\hline 55 & 57487,50 & 0,47 & 0,18 & 55 & 133041,67 & 0,68 & 0,29 \\
\hline 56 & 57700,46 & 0,65 & 0,20 & 56 & 136729,53 & 0,92 & 0,34 \\
\hline 57 & 58400,00 & 0,41 & 0,17 & 57 & 138422,52 & 0,62 & 0,29 \\
\hline 58 & 58622,50 & 0,23 & 0,13 & 58 & 139085,24 & 0,54 & 0,27 \\
\hline 59 & 59130,00 & 0,93 & 0,22 & 59 & 139085,24 & 0,52 & 0,26 \\
\hline 60 & 63324,25 & 0,42 & 0,18 & 60 & 140700,00 & 0,75 & 0,32 \\
\hline 61 & 63769,40 & 0,62 & 0,21 & 61 & 145238,99 & 0,42 & 0,24 \\
\hline 62 & 63829,75 & 0,52 & 0,20 & 62 & 146057,44 & 0,52 & 0,27 \\
\hline 63 & 64237,50 & 0,77 & 0,23 & 63 & 146334,60 & 0,52 & 0,27 \\
\hline 64 & 64402,30 & 0,75 & 0,23 & 64 & 152667,39 & 0,51 & 0,27 \\
\hline 65 & 66068,15 & 0,60 & 0,21 & 65 & 154373,36 & 0,57 & 0,29 \\
\hline 66 & 66334,19 & 0,78 & 0,23 & 66 & 154465,25 & 0,36 & 0,23 \\
\hline 67 & 66766,25 & 0,15 & 0,10 & 67 & 156104,27 & 0,53 & 0,28 \\
\hline 68 & 67105,00 & 0,45 & 0,19 & 68 & 156405,13 & 1,00 & 0,38 \\
\hline 69 & 67847,50 & 0,46 & 0,19 & 69 & 157254,00 & 1,00 & 0,38 \\
\hline 70 & 67993,75 & 0,36 & 0,17 & 70 & 161661,55 & 0,49 & 0,27 \\
\hline 71 & 69350,00 & 0,31 & 0,16 & 71 & 164692,10 & 0,85 & 0,36 \\
\hline 72 & 70080,00 & 0,57 & 0,22 & 72 & 166122,71 & 0,64 & 0,32 \\
\hline 73 & 70851,25 & 0,49 & 0,21 & 73 & 166947,47 & 1,00 & 0,39 \\
\hline 74 & 74914,50 & 0,71 & 0,25 & 74 & 167954,75 & 0,55 & 0,30 \\
\hline 75 & 76497,93 & 0,34 & 0,18 & 75 & 171576,10 & 0,45 & 0,27 \\
\hline 76 & 77181,75 & 0,81 & 0,26 & 76 & 172352,63 & 0,41 & 0,25 \\
\hline 77 & 80000,00 & 0,57 & 0,23 & 77 & 184982,67 & 0,63 & 0,34 \\
\hline 78 & 81030,00 & 0,40 & 0,20 & 78 & 185618,94 & 0,59 & 0,33 \\
\hline
\end{tabular}


Tabela 40. Renda bruta, índices de eficiência técnica e limite inferior (método DEA,

orientação produto, retorno constante à escala), para as amostras Brasil e

Minas Gerais.

\begin{tabular}{|c|c|c|c|c|c|c|c|}
\hline \multicolumn{4}{|c|}{ Brasil } & \multicolumn{4}{|c|}{ Minas Gerais } \\
\hline Obs. & $\begin{array}{c}\text { Renda bruta } \\
\qquad(\mathrm{R} \$)\end{array}$ & $\begin{array}{l}\text { Eficiência } \\
\text { técnica }\end{array}$ & $\begin{array}{l}\text { Limite } \\
\text { inferior }\end{array}$ & Obs. & $\begin{array}{l}\text { Renda bruta } \\
\qquad(\mathrm{R} \$)\end{array}$ & $\begin{array}{l}\text { Eficiência } \\
\text { técnica }\end{array}$ & $\begin{array}{l}\text { Limite } \\
\text { inferior }\end{array}$ \\
\hline 79 & 88375,63 & 0,60 & 0,25 & 79 & 185775,10 & 0,58 & 0,32 \\
\hline 80 & 89227,74 & 0,64 & 0,26 & 80 & 191122,28 & 0,54 & 0,31 \\
\hline 81 & 91647,50 & 0,28 & 0,17 & 81 & 194831,92 & 0,39 & 0,26 \\
\hline 82 & 93100,00 & 0,85 & 0,30 & 82 & 196322,50 & 0,50 & 0,30 \\
\hline 83 & 95785,31 & 0,60 & 0,27 & 83 & 203670,37 & 0,56 & 0,33 \\
\hline 84 & 96618,75 & 0,34 & 0,20 & 84 & 208775,10 & 0,67 & 0,37 \\
\hline 85 & 97318,13 & 0,56 & 0,26 & 85 & 219979,08 & 0,64 & 0,37 \\
\hline 86 & 97889,38 & 0,49 & 0,24 & 86 & 224128,49 & 0,48 & 0,31 \\
\hline 87 & 99918,75 & 0,16 & 0,12 & 87 & 234525,57 & 0,55 & 0,34 \\
\hline 88 & 106251,50 & 0,33 & 0,20 & 88 & 245743,31 & 0,50 & 0,33 \\
\hline 89 & 108496,25 & 1,00 & 0,35 & 89 & 254883,85 & 0,69 & 0,41 \\
\hline 90 & 108646,07 & 0,52 & 0,27 & 90 & 258822,45 & 0,59 & 0,37 \\
\hline 91 & 109780,00 & 0,45 & 0,25 & 91 & 263338,42 & 0,62 & 0,38 \\
\hline 92 & 110325,00 & 0,39 & 0,23 & 92 & 266876,34 & 0,59 & 0,38 \\
\hline 93 & 110827,22 & 0,42 & 0,24 & 93 & 289414,62 & 0,99 & 0,53 \\
\hline 94 & 112742,19 & 0,60 & 0,29 & 94 & 289547,89 & 0,50 & 0,35 \\
\hline 95 & 116241,25 & 0,63 & 0,30 & 95 & 293529,47 & 0,39 & 0,29 \\
\hline 96 & 117535,60 & 0,57 & 0,29 & 96 & 297403,62 & 0,64 & 0,41 \\
\hline 97 & 117983,13 & 0,49 & 0,27 & 97 & 308599,87 & 0,58 & 0,39 \\
\hline 98 & 118560,00 & 0,42 & 0,25 & 98 & 309144,64 & 0,68 & 0,43 \\
\hline 99 & 120300,00 & 0,76 & 0,34 & 99 & 329997,84 & 0,59 & 0,40 \\
\hline 100 & 123100,00 & 0,75 & 0,34 & 100 & 335800,00 & 0,83 & 0,51 \\
\hline 101 & 125421,50 & 0,62 & 0,31 & 101 & 336463,45 & 0,56 & 0,39 \\
\hline 102 & 127332,88 & 0,61 & 0,31 & 102 & 352610,90 & 0,33 & 0,27 \\
\hline 103 & 130080,00 & 0,67 & 0,33 & 103 & 372158,81 & 0,73 & 0,49 \\
\hline 104 & 136875,00 & 0,45 & 0,27 & 104 & 380911,79 & 1,00 & 0,60 \\
\hline 105 & 136892,50 & 0,44 & 0,27 & 105 & 410695,02 & 0,65 & 0,46 \\
\hline 106 & 138100,00 & 0,31 & 0,21 & 106 & 411157,95 & 0,75 & 0,51 \\
\hline 107 & 140525,00 & 0,60 & 0,32 & 107 & 480087,43 & 0,53 & 0,41 \\
\hline 108 & 149439,50 & 0,30 & 0,21 & 108 & 536088,70 & 0,72 & 0,53 \\
\hline 109 & 150142,75 & 0,56 & 0,32 & 109 & 634186,06 & 1,00 & 0,71 \\
\hline 110 & 150350,00 & 0,65 & 0,35 & 110 & 707085,86 & 0,58 & 0,48 \\
\hline 111 & 153947,50 & 0,51 & 0,31 & 111 & 713408,00 & 1,00 & 0,74 \\
\hline 112 & 154550,00 & 0,61 & 0,34 & 112 & 804622,27 & 1,00 & 0,76 \\
\hline 113 & 157353,82 & 0,58 & 0,33 & 113 & 1009272,59 & 0,83 & 0,69 \\
\hline 114 & 159060,00 & 0,61 & 0,34 & 114 & 1100187,57 & 1,00 & 0,81 \\
\hline 115 & 160070,00 & 0,83 & 0,41 & & & & 031 \\
\hline 116 & 160757,50 & 0,31 & 0,23 & MEDIA & 188413,13 & 0,52 & 0,31 \\
\hline 117 & 177881,25 & 1,00 & 0,47 & & & & \\
\hline 118 & 178469,37 & 0,91 & 0,45 & & & & \\
\hline 119 & 179231,25 & 0,75 & 0,41 & & & & \\
\hline
\end{tabular}


Tabela 40. Renda bruta, índices de eficiência técnica e limite inferior (método DEA, orientação produto, retorno constante à escala), para as amostras Brasil e Minas Gerais.

\begin{tabular}{|c|c|c|c|c|c|c|c|}
\hline \multicolumn{4}{|c|}{ Brasil } & \multicolumn{4}{|c|}{ Minas Gerais } \\
\hline Obs. & $\begin{array}{l}\text { Renda bruta } \\
\text { (R\$) }\end{array}$ & $\begin{array}{l}\text { Eficiência } \\
\text { técnica }\end{array}$ & $\begin{array}{l}\text { Limite } \\
\text { inferior }\end{array}$ & Obs. & $\begin{array}{l}\text { Renda bruta } \\
\text { (R\$) }\end{array}$ & $\begin{array}{l}\text { Eficiência } \\
\text { técnica }\end{array}$ & $\begin{array}{l}\text { Limite } \\
\text { inferior }\end{array}$ \\
\hline 120 & 180645,00 & 0,73 & 0,40 & & & & \\
\hline 121 & 181770,00 & 0,89 & 0,45 & & & & \\
\hline 122 & 182257,50 & 0,49 & 0,32 & & & & \\
\hline 123 & 184690,00 & 1,00 & 0,48 & & & & \\
\hline 124 & 187615,00 & 0,53 & 0,34 & & & & \\
\hline 125 & 199158,41 & 0,53 & 0,35 & & & & \\
\hline 126 & 210656,25 & 0,57 & 0,37 & & & & \\
\hline 127 & 216615,00 & 0,58 & 0,38 & & & & \\
\hline 128 & 220727,38 & 0,52 & 0,35 & & & & \\
\hline 129 & 224510,00 & 1,00 & 0,53 & & & & \\
\hline 130 & 233321,00 & 0,65 & 0,42 & & & & \\
\hline 131 & 234200,00 & 1,00 & 0,54 & & & & \\
\hline 132 & 237266,40 & 1,00 & 0,54 & & & & \\
\hline 133 & 269887,25 & 0,68 & 0,45 & & & & \\
\hline 134 & 308640,00 & 0,74 & 0,50 & & & & \\
\hline 135 & 317300,38 & 0,70 & 0,48 & & & & \\
\hline 136 & 327900,00 & 1,00 & 0,62 & & & & \\
\hline 137 & 390400,00 & 0,80 & 0,57 & & & & \\
\hline 138 & 454675,00 & 1,00 & 0,69 & & & & \\
\hline 139 & 466575,00 & 1,00 & 0,70 & & & & \\
\hline 140 & 588827,75 & 0,98 & 0,73 & & & & \\
\hline 141 & 698256,25 & 0,96 & 0,75 & & & & \\
\hline 142 & 765664,80 & 0,97 & 0,77 & & & & \\
\hline 143 & 885776,25 & 1,00 & 0,82 & & & & \\
\hline MÉDIA & 119862,64 & 0,41 & 0,24 & & & & \\
\hline
\end{tabular}

Fonte: Resultados da pesquisa. 